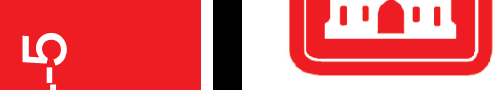

US Army Corps of Engineers $s_{\circledast}$ Engineer Research and Development Center

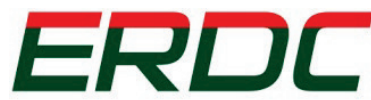

INNOVATIVE SOLUTIONS for a safer, better world

Environmental Quality/Installations Research and Development Program

Center for Nation Reconstruction and Capacity Development

\title{
Cost Analysis of Remediation Systems for Depleted Uranium
}

Joseph Walters, Jarrett Mackey, Kahlan Maki, April 2014

Raymond Northcutt, John V. Farr, W. Andy Martin,

Steven L. Larson, John H. Ballard, and Catherine Nestler 
The US Army Engineer Research and Development Center (ERDC) solves the nation's toughest engineering and environmental challenges. ERDC develops innovative solutions in civil and military engineering, geospatial sciences, water resources, and environmental sciences for the Army, the Department of Defense, civilian agencies, and our nation's public good. Find out more at www.erdc.usace.army.mil.

To search for other technical reports published by ERDC, visit the ERDC online library at http://acwc.sdp.sirsi.net/client/default. 


\section{Cost Analysis of Remediation Systems for Depleted Uranium}

Joseph Walters, Jarrett Mackey, Kahlan Maki, Raymond Northcutt, and John V. Farr

Center for Nation Reconstruction and Capacity Development

Department of Systems Engineering

United States Military Academy

West Point, NY 10996

W. Andy Martin, Steven L. Larson, and John Ballard

Environmental Laboratory

US Army Engineer Research and Development Center

3909 Halls Ferry Rd.

Vicksburg, MS 39180-6199

Catherine Nestler

Applied Research Associates, Inc.

119 Monument Place

Vicksburg, MS 39180

Final report

Approved for public release; distribution is unlimited.

Prepared for U.S. Army Corps of Engineers

Washington, DC 20314-1000

Under Work Unit 33143 


\section{Abstract}

The United States (US) Army and the other services are mandated to comply with all federal, state, and local environmental regulations. Recent concerns over potential human exposure to depleted uranium (DU) at US Army test ranges, primarily, have resulted in research into numerous innovative remediation technologies. Developing methods and processes for estimating the life cycle costs (LCC) of implementing these various techniques is important in identifying cost-effective solutions. Total ownership costs (TOC) models were developed for four candidate alternatives using two new technologies; Alternative 1- Physical Separation and Chemical Treatment; Alternative 2- Selective Excavation; Alternative 3- Selective Excavation with Physical Separation and Chemical Treatment; Alternative 4- Containment and Monitoring. The team chose a generic sandy soil site roughly 10 miles square for cost estimates. A bottom up estimate was applied to all alternatives in order to get a baseline cost; Alternative 3 had the best estimate for an efficient and effective remediation method. A costestimating relationship was generated and simulation-based costing (SBC) was then applied to Alternative 3. Lastly, two alternatives were evaluated for DU remediation of catchboxes. Identifying the key cost drivers from SBC modeling is significant to future investments in research and development.

DISCLAIMER: The contents of this report are not to be used for advertising, publication, or promotional purposes. Citation of trade names does not constitute an official endorsement or approval of the use of such commercial products. All product names and trademarks cited are the property of their respective owners. The findings of this report are not to be construed as an official Department of the Army position unless so designated by other authorized documents. 


\section{Contents}
Abstract ii

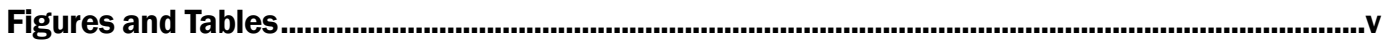

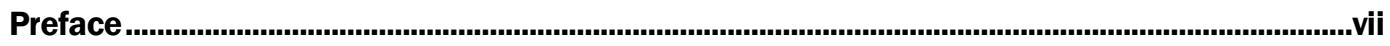

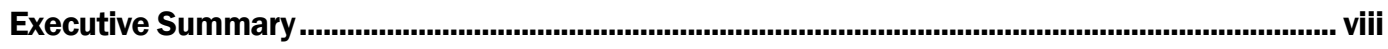

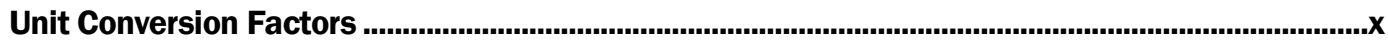

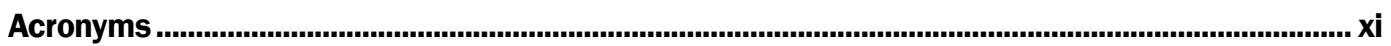

1 Introduction ................................................................................................................................ 1

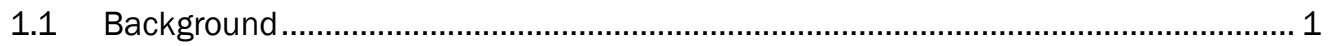

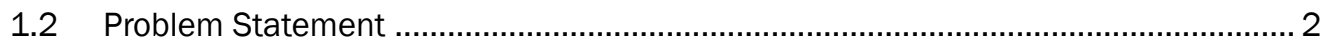

1.3 Research Objectives ....................................................................................... 3

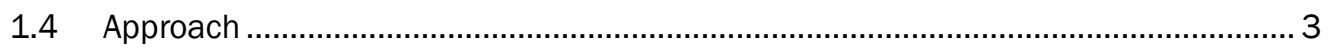

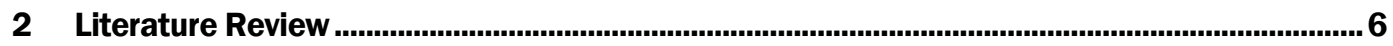

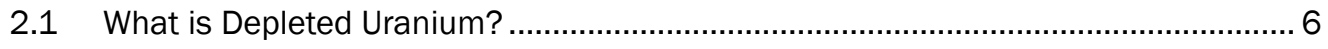

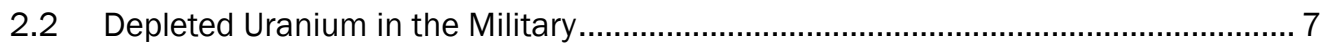

2.3 Environmental Risk....................................................................................... 8

2.4 Remediation Technologies ................................................................................ 9

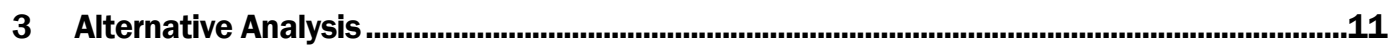

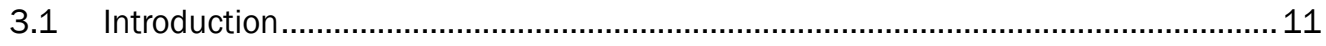

3.2 Alternative 1: Physical Separation and Chemical Treatment .................................13

3.3 Alternative 2: Selective Excavation ............................................................. 15

3.4 Alternative 3: Selective Excavation with Physical Separation and Chemical

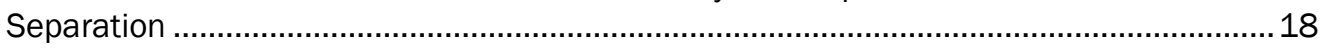

3.5 Alternative 4: Containment and Monitoring .........................................................20

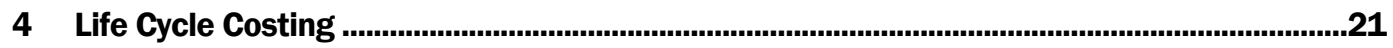

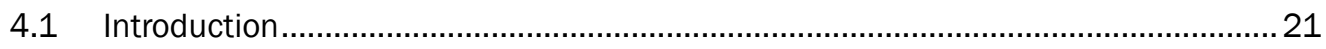

4.2 Bottom-Up Build ............................................................................................. 21

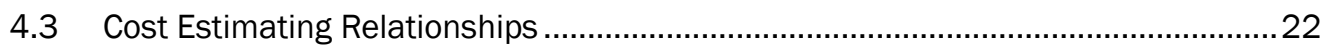

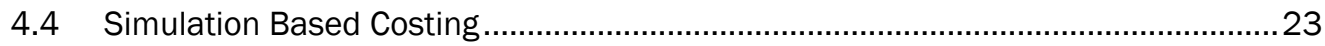

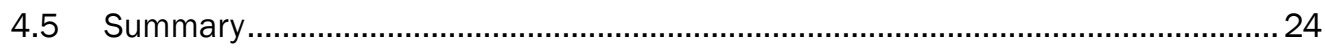

5 Life Cycle Cost Analysis Methodology using a Sandy Soil Demonstration Site ...................25

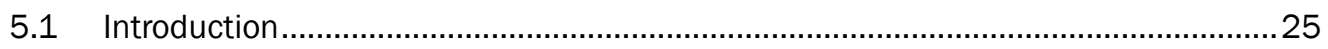

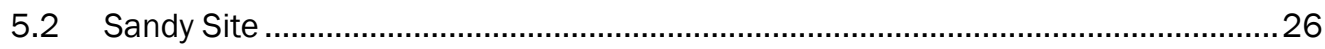

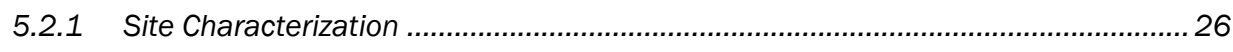

5.2.2 Sandy Site Bottom up Based LCC Estimate ....................................................... 26 
5.2.3 Simulation Based Costing Estimate of Alternative.................................................. 37

5.2.4 CER Model for Alternative 3 ............................................................................. 39

5.2.5 Sensitivity Analysis of Major Cost Drivers ............................................................. 41

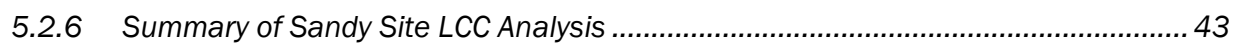

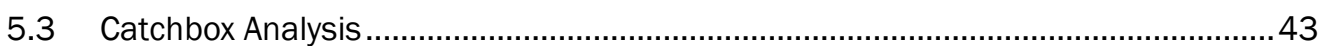

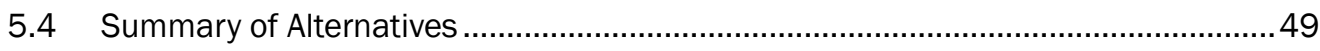

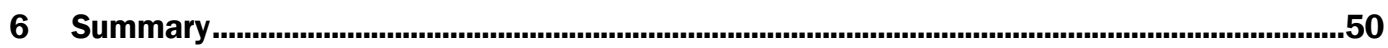

6.1 Comparison of Costs for Treatment Alternatives .................................................50

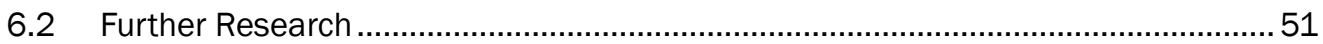

References .....................................................................................................................................52

Appendix A: Bottom Up High Resolution Spreadsheet Model...................................................54

Appendix B: High Resolution Excavation and Hauling Model ........................................................62

\section{Report Documentation Page}




\section{Figures and Tables}

\section{Figures}

Figure 1-1. Process to be used to develop LCC models for depleted uranium disposal...................... 2

Figure 1-2. Typical catchbox at an Army test range (from Larson et al. 2009).....................................

Figure 1-3. Steps in the DU remediation process............................................................................. 4

Figure 2-1. Sabot structure separating from DU penetrator. ..................................................................

Figure 2-2. Depleted uranium versus tungsten heavy alloys (Photographs provided by

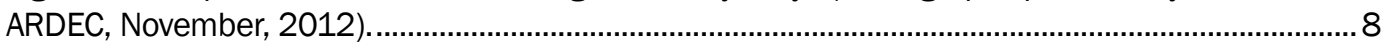

Figure 3-1. Sensitivity analysis of disposal cost.................................................................................13

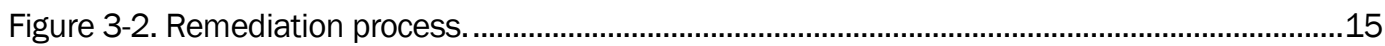

Figure 3-3. Equipment used to map DU contaminated soil.............................................................16

Figure 3-4. DU site contamination mapping...............................................................................16

Figure 3-5. Resolution of GPS mapping system. ......................................................................17

Figure 3-6. Amount of material to be excavated as part of the selective excavation

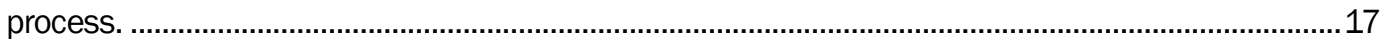

Figure 3-7. Process for selective hot spot excavation and no chemical reduction of DU..................18

Figure 3-8. Selective hot spot excavation with chemical reduction of DU contaminated

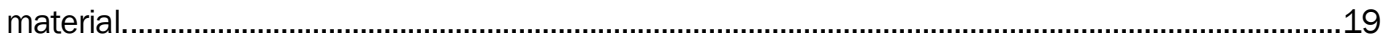

Figure 5-1. Simulation based costing of Alternative 3. ……….........................................................37

Figure 5-2. Sensitivity analysis of Alternative 3..........................................................................38

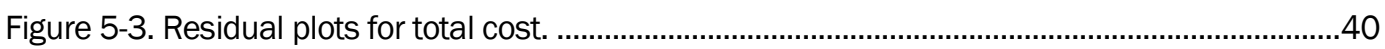

Figure 5-4. Effect of disposal cost on total cost for Alternative 1: Physical Separation and Chemical Treatment..................................................................................................................... 41

Figure 5-5. Number of hotspots sensitivity analysis for Alternative 3: Selective excavation with physical and chemical separation.

Figure 5-6. Depleted uranium sensitivity plot for Alternative 3: Selective excavation with physical separation and chemical treatment.............................................................................43

Figure 5-7. Yuma Proving Ground DU Catchbox (from Martinell and Dillard 2010)...........................45

Figure 5-8. Heavy sifting equipment (from Martinell and Dillard 2010)............................................46

Figure A1. Remediation flow chart...........................................................................................

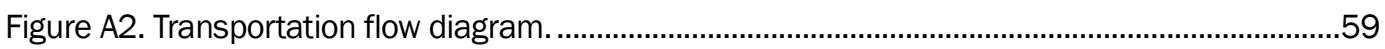

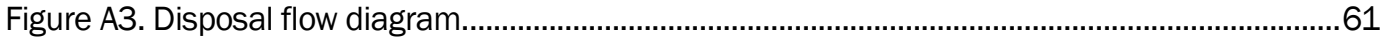

Figure B1. Schematic of excavation and transportation process......................................................62

\section{Tables}

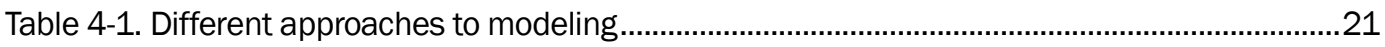

Table 5-1. Test range scenarios for which LCC are determined........................................................25

Table 5-2. Catchbox scenarios for which LCC are determined ..........................................................25 
Table 5-3. Data variable sheet for DU remediation stochastic and bottom-up detailed

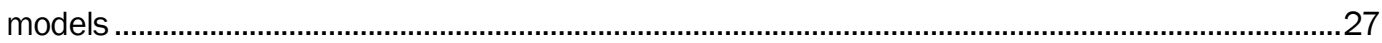

Table 5-4. Cost Summary for Alternative 1: Physical Separation and Chemical Treatment..............34

Table 5-5. Cost Summary for Alternative 2: Selective Excavation .......................................................35

Table 5-6. Cost Summary for Alternative 3: Selective Excavation with Physical Separation and Chemical Treatment...............................................................................................................

Table 5-7. Cost Summary for Alternative 4: Containment and Monitoring...........................................37

Table 5-8. CER regression model: Total cost versus hotspots and DU for Alternative 3 .....................40

Table 5-9. Cost summary for Alternative 5a: Chemical Filtration, Catchbox.......................................44

Table 5-10. Cost Summary for Alternative 5b: Hot Spot Scan and Haul Away, Sandy Site .................44

Table 5-11. Data variable sheet for Catchbox .................................................................................46

Table A1. Cost summary for Alternative 1: Physical and chemical remediation. .............................55

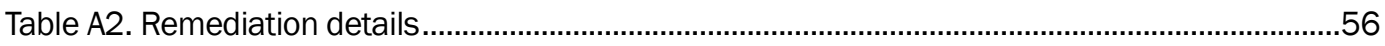

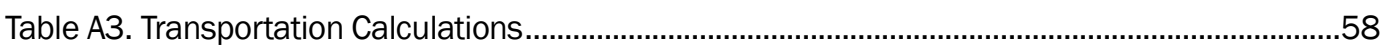

Table A4. Disposal cost calculations of DU waste chemicals and filters..........................................60 


\section{Preface}

The work reported herein was conducted by faculty and cadets of the United States Military Academy (USMA) located in West Point, NY and monitored by Dr. John V. Farr of the Center for Nation Reconstruction and Capacity Development. Funding was provided by the US Army Research and Development Center, Environmental Laboratory, Vicksburg, MS under MIPR Number W81EWF22448206.

This report is a life cycle cost analysis comparing three alternatives for remediation of DU in soil and two alternatives for remediation of DU in catchbox sand. Cadets Joseph Walters Jarrett Mackey, Kahlan Maki, and Raymond Northcutt prepared the analysis under the supervision of Dr. John V. Farr, USMA, Department of Systems Engineering. Information for the analysis was provided by Dr. Steven Larson and John Ballard, ERDC-Environmental Laboratory (EL), Vicksburg, MS and members of the Armament Research, Development and Engineering Command (ARDEC) at Picatinny Arsenal, NJ.

This study is part of the EQ/I focus area "Depleted Uranium (DU) Munitions \& Munitions Residues Management for Range Sustainability and Legacy Sites," Task 3 "Removal of Uranium in Soils Containing DU Munitions Residues," directed by Dr. Steven Larson. This focus area is under the direct supervision of John Ballard, Assistant Technical Director, ERDC-EL, and under the general supervision of Dr. Elizabeth Ferguson, Technical Director for Military Materials in the Environment, ERDC-EL. Dr. Jack Davis was Deputy Director, ERDC-EL; and Dr. Beth Fleming was Director, ERDC-EL.

COL Jeffrey R. Eckstein was Commander of ERDC and Dr. Jeffery P. Holland was Director of ERDC. 


\section{Executive Summary}

While meeting mission requirements is first and foremost, the United States (US) Army and the other services are mandated to comply with all federal, state, and local environmental regulations. Compliance with environmental regulations can become an important factor in test and evaluation, training, material availability and ultimately combat readiness. Like any private company, the US Army is subject to possible fines and production shut downs if not in compliance with environmental regulations. Recent concerns over potential human exposure to depleted uranium (DU) at US Army test ranges, primarily, have resulted in research into numerous innovative remediation technologies. Developing methods and processes for estimating the life cycle costs (LCC) of implementing these various techniques is important in identifying cost-effective solutions.

Depleted uranium is classified as a radioactive medium that is ideal for use in armor-penetrating munitions. Many environmental groups consider DU an environmental concern because of questions about the potential longterm effects of exposure. In order to mitigate exposure risks, innovative and cost-effective remediation techniques are needed. Thus, the purpose of this research is to develop LCC models for the evaluation of candidate DU remediation methods. Though focused mainly on Army training ranges, the methodology can be used for a host of environmental remediation problems. Life cycle cost models can help stakeholders in selecting the most suitable remediation method by providing a direct, transparent, and unbiased comparison of remediation methods.

Total ownership costs (TOC) models were developed for four candidate alternatives using two new technologies. Alternatives evaluated include the following: Alternative 1- Physical Separation and Chemical Treatment Alternative 2- Selective Excavation, Alternative 3- Selective Excavation with Physical Separation and Chemical Treatment, and Alternative 4Containment and Monitoring. Physical separation and chemical treatment consists of physically separating the DU from the soil matrix and then chemically treating the remaining soil. Selective excavation entails using modern hotspot scanning in order to pinpoint DU rich areas in order to completely excavate and dispose of the contaminated material. Selective excavation with physical separation and chemical treatment includes 
hotspot scanning followed by physical separation and chemical treatment. Lastly, containment and monitoring consists of closing off the site with fencing and monitoring potential transfer of DU using groundwatermonitoring wells. The team chose a generic sandy soil site roughly 10 miles square for cost estimates. A bottom up estimate was applied to all alternatives in order to get a baseline cost; consequently, the team found that Alternative 3 had the best estimate for an efficient and effective remediation method. A cost-estimating relationship was generated and simulation-based costing (SBC) was then applied to Alternative 3. Lastly, two alternatives were evaluated for DU remediation of catchboxes.

In addition to capturing the TOC for the four alternatives, identifying the key cost drivers from SBC modeling is significant to future investments in research and development. 


\section{Unit Conversion Factors}

\begin{tabular}{|c|c|c|}
\hline Multiply & By & To Obtain \\
\hline acres & $4,046.873$ & square meters \\
\hline acre-feet & 1,233.5 & cubic meters \\
\hline cubic feet & 0.02831685 & cubic meters \\
\hline cubic inches & 1.6387064 E-05 & cubic meters \\
\hline cubic yards & 0.7645549 & cubic meters \\
\hline feet & 0.3048 & meters \\
\hline gallons (US liquid) & $3.785412 \mathrm{E}-03$ & cubic meters \\
\hline hectares & $1.0 \mathrm{E}+04$ & square meters \\
\hline inches & 0.0254 & meters \\
\hline miles (US statute) & $1,609.347$ & meters \\
\hline ounces (mass) & 0.02834952 & kilograms \\
\hline ounces (US fluid) & 2.957353 E-05 & cubic meters \\
\hline pounds (mass) & 0.45359237 & kilograms \\
\hline pounds (mass) per cubic foot & 16.01846 & kilograms per cubic meter \\
\hline pounds (mass) per cubic inch & $2.757990 \mathrm{E}+04$ & kilograms per cubic meter \\
\hline pounds (mass) per square foot & 4.882428 & kilograms per square meter \\
\hline pounds (mass) per square yard & 0.542492 & kilograms per square meter \\
\hline square feet & 0.09290304 & square meters \\
\hline square inches & $6.4516 \mathrm{E}-04$ & square meters \\
\hline square miles & $2.589998 \mathrm{E}+06$ & square meters \\
\hline square yards & 0.8361274 & square meters \\
\hline tons (long) per cubic yard & $1,328.939$ & kilograms per cubic meter \\
\hline tons $(2,000$ pounds, mass $)$ & 907.1847 & kilograms \\
\hline tons ( 2,000 pounds, mass) per square foot & $9,764.856$ & kilograms per square meter \\
\hline yards & 0.9144 & meters \\
\hline
\end{tabular}




\section{Acronyms}

\begin{tabular}{|c|c|}
\hline ALT & Alternative \\
\hline ARDEC & Armament Research, Development, and Engineering Center \\
\hline $\mathrm{B} / \mathrm{C}$ & Benefit/Costs \\
\hline CER & Cost Estimating Relationship \\
\hline DoD & Department of Defense \\
\hline DU & Depleted Uranium \\
\hline ERDC & Engineer Research and Development Center \\
\hline $\mathrm{ft}$ & Feet \\
\hline $\mathrm{ft}^{2}$ & Square Feet \\
\hline $\mathrm{ft} 3$ & Cubic Feet \\
\hline $\mathrm{g} / \mathrm{cm}^{3}$ & Grams per Cubic Centimeter \\
\hline GPS & Global Positioning System \\
\hline IRR & Internal Rate of Return \\
\hline lbs & Pounds \\
\hline LCC & Life Cycle Cost \\
\hline M & Million \\
\hline MS & Mississippi \\
\hline NA & Not Applicable \\
\hline NJ & New Jersey \\
\hline NASA & National Aeronautics and Space Administration \\
\hline NORM & Naturally Occurring Radioactive Material \\
\hline NPV & Net Present Value \\
\hline NRC & Nuclear Regulatory Commission \\
\hline PCM & Parametric Cost Model \\
\hline PVC & Polyvinyl Chloride \\
\hline ROI & Return on Investment \\
\hline SBC & Simulation Based Costing \\
\hline ME & Subject Matter Experts \\
\hline DC & Total Ownership Cost \\
\hline
\end{tabular}




$\begin{array}{ll}\text { US } & \text { United States } \\ \text { WBS } & \text { Work Breakdown Structure } \\ \text { WHA } & \text { Tungsten Heavy Alloys } \\ \text { WHO } & \text { World Health Organization } \\ \text { yd } & \text { Yards } \\ \text { yd } 3 & \text { Cubic Yards } \\ \text { YPG } & \text { Yuma Proving Ground }\end{array}$




\section{Introduction}

\subsection{Background}

Commercially, depleted uranium (DU) is used in medicine, space, aviation, and petroleum exploration. Particular applications include radiation shielding for the medical field and industry, counterweight components of aircraft elevators, landing gear, rotor blades, and radar antennae, ballast in satellites, missiles and other crafts, and drilling equipment used in petroleum exploration (http://www.fas.org/man/dod-101/sys/land/docs/du.html, accessed 20 October 2012). In military applications, when alloyed, DU is ideal for use in armor-penetrating munitions.

The United States (US) Army in some instances assumes stewardship for proper remediation of DU for its test ranges and manufacturing facilities. These responsibilities arise from the wide range of environmental concerns driven by policy, regulations, and public laws and the requirment to put "mission first." Typical DU remediation consists of wholesale excavation of DU-contaminated soil to a disposal facility for permanent containment. Disposal facilities are designed to store and contain the material and prevent the release of harmful pollutants to the environment. DU remediation is a high-cost operation requiring the creation of alternative methods that reduce cost, maximize effectiveness, and optimize efficiency. The latest breakthrough in available alternatives is large-scale physical separation augmented with chemical separation of DU from soil to reduce the volume of material that must be disposed. This advancement in technology should produce a cost- effective process for DU remediation. Initial testing has yielded promising results, but better-detailed cost estimation is necessary to compare the benefits/costs (B/C) of excavation, separation, containment, or a combination of these alternatives.

Since DU is a radioactive material, handling and test-firing may only occur at sites licensed by the Nuclear Regulatory Commission (NRC). Currently, the US Army holds 14 different NRC licenses for DU, while the Navy and Air Force hold "master" licenses that cover many different sites. DU firing sites have included: Yuma Proving Ground (YPG) in Arizona, Camp Roberts in California, Eglin Air Force Base in Florida, Jefferson Proving Ground in Indiana, Aberdeen Proving Ground in Maryland, Nellis Air Force Base in Nevada, and Ethan Allen Firing Range in Vermont (http://www.dmzhawaii.org/wpcontent/uploads/2009/02/depleted-uranium-fact-sheet.pdf, accessed 14 January 2012). 


\subsection{Problem Statement}

Many environmental groups consider DU an environmental concern; in order to mitigate exposure risks, innovative and cost-effective remediation techniques are needed. Life cycle cost (LCC) models quantify the benefit/ $\operatorname{cost}(\mathrm{B} / \mathrm{C})$ of different remediation technologies and help stakeholders select the appropriate method. In order to develop a LCC model - or total ownership cost (TOC) model - the following methodology as shown in Figure 1-1 is proposed.

Figure 1-1. Process to be used to develop LCC models for depleted uranium disposal.

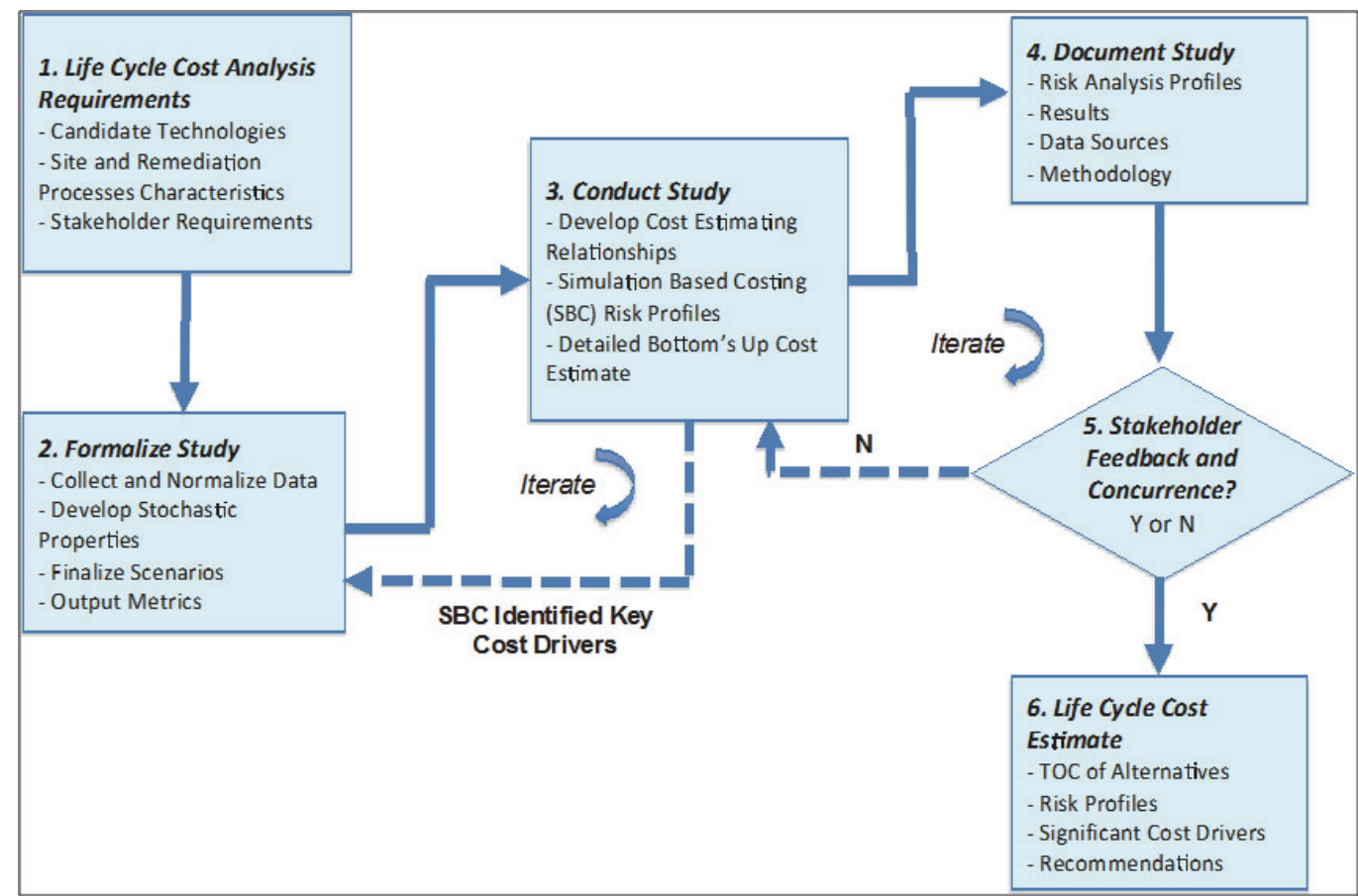

These LCC models will be used to evaluate four candidate remediation processes with the new technologies: Alternative 1-Physical Separation and Chemical Treatment; Alternative 2-Selective Excavation; Alternative 3Selective Excavation with Physical Separation and Chemical Treatment; and Alternative 4-Containment and Monitoring. Each alternative is applied to a 10 square mile sandy site which is considered "typical" for an Army test range. The LCC models will also be used to evaluate two remediation processes for a typical catchbox located on the firing grounds. Catchboxes (Figure 1-2) are used to trap DU penetrators and allow for their recovery when required. Periodic sifting of the material in each catchbox has been conducted to remove the larger DU fragments, as detailed in Martinell et al. (2010). The catchbox analysis conducted includes both total excavation and excavation followed by chemical remediation. 
Figure 1-2. Typical catchbox at an Army test range (from Larson et al. 2009).

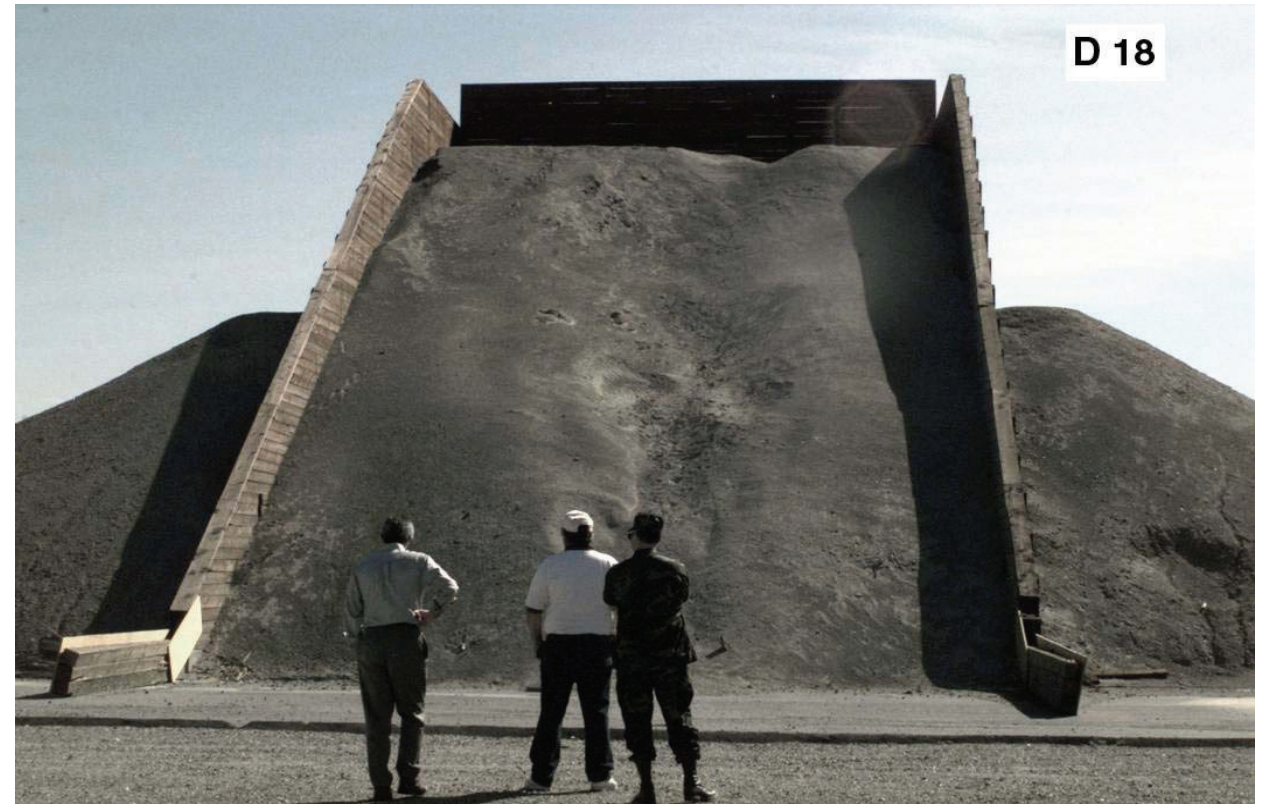

\subsection{Research Objectives}

The purpose of this research is to develop an LCC model for the evaluation of candidate DU remediation methods and technologies for soil remediation at military test ranges. The disposal of DU contaminated soil consists of the high level processes shown in Figure 1-3. The underlying objective is to develop usable cost estimating tools that will allow the user to get an accurate estimation of the DU disposal costs. Stakeholders will be able to get a direct, transparent, and unprejudiced comparison on candidate remediation methods. The return on investment (ROI) for additional research and development can also be assessed.

\subsection{Approach}

Depleted uranium remediation technologies being analyzed typically involve one or more of the following activities: excavation and earth moving, physical separation, chemical separation, and disposal of contaminated material. Unless an in-place stabilization technique is acceptable and utilized, earthmoving processes are required. The scope of this activity ranges from excavating and disposing of all contaminated soil to excavating, treating and re-emplacing the soil. There are health and environmental hazards associated with any earthmoving project. These are compounded by the uncertain toxicological and radiological effects of DU and the possibility of unexploded ordinance, which may exist on test ranges and proving grounds. 
Figure 1-3. Steps in the DU remediation process.

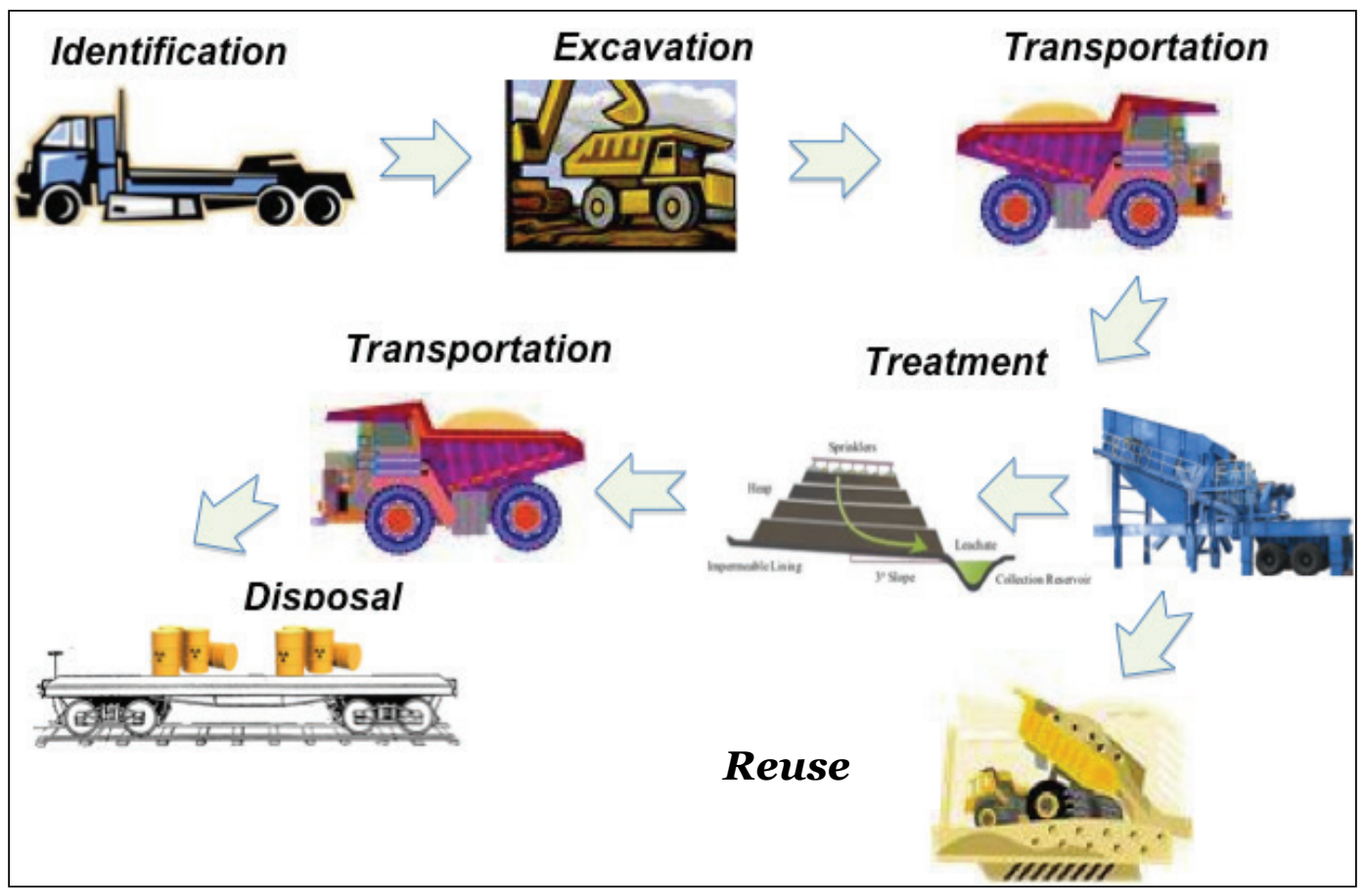

Physical separation techniques use the characteristics of the contaminant (density, particle size, shape, radioactivity, etc.) to segregate it from the soil. These techniques range from simply having personnel pick up DU fragments by hand (a technique the Army commonly uses on its test ranges) to increasingly complex technologies such as screening, sedimentation, centrifugation, filtration, and reverse osmosis. Physical separation techniques do not change the state of the contaminant.

A number of chemical treatment processes can be used to separate DU from contaminated soil. Although experience in remediating DU contamination is limited, these processes have long been used to separate other heavy metals (e.g., lead, gold, silver, cadmium, chromium) from soils in the mining and environmental remediation industries. The industry standard is soil washing. Soil-washing systems consist of first passing a fluid through the soil to dissolve the metal; then the chemistry of the solution is altered, causing the metal to precipitate. The soil can be excavated or treated in place.

In shallow soil, heavy metal contaminants can often be stabilized in place. This strategy uses a chemical binding agent that reacts with the metal to render it insoluble under a wide range of environmental conditions. Because the chemistry of DU is similar to that of other heavy metals, 
applying this technology to stabilize DU in situ should be similarly successful. The major disadvantage of in situ stabilization is that the metal remains in the soil; thus, under unforeseen circumstances, the metal could again become mobile in the environment. The depth of interest for this modeling effort is up to three feet; therefore, this alternative was not explored.

For this research, a robust LCC model was developed to analyze candidate alternatives involving hauling, physical separation, and chemical separation of the DU containment material. The LCC model will be a product of past data, expert solicitation, and scientific research. Based on the data gathered, the LCC model will develop a transparent estimate of the life cycle remediation costs. The process will include three phases that will affect cost:

- Separation and Loading - clear and grub site, excavation and short haul costs, physical separation, chemical separation, and excavation-site closing

- Hauling - transportation by rail and truck to the disposal and storage site

- Disposal - contaminated soil, DU waste chemicals, filters, etc. 


\section{Literature Review}

\subsection{What is Depleted Uranium?}

Uranium occurs naturally as a radioactive metal in all rocks and soils. There are three existing uranium isotopes, and all three are radioactive and emit decay products upon radioactive disintegration. Uranium is often used to power nuclear reactors and nuclear weapons. To make this possible, natural uranium must first be enriched - concentrating two of the uranium isotopes in the product material. Enrichment causes a byproduct of DU. Depleted uranium is 1.7 times more dense than lead, so it serves many civil and military purposes. Both uranium and DU may cause adverse health effects. The main hazard of uranium is the chemical toxicity of soluble forms of uranium. If internalized, uranium will cause health problems, as is the case with other heavy metals such as lead and cadmium. If either uranium or DU is inhaled, radiological hazards may exist as well.

According to the International Atomic Energy Agency

(http://www.iaea.org/newscenter/features/du/faq_depleted_uranium.shtml, accessed

14 January 2013) DU heath discussions include the following:

- Based on credible scientific evidence, there is no proven link between DU exposure and increases in human cancers or other significant health or environmental impacts.

- The most definitive study of DU exposure is of Gulf War veterans who have embedded DU shrapnel in their bodies that cannot be removed. To date, none has developed any health abnormalities due to uranium chemical toxicity or radio toxicity.

- It is a common misconception that radioactivity is the main health hazard of DU rather than chemical toxicity. Like other heavy metals, DU is potentially poisonous. In sufficient amounts, if DU is ingested or inhaled, it can be harmful because of its chemical toxicity. High concentrations could cause kidney damage.

According to the World Health Organization (WHO), very large amounts of DU dust would have to be inhaled to cause lung cancer from radio toxicity. Risks of other radiation-induced cancers, including leukemia, are considered to be very much lower still. 


\subsection{Depleted Uranium in the Military}

The US military uses DU for a variety of different purposes, including antiarmor tank penetrators and tank armor. Figure 2-1 is a photograph of a sabot round after leaving the barrel of a weapon system. After firing, the penetrator is flying straight toward the target as the sabot casing is breaking off. The sabot type round is used mainly for the M1 battle tank and Stryker MGS. The purpose of the sabot is to pick up the pressure of the burning propellant gasses and propel and launch the sub-caliber penetrator, which ensures the penetrator will strike the target accurately. Due to its mass and velocity, the DU penetrator breaks through the walls of an enemy tank and sends shrapnel flying inside the tank.

Figure 2-1. Sabot structure separating from DU penetrator.

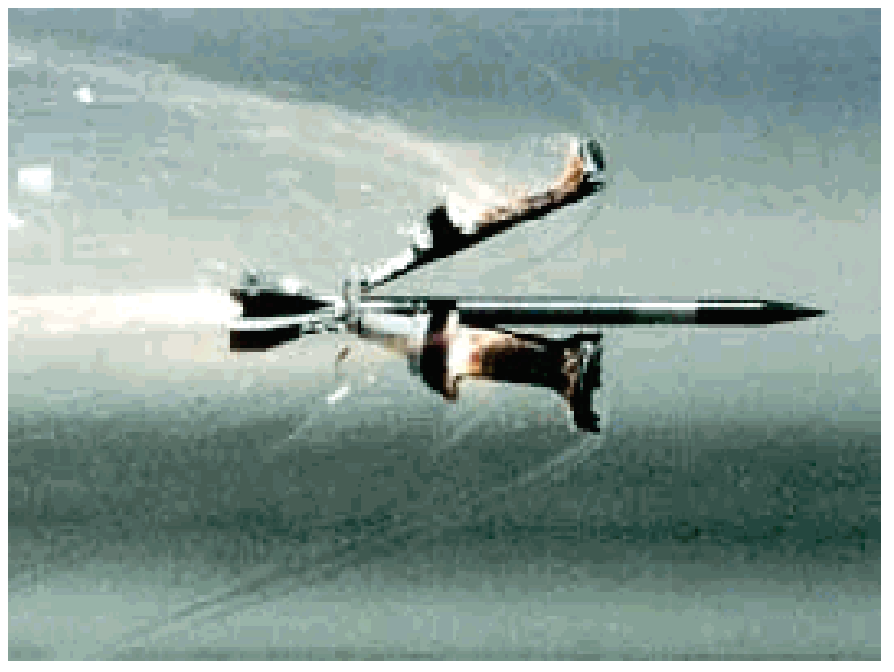

The physical properties and tendencies of DU are what make it so valuable to the US military. Due to its extremely high density, self-sharpening ability, and pyrophoric properties, DU is unmatched in its lethality and usefulness on the battlefield. In fact, the DU long rod kinetic energy penetrators outperform their modern conventional Tungsten Heavy Alloys (WHA) counterparts by about 8-10\%. Depleted uranium has a density of $18.9 \mathrm{~g} / \mathrm{cm}^{3}$ versus $17.6 \mathrm{~g} / \mathrm{cm}^{3}$ of WHA. Also, DU has a high rate of deformation, which allows it to "self-sharpen," causing a deeper, narrower cavity in the target. DU does not "mushroom" at the tip like WHA does during penetration, which makes DU much more effective. Additionally, the pyrophoric properties, such as the spalling of metal, make DU the more preferred metal. Therefore, the US military uses DU as its main source of armor-piercing munitions. A visual representation of the 
advantage of DU over WHA is shown in Figure 2-2. As shown, the DU sharpens as it pierces the armor; whereas WHA has the opposite effect as it mushrooms when penetrating the armor.

Figure 2-2. Depleted uranium versus tungsten heavy alloys (Photographs provided by ARDEC November, 2012).

$D U$ self-sharpens as it pierces armor, which reduces size of penetrator nose and increases its penetrating ability -forming a narrower, deeper cavity. With a density of $18.9 \mathrm{~g} / \mathrm{cm}^{3}$, it is $60 \%$ denser than lead. The photograph shows how DU is spalling by creating a dynamic fracture that creates small flecks of metal.

WHA tends to deform at the tip into a blunt mushroom shape as it penetrates armor, which limits its effectiveness. With a density of $17.6 \mathrm{~g} / \mathrm{cm}^{3}$ it weighs less than DU.

Uranium oxidizes as it weathers, producing uranyl oxides and salts, evident as black and yellow coatings on the solid surface (Mellini and Riccobono 2005). Chemical analysis and X-ray diffraction studies of DU found as corrosion products on the penetrator rods and in the surrounding soil from test ranges has shown heterogeneity in the oxidation products on both the rod surface and the surrounding soil. Both U(IV) and U(VI) are present in the yellow mineral (Mellini and Riccobono 2005), which is the one most commonly found in the soil surrounding the rods and is composed of a number of different minerals, including metaschoepite, becquerelite, billietite, and uranium oxide (Buck et al. 2004). Other minerals present include zippeite, and U-molybednum minerals. These compounds have relatively high solubility in water (Meinrath et al. 2003). The uranium oxides have significant solubility in water and the resulting ionic uranium can form uranium-based salts with lower densities, as well as sorb to clays and organic matter in soil and form complexes with soil particles (Johnson et al. 2004, Dong et al. 2006, Choy et al. 2006).

\subsection{Environmental Risk}

Depleted uranium can contaminate the environment through several different means: soil, water, biota, and as airborne particles. Depleted 
uranium will naturally act differently when exposed to different surroundings. For example, in a swampy, wet environment, DU naturally assumes a state in which it is generally insoluble; therefore, it precipitates and becomes immobile. Depleted uranium on the surface or in shallow water will likely be exposed to oxidizing conditions. Under these conditions, the DU will oxidize to a soluble state in which it can dissolve and be transported by water. This is, arguably, the highest risk that DU poses.

However, according to the International Atomic Energy Agency, the corrosion of DU penetrators varies. For example, in quartz sand or acidic volcanic rock, high solubilization rates could lead to local contamination of groundwater. However, the risk would be minimal to people living in the area as dose rates are unlikely to be much greater than normal background radiation levels (http://www.iaea.org/newscenter/features/du/faq_depleted_uranium.shtml\#q3, Acessed 14 January, 2013).

\subsection{Remediation Technologies}

In order to reduce the health risks that DU poses, several remediation technologies have been developed to separate and remove DU from a contaminated segment of soil or water. For contaminated soil, there are two generally accepted solutions: excavating the contaminated soil and hauling it to a low-level waste repository, or excavating the soil and then using a treatment process to remove the DU. Treatment processes include physical separation using a screening device in conjunction with magnetic separation, gravimetric separation, or a device called the Segmented Gate System. All of these methods effectively reduce the volume of contaminated soil; hence, these methods reduce the cost of treating or disposing of the contaminant. The uncontaminated soil can then be further treated or returned to the original location. Chemical processes (soil washing) used to treat contaminated soil include heap leaching (Kappes 2002). Certain chemical additives are mixed with water, and when the water is added to the soil, it causes the DU to become more soluble. After draining, all the contaminants are dissolved in the water, and the soil is then returned to the original site.

There are two prominent methods of dealing with contaminated groundwater: the pump and treat method and the use of a permeable reactive barrier. The pump and treat method simply consists of pumping the contaminated water out of the ground, treating it, and returning it. The second method is a more permanent system consisting of placing a reactive substance below the ground in the contaminated aquifer. This substance 
reacts with the contaminant and immobilizes it; therefore, the groundwater is decontaminated as it passes through the permeable barrier.

Other methods that work with soil and water include in-situ stabilization and phytoremediation. In-situ stabilization includes the use of amendments, capping, and grouting to immobilize the contaminant in its current location. Adding amendments to the soil solidifies the DU into insoluble particles. Phytoremediation is the use of plants to help reduce the amount of DU in the soil or water. Certain plants - such as sunflowers and the Indian mustard plant - uptake a small amount of uranium as a part of their natural rhizofiltration process. 


\section{Alternative Analysis}

\subsection{Introduction}

The LCC model was developed based on a 10-square-mile sandy site. This site is not meant to represent any specific test range, but does represent the vastness of many of the US military test areas. This is typical for a test range where DU rounds might be fired from an M1 tank in a desert environment. Fortunately, extensive data exists from YPG. However, the intention was not to model that site specifically, but to provide relative costs of different candidate technologies for a sandy site. Also, sandy soils were used because heap leaching seems to work best for this type of soil. Heap leaching can be used to extract metals from ore and contaminated soil via a series of chemical reactions that absorbs these metals/ minerals and then separates them after their division from other earth materials. Heap leach mining differs in that it uses a liner and a drainage system to contain the ore and then adds the chemicals via drip systems to the ore (Kappes 2002).

Several candidate technologies exist for DU remediation. For this research, four candidates, summarized below, were used.

- Alternative 1 - Physical Separation and Chemical Treatment. This process is described in detail in Section 3.2. In essence, all of the contaminated material will be hauled to an approved disposal site after selective removal of DU concentrated soils using physical and chemical processes.

- Alternative 2 - Selective Excavation. This process is described in more detail in Section 3.3. It consists of using a completed mapping process that tracked where the DU exists in the soil. Only these "hot spots" will be excavated and the material disposed of to an approved low level or mixed radiation disposal site.

- Alternative 3-Selective Excavation with Physical Separation and Chemical Treatment. This process is discussed in further detail in Section 3.4. This alternative is very similar to Alternative 2, with the addition of a physical and chemical treatment process. After the hot spots are excavated, the contaminated soil is physically and chemical treated. 
- Alternative 4-Containment and Monitoring. Containment and monitoring includes the practice of closing the site, placing security fences around the site with security cameras as needed, using groundwater wells to determine whether the contaminate (e.g., DU) is or has migrated from the site, and hiring an engineering firm to routinely test the site. This alternative might not be viable due to policy and other considerations. However, the incremental cost of remediating the site is of interest. This alternative is described in Section 3.5.

Life cycle costing has emerged as an extremely important tool when analyzing multiple alternatives because it allows decision makers to make better informed and prudent decisions. The LCC needs to contain the complete set of cost factors and incorporate risk in order to determine the net present value (NPV) or the total LCC that should be allocated to operate the system in the future. The NPV also allows a fair assessment and comparison of multiple alternatives that have different remediation time constraints.

Due to the Nuclear Regulatory Commission (NRC) changing the classification of DU from naturally occurring radioactive material (NORM) to a nuclear by-product, the disposal costs for permanent disposal of DU have risen sharply. In the oxide form, uranium can be disposed of as lowlevel radioactive waste at an approved disposal facility. Current projected disposal costs are $\$ 1,300$ per yd 3 ; such costs make volume reduction in the form of chemical remediation, selective excavation - or both - imperative to reducing costs. To excavate a 10-square-mile training area to a depth of 3 feet without using some type of physical/chemical separation would require the disposal of nearly 31 million cubic yards of soil. The high-end estimate of the current project disposal cost is $\$ 1,388$ per yd $\mathrm{d}^{3}$ (\$2013), which would drive the total cost well over $\$ 40$ billion. The most likely estimate for disposal cost is $\$ 756$ per yd 3 , but even if disposal costs were reduced because of economies of scale to the $\$ 200-\$ 300$ per yd3 range as shown in Figure 3-1, the total cost would still exceed $\$ 6$ billion. For this reason, total excavation is simply infeasible; it is necessary either to selectively excavate or to use physical separation and chemical remediation techniques to reduce the volume of material destined for disposal. 
Figure 3-1. Sensitivity analysis of disposal cost.

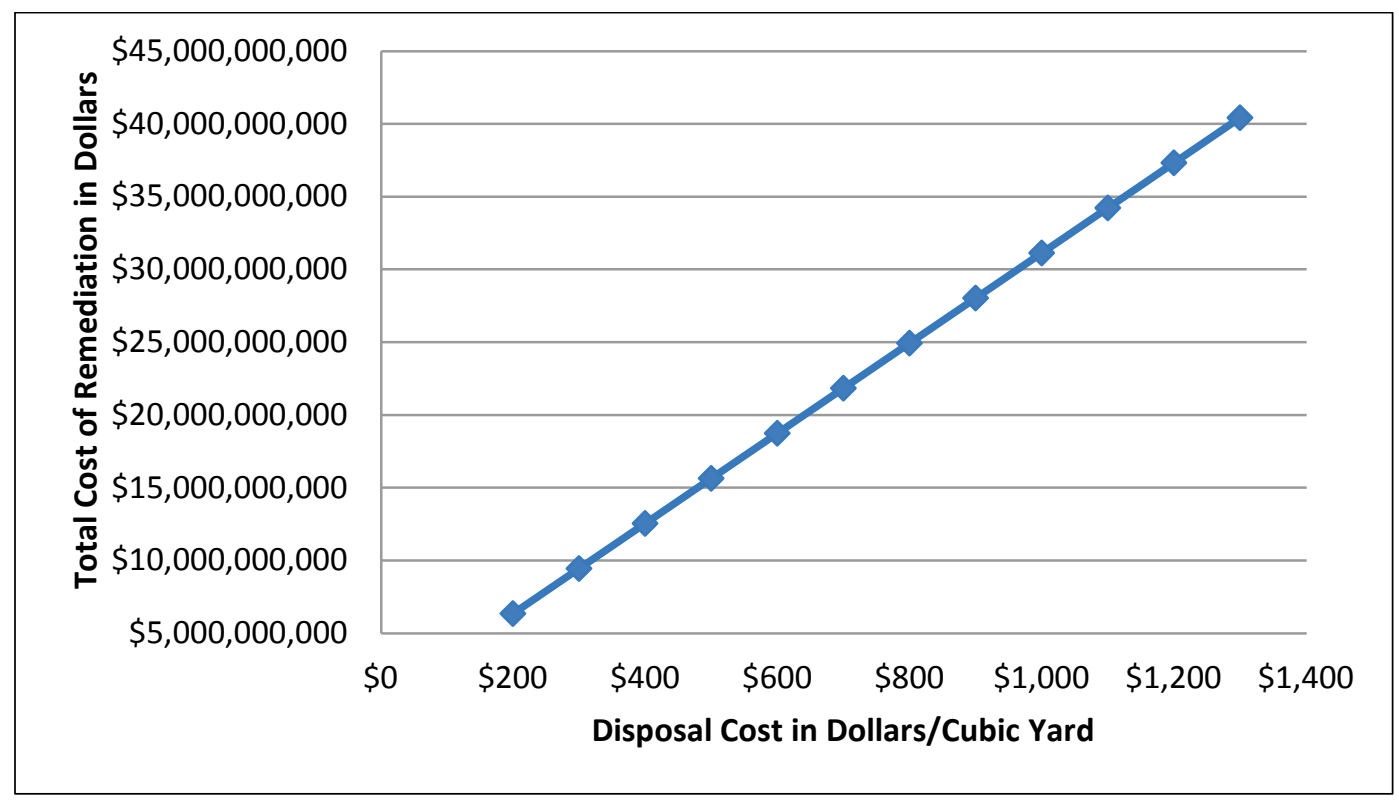

\subsection{Alternative 1: Physical Separation and Chemical Treatment}

This alternative combines physical separation and chemical treatment techniques to remove DU from contaminated soil. For this alternative, all of the range soil that has been removed to a depth of $3 \mathrm{ft}$ will be sifted and filtered. This remediation technique consists of two separation processes, which will be broken down into four stages for explanation.

Stage 1 is the dry separation process, which is characterized by the physical separation of the DU via a physical barrier, such as a screen or sieve. Ideally in this process, a majority of the DU can be removed from the soil by using Geiger counters or similar devices to separate the DU from the soil. The screen size that has traditionally been used filters out DU fragments larger than $4.76 \mathrm{~mm}$. Smaller screen sizes can lead to issues of filter clogging in heavy clay soils. The screen size can be adjusted dependent on the location of the contaminated soil and the soils composition. After the fragmented DU is removed from the soil via physical separation, a secondary process, such as chemical filtration, is implemented to treat the remaining soil fines.

Stage 2 involves a chemical separation of the DU from the soil fines, which removes the remainder of the DU before the soil is returned to the original site. The general process that is used starts with the contaminated soil being flushed with a chemical bath that dissolves the DU and catches the DU saturated liquid in a drip pan below the soil. Depending on the size and scale of the operation, a catchbox may be used as an intermediate 
step. The drip pan uses gravity separation, which allows all of the sediment to fall to the bottom and the DU saturated liquid to stay at the top. The sediment free fluid then flows out of the drip pan onto a filter. The filter extracts the DU from the saturated liquid using fishbone or chitin membranes. The DU is extracted and left in the filter. The filtered liquid is cleansed of DU and allowed to run back through and continue to dissolve another iteration of DU saturated soil. The soil is now DU free and allowed to be returned to the original site. The separated DU held in the filters as well as the solid DU separated through the physical separation - can now be moved to a radioactive waste landfill.

Stage 3 begins with piles of decontaminated soil and ends when this soil is returned to its original excavation site. Once the soil is returned to the sites, each site is bulldozed in order to make the sites presentable.

Stage 4 consists of transporting the DU and other contaminated soil from the stockpile at the chemical filtration site to the train station. For demonstration purposes, the team used 15 miles since most military facilities have a rail head. Depending on the amount of DU removed, this process will only be necessary approximately once per year. Stage 4 is complete once all the contaminated material from the stockpile is loaded on the train and ready for transportation. For more explanation of these steps, please refer to the high resolution processes presented in Appendix A and the details of the hauling model contained in Appendix B.

Figure 3-2 illustrates the site remediation from start to finish provided the site is not contained or organic material used to leach the DU from the soil. The first step is excavation of the site or catchbox. This contaminated soil is then run through a physical separation where a percentage of the DU is removed from the soil. Then, the partially contaminated soil is run through a chemical filtration process that removes the remaining DU from the soil. The deliverables from this process are cleansed range soil, which is returned to the site, and DU waste in the form of solid DU, DU filtration fluid, and used DU filters. These materials are then hauled off to a disposal site where they are stored.

This is a very effective remediation technique with large pieces being physically removed. Also, the small pieces that are not removed during physical separation and soil that has been contaminated because of oxidation are treated with the chemical treatment process. However, this 
Figure 3-2. Remediation process.

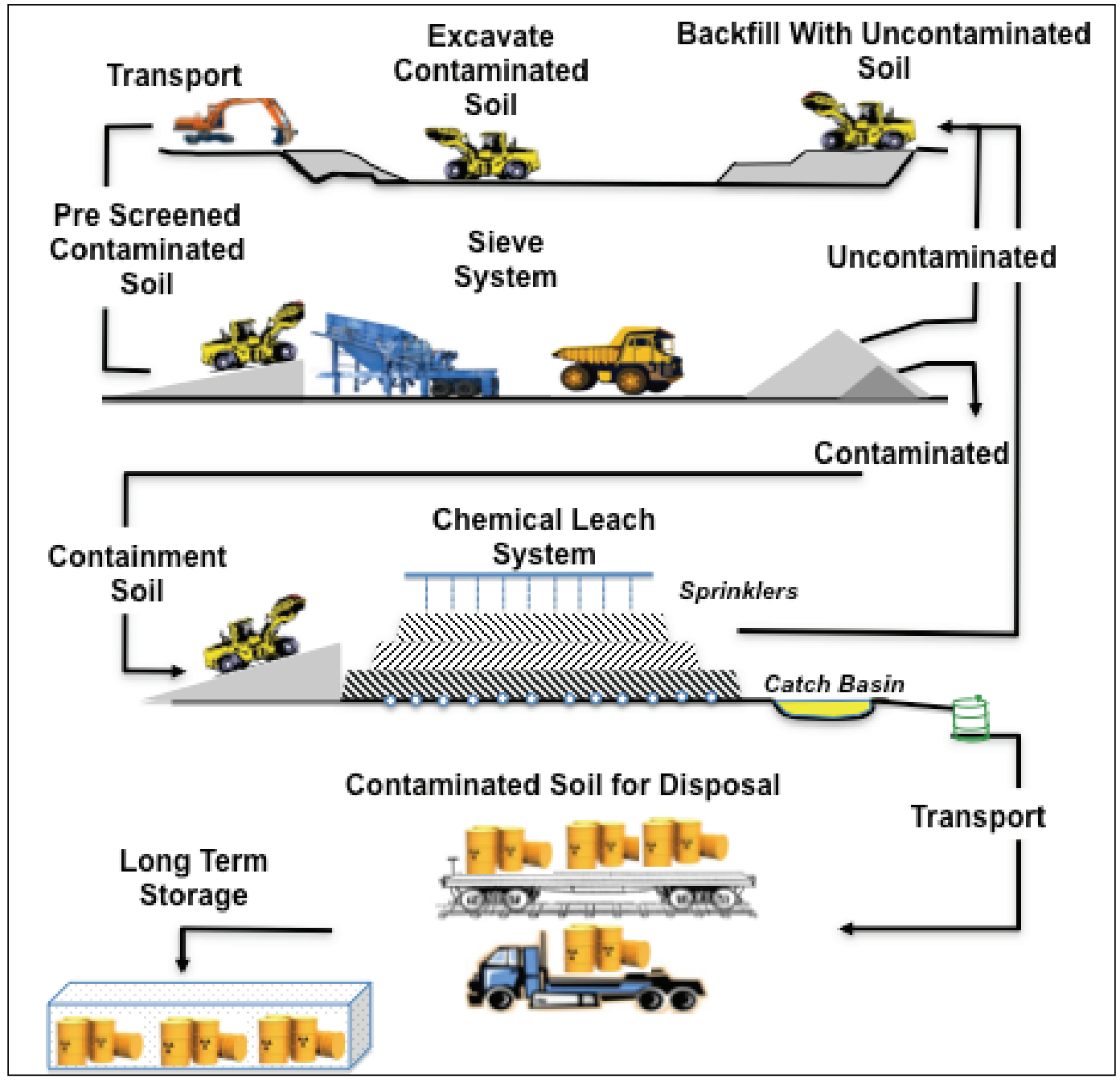

is a very expensive process because the entire contaminated area must be excavated, treated, and then restored. As previously stated this involved two way hauling of 31 million cubic yards of material. Many of the areas of interest are many square miles making this alternative cost prohibited.

\subsection{Alternative 2: Selective Excavation}

Subject matter experts (SME) at the US Army Armament Research, Development, and Engineering Center (ARDEC) at Picatinny Arsenal proposed the use of a technology (see Figure 3-3) that could be used to map high concentrations of DU contaminated soil (i.e., hotspots). Identifying and selectively remediating these hotspots would drastically decrease the amount of soil to be excavated and treated. Figure 3-4 shows the results of this sensing and mapping technology at YPG where the technology was demonstrated. These red spots correlated to significant concentrations of 
DU. After mapping the site of all the DU hotspots, a $2 \mathrm{ft} \times 2 \mathrm{ft}$ area would be excavated down to a depth of $3 \mathrm{ft}$ as shown in Figure 3-5. Figure 3-6 shows how the GPS mapping systems used has some inherent error. The $2 \mathrm{ft}$ by $2 \mathrm{ft}$ area is well within the mapping error. For this alternative, all of the DU and contaminated soil would be completely removed from each of these hot spots. This DU contaminated material is then hauled to a storage facility. With the use of the mapping process the amount of excavated material would be significantly decreased, dramatically reducing the hauling cost.

Figure 3-3. Equipment used to map DU contaminated soil.

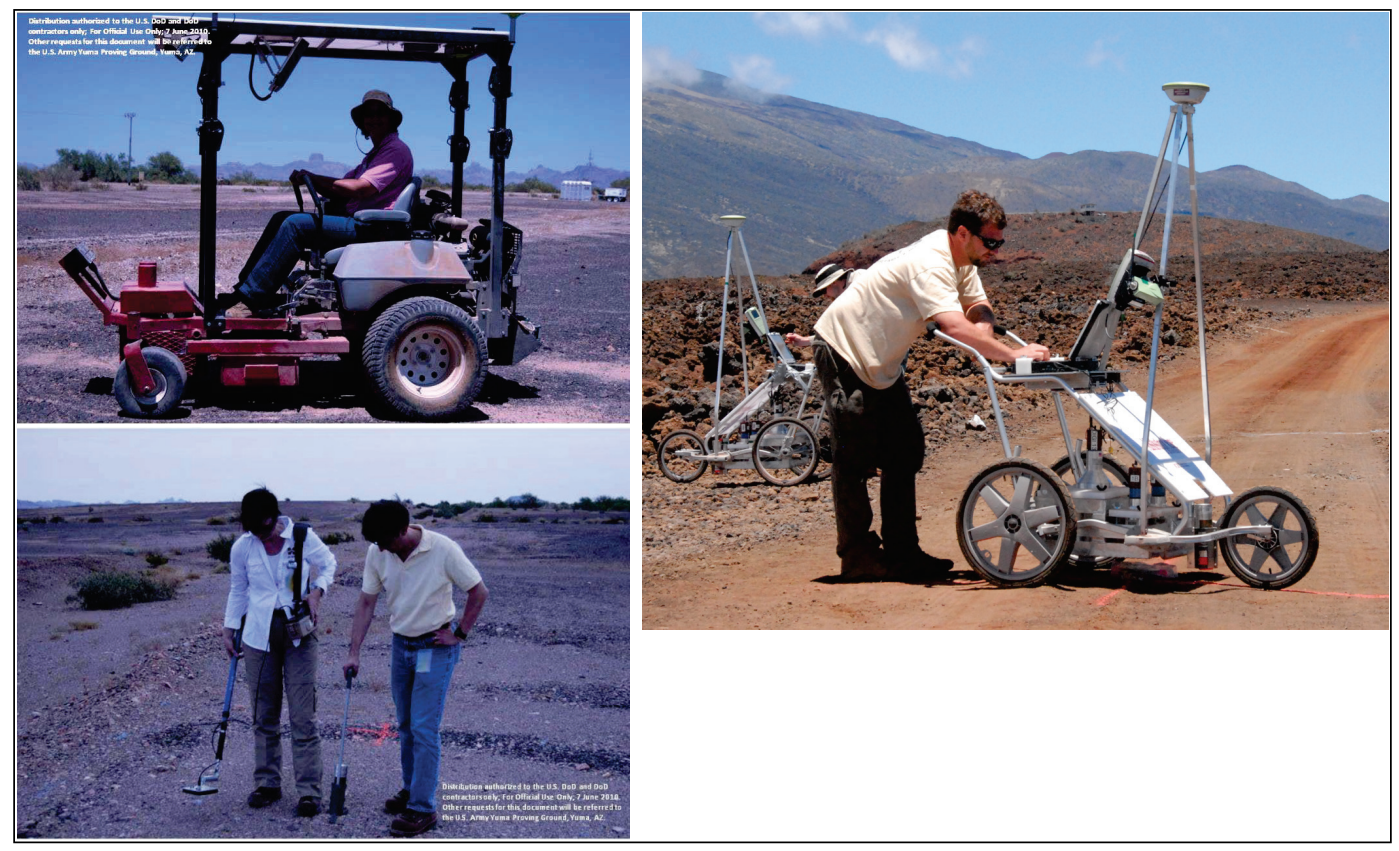

Figure 3-4. DU site contamination mapping.

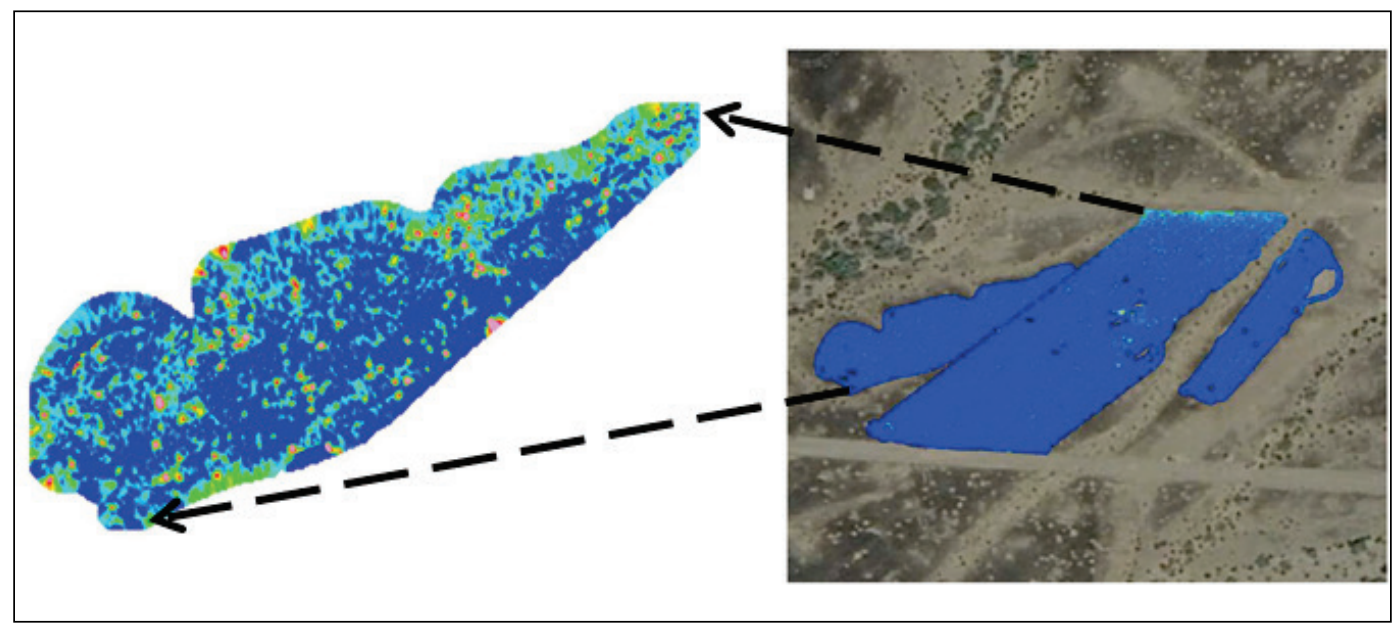


Figure 3-5. Resolution of GPS mapping system.

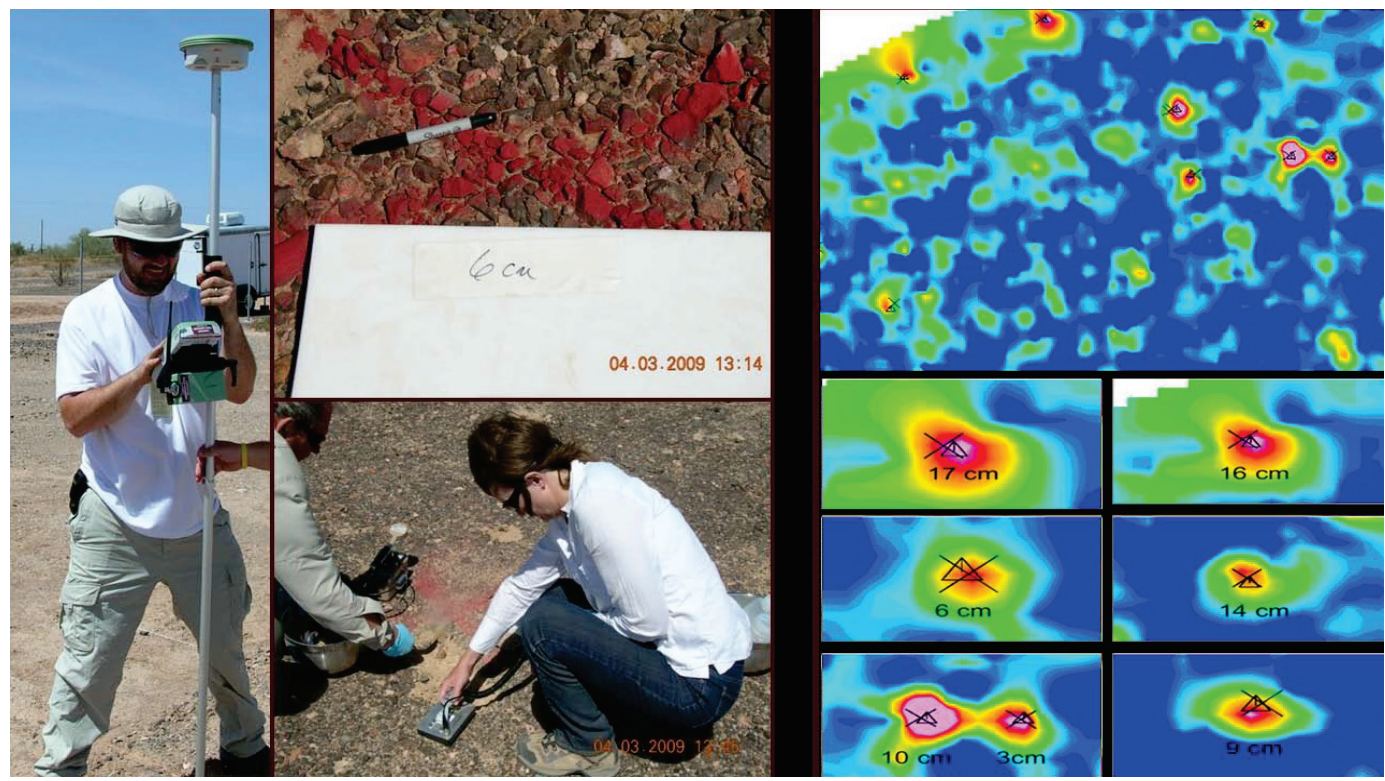

Figure 3-6. Amount of material to be excavated as part of the selective excavation process.

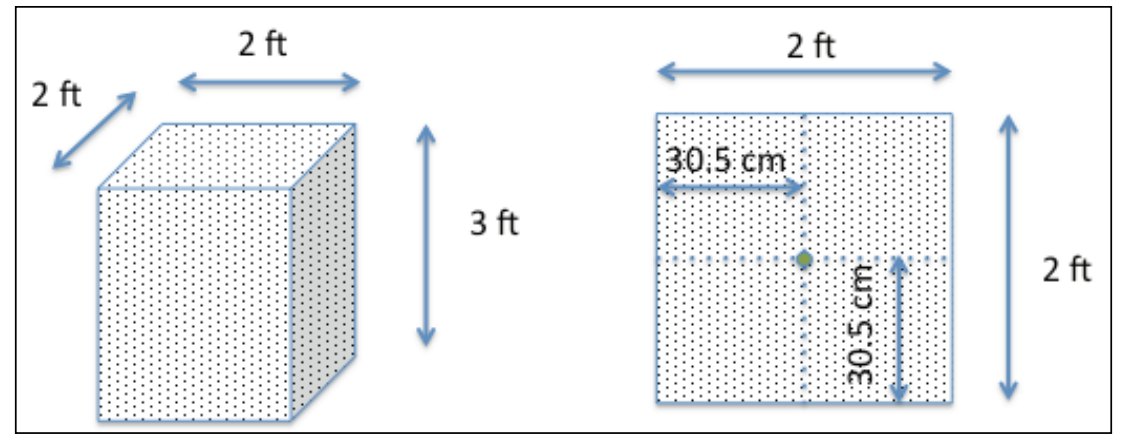

Because of the high disposal cost, further research into better mapping and identification technology should be considered. Any technology that contributes to identifying localized DU contamination will lead to reduced hauling, remediation, and ultimately, disposal costs. The amount of DU hauled and disposed are the significant cost drivers for this alternative.

Figure 3-4 and Figure 3-5 show the DU contaminated hot spots from a test site at YPG used to test various mapping techniques. This was used as typical for DU density for the general model. The image to the left (Figure 3-4) is an enhanced view of the contaminated area. Upon closer examination, it was estimated that a total of 123 hotspots were present in the sample area. This would require the excavation and removal of $1,476 \mathrm{ft}^{3}$, or about $55 \mathrm{yds}^{3}$ (123 hotspots by $4 \mathrm{ft}^{2}$ by $3 \mathrm{ft}$ deep) from this test site, which is approximately $375,000 \mathrm{ft}^{3}$ (Figures 3-5 and 3-6) in volume. This was extrapolated 
to represent the entire site. This representation is probably extremely conservative since the terrain naturally limits firing in some areas. The authors will present some sensitivity analysis in Chapter 5 in an effort to bound this problem.

The process of selective excavation without further soil treatment is outlined in Figure 3-7.

Figure 3-7. Process for selective hot spot excavation and no chemical reduction of DU.

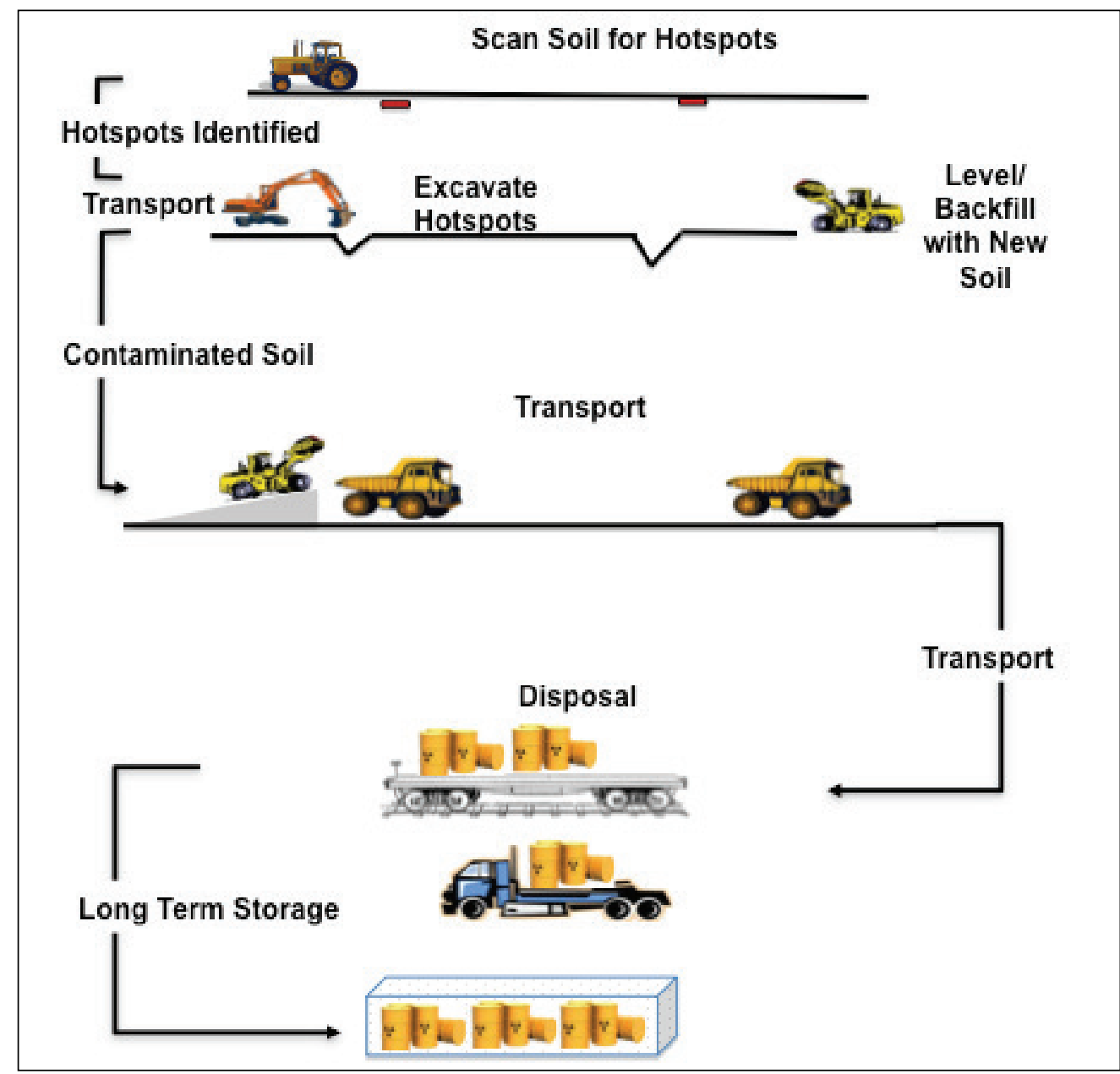

\subsection{Alternative 3: Selective Excavation with Physical Separation and Chemical Separation}

This alternative uses the same process as the previous option with the addition of the physical and chemical separation processes outlined in Alternative 1. Essentially, it combines Alternatives 1 and 2 but for only the material excavated from the hotspots. After the hot spots are excavated, the removed soil is physically treated to separate the large pieces of DU. Once 
this physical separation process is complete, the soil is still contaminated with smaller, finer DU particles that slipped through the physical separation. Therefore, the soil is treated again through a chemical process to extract the rest of the DU. Once this process is complete, the large DU fragments from the physical separation process and the contaminated byproducts of the chemical treatment process are transported to a storage facility. This option drastically reduces the amount of material that must be transported to the storage and processing facility as compared to Alternatives 1 and 2. For more detailed information on the excavation process or the physical and chemical treatment processes, refer to Section 3.2 or 3.3, respectively. This process is presented visually in Figure 3-8.

Figure 3-8. Selective hot spot excavation with chemical reduction of DU contaminated material.

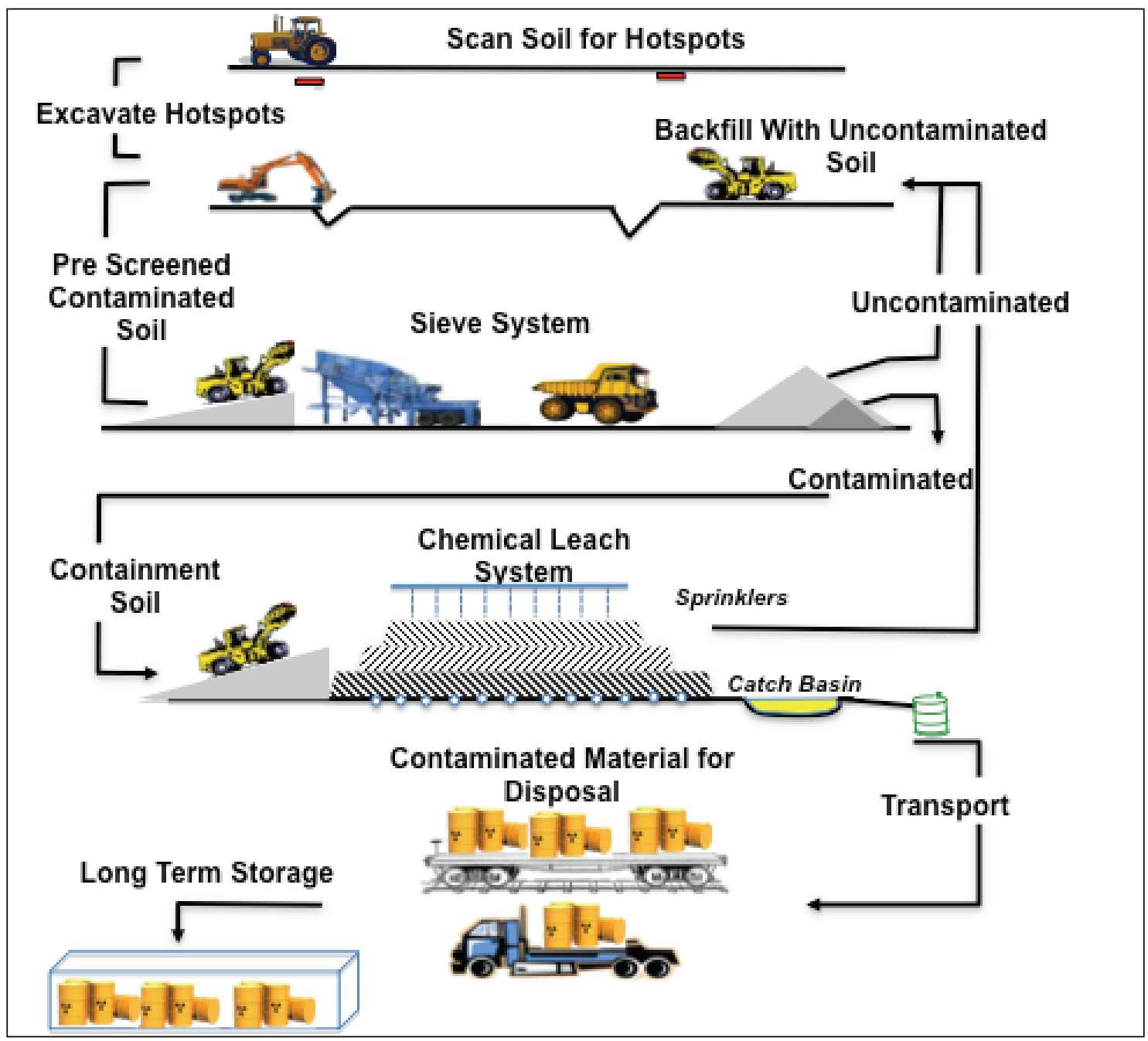




\subsection{Alternative 4: Containment and Monitoring}

There are several possible approaches that could meet the intent behind the all-encompassing need of site remediation. The simplest of which is to do nothing at all. A possible site remediation technique is simple site closure, which would simply fence the site in, monitor ground water, etc., and allow for nature to run its course on the DU remains. Another possible addition to this remediation technique would be the use of vegetation to absorb the DU in the soil. The cost effectiveness of this technique would vary dependent on the time frame that the site needed to be remediated, the amount of precipitation the site receives and the soils ability to maintain plant life. Trees have been used in the past to leach heavy metals with limited success from the soil and this technique could be implemented on a DU range in need of clean up. Information available on this process is very limited and environmental dependence of this solution causes it to be difficult to do any significant analysis. Depending on the site characteristics such as proximity to local population and how the site fits into the water cycle would affect the extent of remediation required at the site. The long term and indirect costs (i.e., health problems caused by heavy metals, etc.) that are unforeseeable which make this option seem like the most cost effective, but these unforeseeable costs may have significance in the future. There also may be political/environmental issues that rule out this option. 


\section{Life Cycle Costing}

\subsection{Introduction}

Recent environmental awareness and a significant reduction in the Department of Defense (DoD) budget have made good cost estimation practices a necessity. When combined with the enormous cost of environmental remediation and the potential for long-term problems, LCC has emerged as an extremely important tool when analyzing multiple alternatives because it allows decision makers to make better informed and prudent decisions. The LCC needs to contain the complete set of cost factors and incorporate risk in order to determine the TOC that should be allocated to operate the system in the future. Transparent LCC models allows for a fair assessment and comparison of multiple alternatives that have different remediation times. In order to understand the true scope of this system, and model it correctly, a bottom-up approach was used as opposed to a topdown approach, as seen in Table 4-1.

Table 4-1. Different approaches to modeling.

\begin{tabular}{|l|l|l|l|}
\hline \multicolumn{2}{|c|}{ Bottom-up Approach } & \multicolumn{2}{c|}{ Top-down Approach } \\
\hline Pros & Cons & Pros & Cons \\
\hline $\begin{array}{l}\text { Much higher } \\
\text { degree of } \\
\text { accuracy }\end{array}$ & $\begin{array}{l}\text { Time consuming and } \\
\text { not always feasible } \\
\text { because of the lack of } \\
\text { details }\end{array}$ & $\begin{array}{l}\text { Can be completed very } \\
\text { quickly }\end{array}$ & $\begin{array}{l}\text { Global estimate (not } \\
\text { very accurate) }\end{array}$ \\
\hline & $\begin{array}{l}\text { Requires extensive } \\
\text { knowledge of system } \\
\text { and inner workings }\end{array}$ & $\begin{array}{l}\text { Can be performed with } \\
\text { limited knowledge of } \\
\text { system }\end{array}$ & \\
\hline
\end{tabular}

When done correctly, proper cost estimation can provide benefits that greatly surpass the costs to perform it. Cost estimation can result in: lowering the cost of doing business, increasing the probability of winning new contracts, increasing and broadening the skill-level of staff members, acquiring a deeper knowledge of the proposed project, and understanding, refining, and applying the proper LCC procedures (DoD 1995).

\subsection{Bottom-Up Build}

A bottom-up build refers to modeling the system in the most accurate way possible by first understanding all of the intricate inner workings and cost 
drivers. This allows us to understand how the individual drivers come together to impact the entire system or project cost. It is important to maintain an organized and in-depth understanding of the alternatives and associated processes in order to ensure all factors are properly accounted for in the model build. Proper data collection is also essential in order to properly represent the impact that each factor will have on the total project cost. This methodology, along with process maps used to develop the team's model, is detailed in Appendix A.

\subsection{Cost Estimating Relationships}

A cost estimating relationship (CER) is an algorithm relating the cost of an element to the physical or functional characteristics of that cost element or a separate cost element, or relating the cost of one element to the cost of another element. It is a mathematical expression that describes for predicative purposes, the cost of an item or activity in terms of one or more independent variables. They can be found using regression analysis on old data to find a function that best matches the historical observed costs. To develop CERs, the following information is required (DoD 1995):

- Reliable historical cost, schedule, and technical data;

- Work breakdown structure (WBS), WBS dictionary, product tree, detailed process map, and/or physical architecture;

- Analysis to determine significant cost drivers; and

- Knowledge of basic statistics and software.

A parametric cost model (PCM) is "a physical, mathematical, or logical representation of a system, entity, phenomenon, or process" (Farr 2011). "The origins of parametric cost estimating date back to World War II. The war caused a demand for military aircraft in numbers and models that far exceeded anything the aircraft industry had manufactured before. While there had been some rudimentary work from time to time to develop parametric techniques for predicting cost, there was no widespread use of any cost estimating technique beyond a laborious buildup of labor-hours and materials" (DoD 1995). A PCM is defined as: "a group of cost estimating relationships used together to estimate entire cost proposals or significant portions thereof. These models are often computerized and may include many inter-related CER's" (DoD 1995). Good CERs can provide quick rough-order estimates that are extremely useful due to the level of detail that goes into creating a CER with this bottom-up approach to modeling. This allows separation of all of the analysis, simulation, and 
data collection from the decision maker. The decision maker can be presented with a quick and tested equation they can manipulate based on changing input variables, and they will still be returned a relatively accurate cost estimate very quickly.

\subsection{Simulation Based Costing}

A simulation is a "stochastic implementation of a model over time. It is a technique that can be used for design, testing, analysis, or training" (Farr 2011). Risk is inherent in specific estimates of system cost and must be factored into any suitable model. The advantages of simulation include the following:

- Models are easier to explain and understand than a closed-form mathematical equation,

- Simulation can be used for complex, real-world situations or conditions that are not included in analytical models,

- Extended periods of time can be simulated in a short period of time using a computer,

- It is much less expensive to construct a computer model of a system than to build a physical system for experimentation,

- Simulation allows for easier "what-if" analysis,

- Relatively straightforward, minimal cost,

- Greater flexibility in representing the system and has fewer underlying assumptions, and

- A model can be used repeatedly.

It is important to distinguish "between uncertainty (lack of knowledge or decisions regarding program definition or content) and risk (the probability of a predicted event occurring and its likely effect or impact on the program)" (NASA 2008). Risk is represented by cost risk distributions displaying a given cost estimate range and the likelihood of occurrence along that predicted range. Monte Carlo simulation and CERs are particularly useful for these types of problems. Monte Carlo simulations give a point estimate and probabilistic distribution for each individual cost factor. Cost estimating relationships break the project cost into several smaller parts and provide an estimate by using least squares regression analysis of similar data from the past. Cost estimating relationships are especially useful when paired with the probability distributions such as uniform, normal, and Poisson distributions offered by Monte Carlo simulation. Once all of the appropriate cost distributions have been applied, 
simulation based costing (SBC) can be used to provide the total cost risk profile through repeated simulation runs of the various cost distributions. Decision makers can be given an expected cost range interval and an associated level of confidence, which they can change however they deem necessary. Modeling and simulation is the only tool that can relate risk to cost for complex problems.

When developing LCC models for problems where research and development are still needed and some of the input is either unknown or has a low degree of confidence, SBC can help with conducting solid analysis. Specifically, SBC can be used to identify those inputs that have the biggest contribution to the total answer. Thus SBC can be used to identify the inputs that are the key cost drivers. Subsequently, investment can be made in research and/or effort in better developing that input or better conducting meaningful sensitivity analysis. The SBC results can also be used to develop CERs that use as input the key cost drivers. In Chapter 5 , the results of sensitivity analysis is presented on such key variables as the percentage of DU in the soil and the volume of material solely based upon the SBC results identifying these inputs as the two key inputs.

\subsection{Summary}

In lieu of simply developing a spreadsheet bottom-up model, a SBC model was conducted in order to assess risk. A CER was developed as a simple planning tool which can be utilized for rough order of magnitude TOC for these types of problems. Given the uncertainty of the technology, SBC is important in order to understand cost risk. 


\section{$5 \quad$ Life Cycle Cost Analysis Methodology using a Sandy Soil Demonstration Site}

\subsection{Introduction}

Bottom up cost estimates were formulated to look at all four alternatives for remediation of the generic sandy soil site, from the start of the remediation process to disposal of the DU. The details of the four alternatives were broken into separate Excel models.

Table 5-1 depicts the four different scenarios the team used for the LCC analysis of the candidate test range. For Alternative 3, a CER was developed and cost risk assessed using SBC because it was determined the most likely course of action based upon the bottom up cost analysis. Table 5-2 lists the two catchbox alternatives for which a bottom up TOC estimate was developed.

Table 5-1. Test range scenarios for which LCC are determined.

\begin{tabular}{|l|c|c|c|}
\hline Site & $\begin{array}{l}\text { Bottom Up } \\
\text { Estimate }\end{array}$ & CER & $\begin{array}{l}\text { Stochastic } \\
\text { Model }\end{array}$ \\
\hline Sandy Site & X & & \\
\hline $\begin{array}{l}\text { Alternative 1 - Physical Separation and Chemical } \\
\text { Treatment }\end{array}$ & $\mathrm{X}$ & & \\
\hline Alternative 2 - Selective Excavation & $\mathrm{X}$ & $\mathrm{X}$ & $\mathrm{X}$ \\
\hline $\begin{array}{l}\text { Alternative 3 - Selective Excavation with Physical } \\
\text { Separation and Chemical Treatment }\end{array}$ & $\mathrm{X}$ & & \\
\hline Alternative 4 - Containment and Monitoring & & \\
\hline
\end{tabular}

Table 5-2. Catchbox scenarios for which LCC are determined.

\begin{tabular}{|l|c|}
\hline Site & Bottom Up Estimate \\
\hline Sandy Site & \\
\hline Alternative 5a - Total Excavation & $X$ \\
\hline Alternative 5b - Excavation With Chemical Remediation & $X$ \\
\hline
\end{tabular}




\subsection{Sandy Site}

\subsubsection{Site Characterization}

The generic sandy site is modeled after a theoretical range with desert conditions which include minimal rainfall, little to no stagnant water, and few creeks with little to no running water. The soil is primarily sand with little to no vegetation and wild life. These desert conditions allow for two main avenues that the DU can leave the site. The first is by way of groundwater that is present deep below the surface, and the second is during flash flooding of the site during a rain storm.

Table 5-3 contains the input variables used for the four remediation alternatives. Each variable used in the models is presented in that table along with an expected value, probablisitc distribution, and the data source. The catchbox scenarios and the corresponding input data are presented in Section 5.3. Note that values in which probabilities were not assigned have a NA or not applicable in the table. If these values are fairly well known or do not vary significantly, they are represented with a deterministic value and a probability distribution is not assigned.

\subsubsection{Sandy Site Bottom up Based LCC Estimate}

\subsubsection{Alternative 1. Physical Separation and Chemical Treatment}

The 10 square mile site contains the left and right limits of the testing range; however, most of the rounds were likely concentrated down the center of the range. The pitch of the DU test fire allows the assumption that the DU would not penetrate deeper than $3 \mathrm{ft}$. For this Alternative the entire site would be excavated to a depth of $3 \mathrm{ft}$ and then the excavated material would require physical separation and chemical treatment of the DU to reduce the soil volume. The cleansed soil will be backfilled at the site and the contaminated soil and filters shipped to a disposal site for long-term storage. 
Table 5-3. Data variable sheet for DU remediation stochastic and bottom-up detailed models.

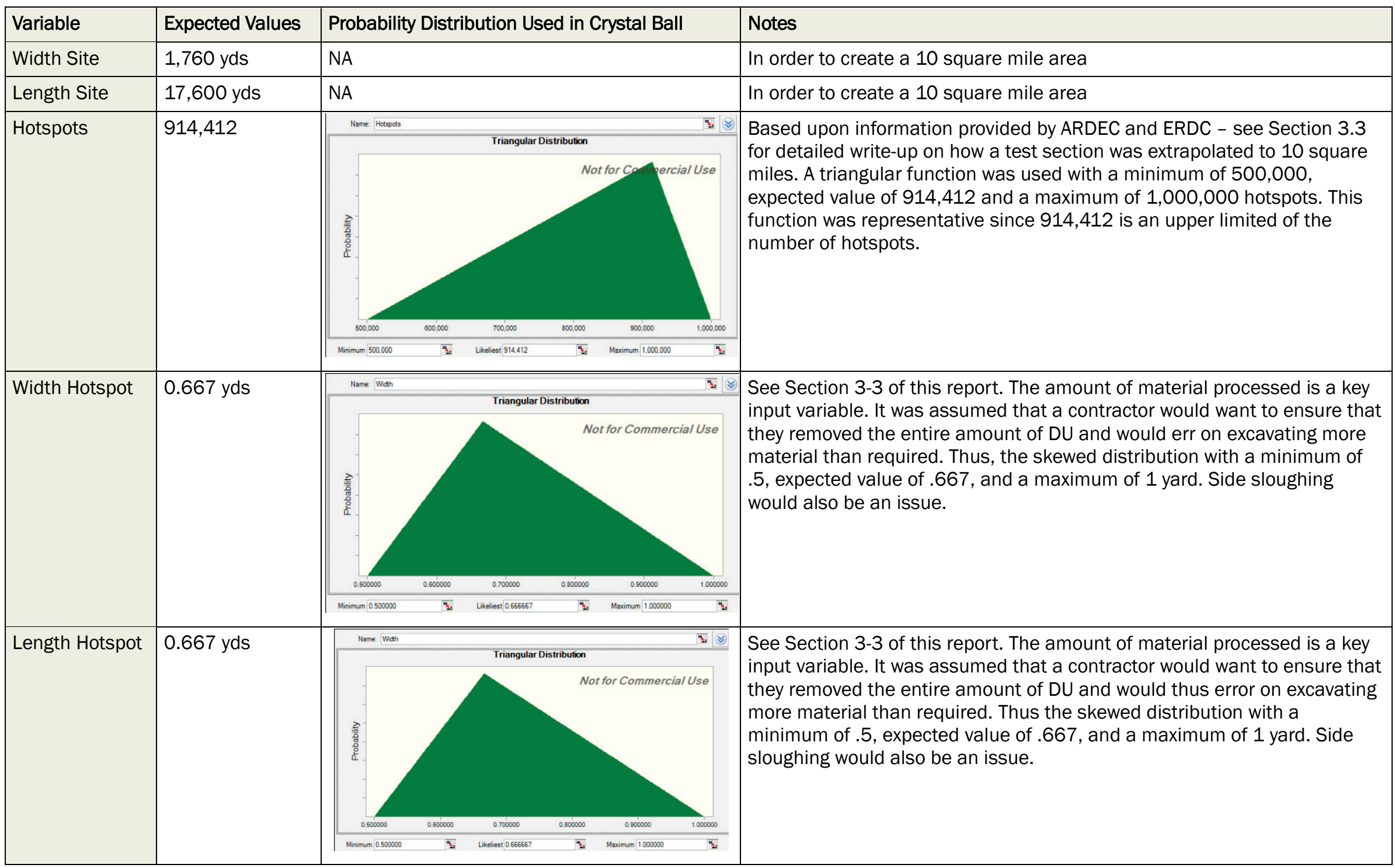




\begin{tabular}{|c|c|c|c|}
\hline Variable & Expected Values & Probability Distribution Used in Crystal Ball & Notes \\
\hline Depth & $1 \mathrm{yd}$ & 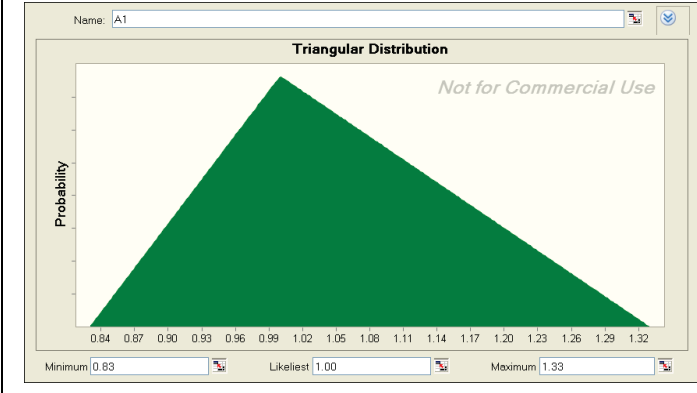 & $\begin{array}{l}\text { See Section } 3.3 \text { of this report. The amount of material processed is a key } \\
\text { input variable. It was assumed that a contractor would want to ensure that } \\
\text { they removed the entire amount of DU and would thus err on excavating } \\
\text { more material than required. Thus the skewed distribution with a } \\
\text { minimum of } .83 \text {, expected value of } 1.0 \text {, and a maximum of } 1.33 \text { yards ( } 4 \\
\text { feet). Side sloughing would also be an issue. }\end{array}$ \\
\hline $\begin{array}{l}\text { Soil Expansion/ } \\
\text { Swell Factor } \\
\text { (Sand) }\end{array}$ & $15 \%$ & 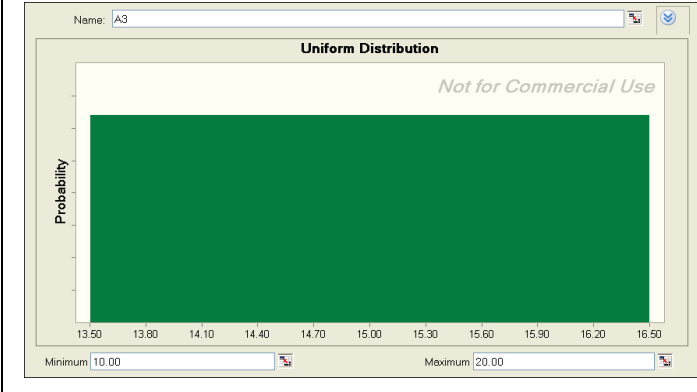 & $\begin{array}{l}\text { Taken from } \mathrm{http}: / / \text { www.engineeringtoolbox.com/soil-rock-bulking-factor- } \\
\text { d } 1557 . \mathrm{html} \\
\text { A value of } 20 \% \text { was suggested by Dr. Larson, ERDC, when excavating the } 2 \\
\text { ft square hole because of side sloughing. A uniform distribution between } \\
10 \text { and } 20 \% \text { was used. }\end{array}$ \\
\hline $\begin{array}{l}\text { Clearing and } \\
\text { Grubbing Costs }\end{array}$ & $\$ 3,560$ per acre & NA & $\begin{array}{l}\text { Ogershok, Dave, and Richard Pray, National Construction Estimator, } \\
\text { Carlsbad, CA, Craftsman Book, } 2011\end{array}$ \\
\hline Soil Weight & $100 \mathrm{lbs} / \mathrm{ft} 3$ & 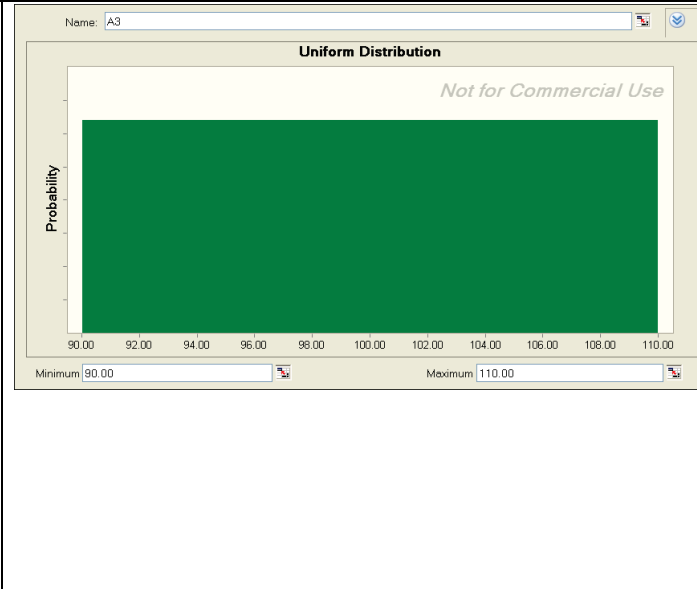 & $\begin{array}{l}\text { A test site as large as } 10 \text { square miles will have tremendous variability in } \\
\text { soil type and thus correspondingly soil density, silt/clay content, water } \\
\text { content, etc. For example, using the YPG as representative of the generic } \\
\text { site, there are at least } 34 \text { different soil and rock formations identified (US } \\
\text { Department of Agriculture, 1980). } \\
\text { A minimum value of } 90 \mathrm{lbs} / \mathrm{ft}^{3} \text { (corresponds to loose sand), expected } \\
\text { value of } 100 \mathrm{lbs} / \mathrm{ft}^{3} \text {, and a maximum value of } 110 \mathrm{lbs} / \mathrm{ft}^{3} \text { (corresponds to } \\
\text { a compacted sand) was used. } \\
\text { References: } \\
\text { Reade Advanced Materials (READE } ®) . \\
\underline{\text { http://www.reade.com/Particle Briefings/spec gra2.html }} \\
\text { Geotechnical Info.com accessed on } 11 \text { December } 2012 \text { at } \\
\text { http://www.geotechnicalinfo.com/soil unit weight.html }\end{array}$ \\
\hline
\end{tabular}




\begin{tabular}{|c|c|c|c|}
\hline Variable & Expected Values & Probability Distribution Used in Crystal Ball & Notes \\
\hline $\begin{array}{l}\text { Hot Spot } \\
\text { Scanning Cost }\end{array}$ & $\$ 0.04 / y d 3$ & NA & $\begin{array}{l}\text { This value was validated by ERDC. Given its small contribution to total cost } \\
\text { it is not a significant cost driver. }\end{array}$ \\
\hline $\begin{array}{l}\text { Capital } \\
\text { Equipment } \\
\text { Costs (Physical } \\
\text { Separation) }\end{array}$ & $\begin{array}{l}\$ 5,000,000 \\
(\mathrm{ALT} 1) \\
\$ 150,000(\mathrm{ALT3})\end{array}$ & NA & This value was validated by ERDC. \\
\hline $\begin{array}{l}\text { Estimated } \\
\text { Percentage of } \\
\text { DU } \\
\text { Contaminated } \\
\text { Soil }\end{array}$ & $0.0002 \%$ (ALT1) & 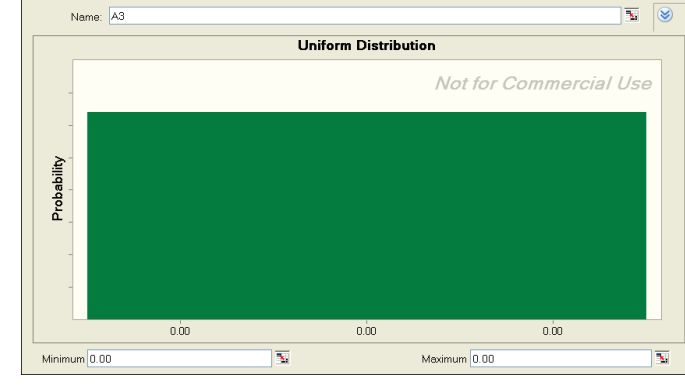 & $\begin{array}{l}\text { This value, a key cost driver, was validated by the SMEs at ERDC. For the } \\
\text { expected value this will produce } 71 \mathrm{yd}^{3} \text { of material for disposal. This is } \\
\text { ONLY for that material that can be identified using an instrument such as } \\
\text { a Geiger counter and can be removed before chemical processing. A } \\
\text { uniform distribution between } .00002 \% \text { and } .00038 \% \text { was used. }\end{array}$ \\
\hline Sand Backfill & $\$ 7$ per yd3 & & Based on information provided by ERDC \\
\hline $\begin{array}{l}\text { Estimated } \\
\text { Percentage of } \\
\text { DU } \\
\text { Contaminated } \\
\text { Soil }\end{array}$ & $0.5 \%($ ALT3) & 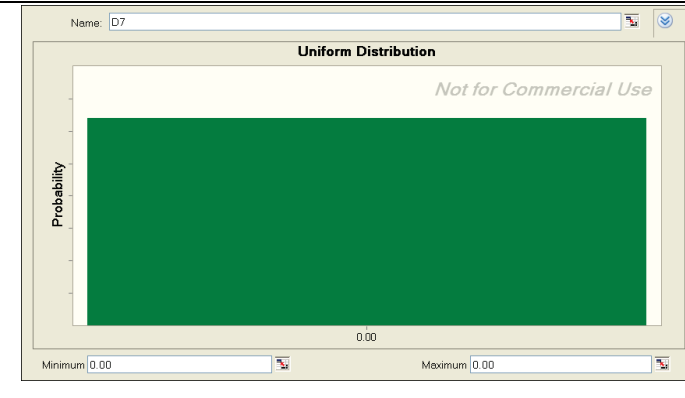 & $\begin{array}{l}\text { This value was validated by the SMEs at ERDC. This number is a key cost } \\
\text { driver. This is ONLY for that material that can be identified using an } \\
\text { instrument such as a Geiger counter and can be removed before chemical } \\
\text { processing.for the excavated hotspots. For the expected value this will } \\
\text { produce } 71 \mathrm{yd}^{3} \text { of material for disposal. A uniform distribution between } .001 \\
\text { (1.2 lbs) and } .01 \text { ( } 12 \mathrm{lbs} \text { ) was selected, which encompasses an expected } \\
\text { value of } 0.005 \text { ( } 6 \mathrm{lbs}) \text {. The numbers shown in parathensis is the total } \\
\text { amount of urainum by weight that would be extracted from each hotspot. }\end{array}$ \\
\hline $\begin{array}{l}\text { Cost of Physical } \\
\text { Separation }\end{array}$ & $\begin{array}{l}\$ 1.50 \text { dollars per } \\
\text { ton (ALT 1) } \\
\$ 3.00 \text { dollars per } \\
\text { ton } \\
\text { (ALT } 2 \& 3 \text { ) }\end{array}$ & NA & Values proposed by SMEs at ERDC \\
\hline $\begin{array}{l}\text { Capital } \\
\text { Equipment Cost } \\
\text { (Chemical } \\
\text { Separation) }\end{array}$ & $\begin{array}{l}\$ 500,000(\text { ALT1) } \\
\$ 100,000 \\
(\text { ALT } 2 \& 3)\end{array}$ & NA & $\begin{array}{l}\text { Values proposed by SMEs at ERDC based on the potential equipment that } \\
\text { would be used. The number varied between } \$ 100 \mathrm{k} \text { and } \$ 500 \mathrm{k} \text { between } \\
\text { all three models }\end{array}$ \\
\hline
\end{tabular}




\begin{tabular}{|c|c|c|c|}
\hline Variable & Expected Values & Probability Distribution Used in Crystal Ball & Notes \\
\hline Price of Filter & $\$ 250$ fixed & NA & Based upon information provided by ERDC \\
\hline $\begin{array}{l}\text { Cubic Yards of } \\
\text { Soil Processed } \\
\text { per Filter }\end{array}$ & 3,000 & 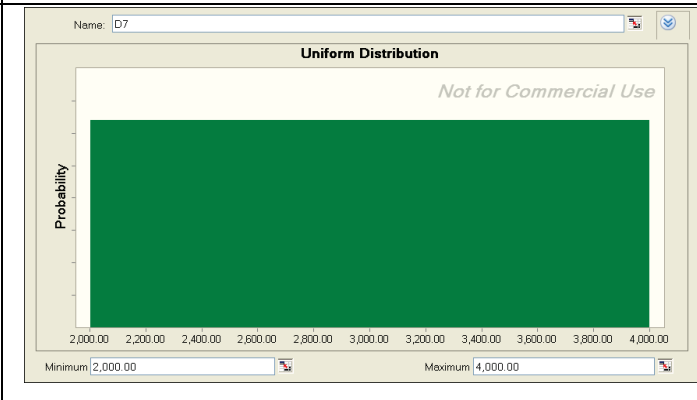 & $\begin{array}{l}\text { Provided by SMEs at ERDC. Used a minimum of } 2,000 \text {, expected value of } \\
3,000 \text {, and a maximum of } 4,000 \text {. }\end{array}$ \\
\hline $\begin{array}{l}\text { Initial } \\
\text { Treatment Fluid } \\
\text { Needed per } \\
\text { Cubic Yard of } \\
\text { Soil }\end{array}$ & $\begin{array}{l}13.26 \text { gallons } \\
\text { per yd3 }\end{array}$ & NA & $\begin{array}{l}\text { Based upon information provided by ERDC. Built into the model is a } \\
\text { recycle factor that suggests only } 2 \text { additional gallons per } \mathrm{yd}^{3} \text { of soil will be } \\
\text { required. }\end{array}$ \\
\hline $\begin{array}{l}\text { Cost per Gallon } \\
\text { of Fluid }\end{array}$ & $\$ .15 /$ gallon & NA & $\begin{array}{l}\text { Numerous web sources list bulk acetic acid for } \$ 1.50 \text { per gallon in } 55 \\
\text { gallon drums. A scale-up assumption of } 10 \% \text { of that price was made based } \\
\text { upon the large amount needed. This price also accounts for dilution of the } \\
\text { acetic acid which reduces the volume required by } 90 \% \text {. } \\
\underline{\text { http://www.alibaba.com/trade/search?fsb=y\&IndexArea=product en\&Cat }} \\
\underline{\text { Id=\&SearchText=acetic+acid+price }}\end{array}$ \\
\hline $\begin{array}{l}\text { Mobilization } \\
\text { Cost }\end{array}$ & $\$ 1,000,000$ & NA & $\begin{array}{l}\text { Mobilization shall include all activities and costs for transportation of } \\
\text { personnel, equipment, and supplies not required or included in the } \\
\text { contract to the site. This is a not a key cost driver. }\end{array}$ \\
\hline $\begin{array}{l}\text { Equipment } \\
\text { Demobilization }\end{array}$ & $\begin{array}{l}\$ 550,000 \text { (ALT1) } \\
\$ 80,000 \text { (ALT2) } \\
\$ 550,000 \text { (ALT3) }\end{array}$ & NA & $\begin{array}{l}\text { Demobilization shall include all activities and costs for transportation of } \\
\text { personnel, equipment, and supplies not required or included in the } \\
\text { contract from the site; including the disassembly, removal, and site } \\
\text { cleanup of offices, buildings, and other facilities assembled on the site } \\
\text { specifically for this contract. This is a not a key cost driver. }\end{array}$ \\
\hline $\begin{array}{l}\text { Reseeding/Site } \\
\text { Restoration }\end{array}$ & $\begin{array}{l}\$ 200 / \text { acre } \\
(\text { ALT1) }\end{array}$ & NA & $\begin{array}{l}\text { The cost is based upon minimal restoration of sand and some limited } \\
\text { replanting, }\end{array}$ \\
\hline
\end{tabular}




\begin{tabular}{|c|c|c|c|}
\hline Variable & Expected Values & Probability Distribution Used in Crystal Ball & Notes \\
\hline $\begin{array}{l}\text { Cost of short } \\
\text { haul }\end{array}$ & $\begin{array}{l}\$ 1.07 \text { per ton } \\
\text { mile (ALT } 1) \\
\$ 2.14 \text { per ton } \\
\text { mile (ALT } 2 \& 3 \text { ) }\end{array}$ & NA & $\begin{array}{l}\text { Ogershok, Dave, and Richard Pray, National Construction Estimator, } \\
\text { Carlsbad, CA, Craftsman Book, 2011. The team doubles costs for ALTs } 2 \\
\text { and } 3 \text { because of the time needed to excavate hotspots and the inability } \\
\text { to use large earthmoving equipment. }\end{array}$ \\
\hline Excavation & $\begin{array}{l}\$ 1.48 \text { per } \mathrm{yd}^{3} \\
(\mathrm{ALT} 1) \\
\$ 2.96 \text { per } \mathrm{yd}^{3} \\
(\text { ALT } 2 \& 3)\end{array}$ & NA & $\begin{array}{l}\text { Ogershok, Dave, and Richard Pray, National Construction Estimator, } \\
\text { Carlsbad, CA, Craftsman Book, 2011. The team doubles costs for ALTs } 2 \\
\text { and } 3 \text { because of the time needed to excavate hotspots and the inability } \\
\text { to use large earthmoving equipment. }\end{array}$ \\
\hline Compacting soil & $\begin{array}{l}\$ 2.05{\text { per } y d^{3}}^{3} \\
(\text { ALT } 1) \\
\$ 4.10 \text { per yd }^{3} \\
\text { (ALT } 2 \& 3)\end{array}$ & NA & $\begin{array}{l}\text { Ogershok, Dave, and Richard Pray, National Construction Estimator, } \\
\text { Carlsbad, CA, Craftsman Book, 2011. The team doubles costs for ALTs } 2 \\
\text { and } 3 \text { because of the time needed to excavate hotspots and the inability } \\
\text { to use large earthmoving equipment. }\end{array}$ \\
\hline $\begin{array}{l}\text { Loading and } \\
\text { Handling Costs }\end{array}$ & $\$ 75$ per ton & NA & Source: http://cms3.tucsonaz.gov/es/content/various-programs \\
\hline $\begin{array}{l}\text { Trucking Cost to } \\
\text { Rail Head }\end{array}$ & $\$ 21.60$ ton-mile & NA & $\begin{array}{l}\text { Source: } \\
\mathrm{http}: / / \text { cab.cati.csufresno.edu/research_publications/99/990301/costs.h } \\
\frac{\mathrm{tm}}{* \text { factor of } 10 \text { increase due to radioactivity }} \\
\text { low and high values were averaged }\end{array}$ \\
\hline $\begin{array}{l}\text { Distance of } \\
\text { Solid/Filters } \\
\text { (Truck) }\end{array}$ & 15 miles & NA & Estimated distance to local rail site \\
\hline $\begin{array}{l}\text { Distance of } \\
\text { Solid/Filters } \\
\text { (Rail) }\end{array}$ & 600 miles & NA & Estimate based on distance to nearest waste site \\
\hline Rail Cost & $\$ 2.68 /$ ton-mile & NA & $\begin{array}{l}\text { Source: } \\
\text { https://wiki.umd.edu/lei/images/9/96/Forkenbrock 2001.pdf } \\
\text { (pg } 327 \text { brought to future and averaged) }\end{array}$ \\
\hline $\begin{array}{l}\text { Weight per } \\
\text { Filter }\end{array}$ & $500 \mathrm{lbs}$ & NA & Estimate based off of the estimated size and weight of Chitin/Fish bones \\
\hline
\end{tabular}




\begin{tabular}{|c|c|c|c|}
\hline Variable & Expected Values & Probability Distribution Used in Crystal Ball & Notes \\
\hline $\begin{array}{l}\text { Long Term Cost } \\
\text { of Disposal for } \\
\text { One Filter (ALT } \\
1 \& \text { ALT 2) }\end{array}$ & $\$ 756$ per yd $^{3}$ & Triangular D Ditetibution & $\begin{array}{l}\text { SMEs at ERDC recommended the use of } \$ 756 \text { per yd } \mathrm{yd}^{3} \text {. A triangular } \\
\text { function was chosen with a minimum of } \$ 605 \mathrm{per}^{\mathrm{yd}} \mathrm{d}^{3} \text { an expected value } \\
\text { of } \$ 756 \text { per } y \mathrm{~d}^{3} \text {, and a maximum of } \$ 832 \text { per } \mathrm{yd}^{3} \text {, based upon the } \\
\text { assumption that given the large amount of material to be disposed that } \\
\text { there might be some economies of scale for ALT1. }\end{array}$ \\
\hline $\begin{array}{l}\text { Long Term Cost } \\
\text { of Disposal for } \\
\text { One Filter (ALT } \\
\text { 3) }\end{array}$ & $\$ 756$ per yd $^{3}$ & $\overline{28}$ & $\begin{array}{l}\text { SMEs at ERDC recommended the use of } \$ 756 \text { per } y d^{3} \text {. A uniform } \\
\text { distribution was chosen to capture the potential for variation of a } \\
\text { minimum of } \$ 605 \text { per } y d^{3} \text { and a maximum of } \$ 1388 \text { per } y d^{3} \text { for ALTs } 2 \\
\text { and } 3 \text {. }\end{array}$ \\
\hline & & \& & \\
\hline $\begin{array}{l}\text { Long Term Cost } \\
\text { of Disposal for } 1 \\
\text { Cubic Yard of DU } \\
\text { Contaminated } \\
\text { Soil (ALT } 1 \& \text { ALT } \\
\text { 2) }\end{array}$ & $\$ 756$ per yd $^{3}$ & Triangular Dilutibution & $\begin{array}{l}\text { SMEs at ERDC recommended the use of } \$ 756 \text { per } \mathrm{yd}^{3} \text {. A triangular } \\
\text { function was chosen with a minimum of } \$ 605 \text { per }^{3} d^{3} \text {, expected value of } \\
\$ 754 \text { per yd } d^{3} \text {, and a maximum of } \$ 832 \text { per } \mathrm{yd}^{3} \text {, based upon the } \\
\text { assumption that given the large amount of material to be disposed that } \\
\text { there might be some economies of scale for ALT1. }\end{array}$ \\
\hline & & 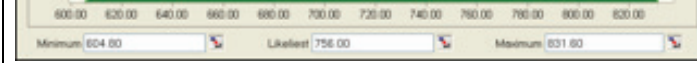 & \\
\hline
\end{tabular}




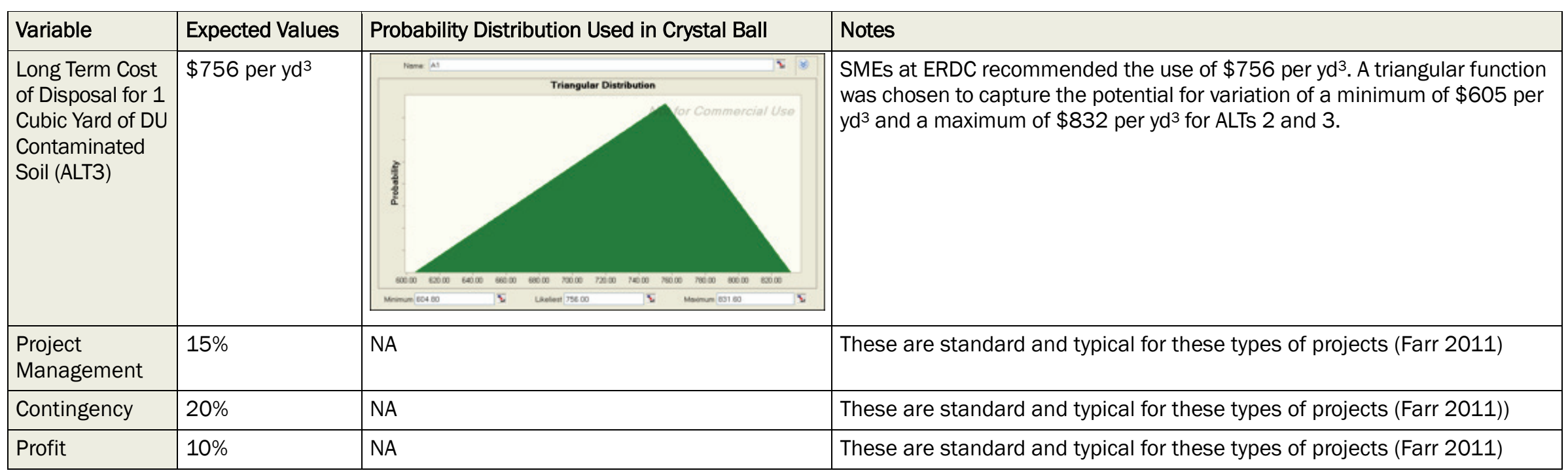


Table 5-4 shows the output of conducting a bottom up build for Alternative 1. There are four main task categories:

1. Remediation costs

2. Disposal costs

3. Miscellaneous costs

4. Transportation costs

Table 5-4. Cost summary for Alternative 1: Physical separation and chemical treatment.

\begin{tabular}{|l|l|r|}
\hline Category & Task & Net present value (\$) \\
\hline \multirow{5}{*}{ Remediation cost } & Clear and grub site & $22,784,000$ \\
\cline { 2 - 3 } & Excavation and short haul costs & $90,837,120$ \\
\cline { 2 - 3 } & Physical separation & $67,726,400$ \\
\cline { 2 - 3 } & Chemical separation & $14,155,451$ \\
\cline { 2 - 3 } & Soil backfill and site clean-up & $112,972,164$ \\
\hline Disposal Costs & $\begin{array}{l}\text { Disposal of waste chemicals, } \\
\text { solid DU, and DU-contaminated } \\
\text { filter material. Cleaned soil is } \\
\text { returned to the site. }\end{array}$ & $9,031,361$ \\
\hline \multirow{2}{*}{ Miscellaneous Costs } & Project management & $182,123,971$ \\
\cline { 2 - 3 } & Contingency & $242,831,962$ \\
\cline { 2 - 3 } & Profit & $121,415,981$ \\
\hline Total Estimate Life Cycle Costs & Rail & $450,294,342$ \\
\cline { 2 - 3 } & Truck & $446,358,971$ \\
\hline
\end{tabular}

The summation of these four categories provides the total estimated life cycle cost which is located in the last row. This is the value used to compare each Alternative.

Rememediation for this alternative entails the excavation, treatment and backfilling of 31 million $\mathrm{yd}^{3}$ of soil.

\subsubsection{Alternative 2: Selective Excavation}

Another way to reduce the volume of waste is to scan the site for DU hotspots, then selectively excavate out the contaminated spots. Clearing and grubbing costs are not included in this alternative under the assumption that the hot spot scanning equipment has the sensitivity to detect DU 
directly under the scanner as well as several meters on either side. If a hot spot is identified under vegetation, the assumption was made that the cost of removing the vegetation would be negligible and covered under the excavation of the hot spot. The "Total Haul Away" alternative requires the entire site to be scanned and then the hot spots are excavated and transported to a waste site. The holes are then back filled with fresh sand. This process takes the cost of remediation equipment out of the equation, but the volume of waste transported to long term disposal is significant.

Table 5-5 shows the output of conducting a bottom up build for Alternative 2. The main tasks were categorized into same four categories as Alternative 1. The summation of these four categories provids the total estimate LCC which is located in the last row. This is the value used to compare each Alternative.

Table 5-5. Cost summary for Alternative 2: Selective excavation.

\begin{tabular}{|l|l|r|}
\hline Category & Task & Net present value (\$) \\
\hline Remediation cost & Excavation and short haul costs & $3,383,567$ \\
\cline { 2 - 3 } & Hot spot scanning & $\mathbf{2 , 4 7 8 , 0 8 0}$ \\
\cline { 2 - 3 } & Soil backfill and site clean-up & $5,841,202$ \\
\hline Disposal Costs & Disposal of DU waste & $353,328,796$ \\
\hline Miscellaneous Costs & Project management & $\mathbf{2 2 6 , 0 9 7 , 2 6 7}$ \\
\cline { 2 - 3 } & Contingency & $301,463,023$ \\
\cline { 2 - 3 } & Profit & $150,731,512$ \\
\hline Transportation Costs & Rail & $\mathbf{9 2 3 , 3 7 3 , 2 3 8}$ \\
\cline { 2 - 3 } & Truck & $218,910,233$ \\
\hline Total Estimate Life Cycle Costs & & $\mathbf{2 , 1 8 5 , 6 0 9 , 9 1 9}$ \\
\hline
\end{tabular}

\subsubsection{Alternative 3: Selective Excavation with Physical Separation and Chemical Treatment}

Alternative 3 combines the hotspot scanning of Alternative 2 with the Physical Separation and Chemical Treatment process used in Alternative 1. This Alternative allows the waste volume to be reduce to the lowest amount possible, however the cost of remediation equipment as well as the scanning costs are now added to the site. 
Table 5-6 shows the output of conducting a bottom up build for Alternative 3. The main tasks were categorized into the same four categories as Alternative 1. The summation of these four categories provides the total estimate LCC which is located in the last row. This is the value used to compare each alternative.

Table 5-6. Cost summary for Alternative 3: Selective excavation with physical separation and chemical treatment.

\begin{tabular}{|l|l|r|}
\hline Category & Task & Net present value (\$) \\
\hline \multirow{4}{*}{ Remediation cost } & Excavation and short haul costs & $8,245,219$ \\
\cline { 2 - 3 } & Hot spot scanning & $2,478,080$ \\
\cline { 2 - 3 } & Physical separation & $1,795,943$ \\
\cline { 2 - 3 } & Chemical separation & 278,511 \\
\cline { 2 - 3 } & Soil backfill and site clean-up & $3,468,144$ \\
\hline \multirow{2}{*}{ Disposal Costs } & Disposal of DU waste chemicals & $1,907,017$ \\
\hline \multirow{2}{*}{ Miscellaneous Costs } & and filter material & $3,704,935$ \\
& Project management & $4,939,913$ \\
\cline { 2 - 3 } & Contingency & $2,469,957$ \\
\cline { 2 - 3 } & Profit & $\mathbf{3 5 , 3 1 3 , 6 9 7}$ \\
\hline \multirow{2}{*}{ Transportation Costs } & Rail & $1,212,954$ \\
\cline { 2 - 3 } & Truck & $\mathbf{3 6 9}$ \\
\hline \multirow{2}{*}{ Total Estimate Life Cycle Costs } & & \\
\hline
\end{tabular}

\subsubsection{Alternative 4: Containment and Monitoring}

Based upon the demonstration study site of 10 square miles with a perimeter of roughly 14 miles, 6 -foot chain link fencing costs $\$ 44,465$ per mile, which amounts to a total cost of $\$ 622,510$. Monitoring the groundwater will require twenty monitoring wells at a price of roughly $\$ 2,000$ each, totaling $\$ 40,000$. If a 24-hour security presence is required, the recurring costs could total over $\$ 1$ million a year. Lastly, numerous soil and water tests would be required. Table 5-7 summarizes the costs for the Containment and Monitoring alternative. Note that the costs of lost training, developing a new training range, etc. were not estimated. This alternative may not be feasible as it requires a large portion of training range to be closed and deemed unusable. There are also significant political and environmentalist pressures against leaving DU in situ. 
Table 5-7. Cost summary for Alternative 4: Containment and monitoring.

\begin{tabular}{|l|l|l|}
\hline Category & Task & Net present value (\$) \\
\hline \multirow{3}{*}{ Non-Recurring Costs } & Fencing & 622,510 \\
\cline { 2 - 3 } & Ground water monitoring wells & 40,000 \\
\cline { 2 - 3 } & Engineering and permitting costs & $\mathbf{1 , 0 0 0 , 0 0 0}$ \\
\hline \multirow{2}{*}{ Recurring Costs } & Security patrols & $1,000,000$ \\
\cline { 2 - 3 } & Water and soil testing & 100,000 \\
\cline { 2 - 3 } & & \\
\hline NPV costs based upon a 50-yr time horizon with security patrols & $\mathbf{9 4 , 9 7 4 , 6 7 5}$ \\
\hline NPV costs based upon a 50-yr time horizon without security patrols & $\mathbf{8 , 0 8 3 , 8 3 0}$ \\
\hline
\end{tabular}

Table 5-7 shows the output of conducting a bottom up build for Alternative 4. The main tasks were categorized into two different categories: recurring and non-reoccurring. The summation of these two categories provides the total estimate life cycle cost which is located in the last two rows. These values include a total estimate with security patrols and without security patrols.

\subsubsection{Simulation Based Costing Estimate of Alternative 3}

A SBC analysis of Alternative 3 is shown in Figure 5-1. This simulation was compiled from 10,000 data points using the probabilistic distributions presented in Table 5-3. The @ Risk (at risk) software was used for the SBC modeling. This software performs risk analysis Monte Carlo simulation to show the likeihood of many possible outcomes. Details can be found at http://www.palisade.com/risk/.

This cumulative probability chart of TOC allows calculation of the estimated cost at multiple different quantities. It shows a minimum cost of $\$ 18.4 \mathrm{M}$ and a maximum of $\$ 84.3 \mathrm{M}$. Within this a $50 \%$ cost estimate of $\$ 39 \mathrm{M}$ and a $90 \%$ estimate of $\$ 55 \mathrm{M}$. This means that there is a $90 \%$ likelihood that the total cost will be less than or equal to $\$ 55 \mathrm{M}$. It is important to note that the $5 \mathrm{O}^{\text {th }}$ percentile value from this simulation is greater than the point estimate provided for Alternative 3 earlier. This is because the team's analysis was performed using probabilistic distributions that were weighted towards the higher side of possible value. If symmetrical distributions had been used, values would have been centered on the most likely values and deviated evenly above and below those values. For example, when modeling the estimated percentage of DU contamination the team assumed a most likely 
value of $0.5 \%$ or 0.005 . During the team's simulation, however, a uniform distribution was used ranging from 0.001 to 0.01 , which captures this most likely value but is heavily weighted towards the high side of possible values due to the uncertainty. A risk analysis was performed of the variables to determine which ones have the largest impact on total cost due to their uncertainty (Figure 5-2).

Figure 5-1. Simulation-based costing of Alternative 3.

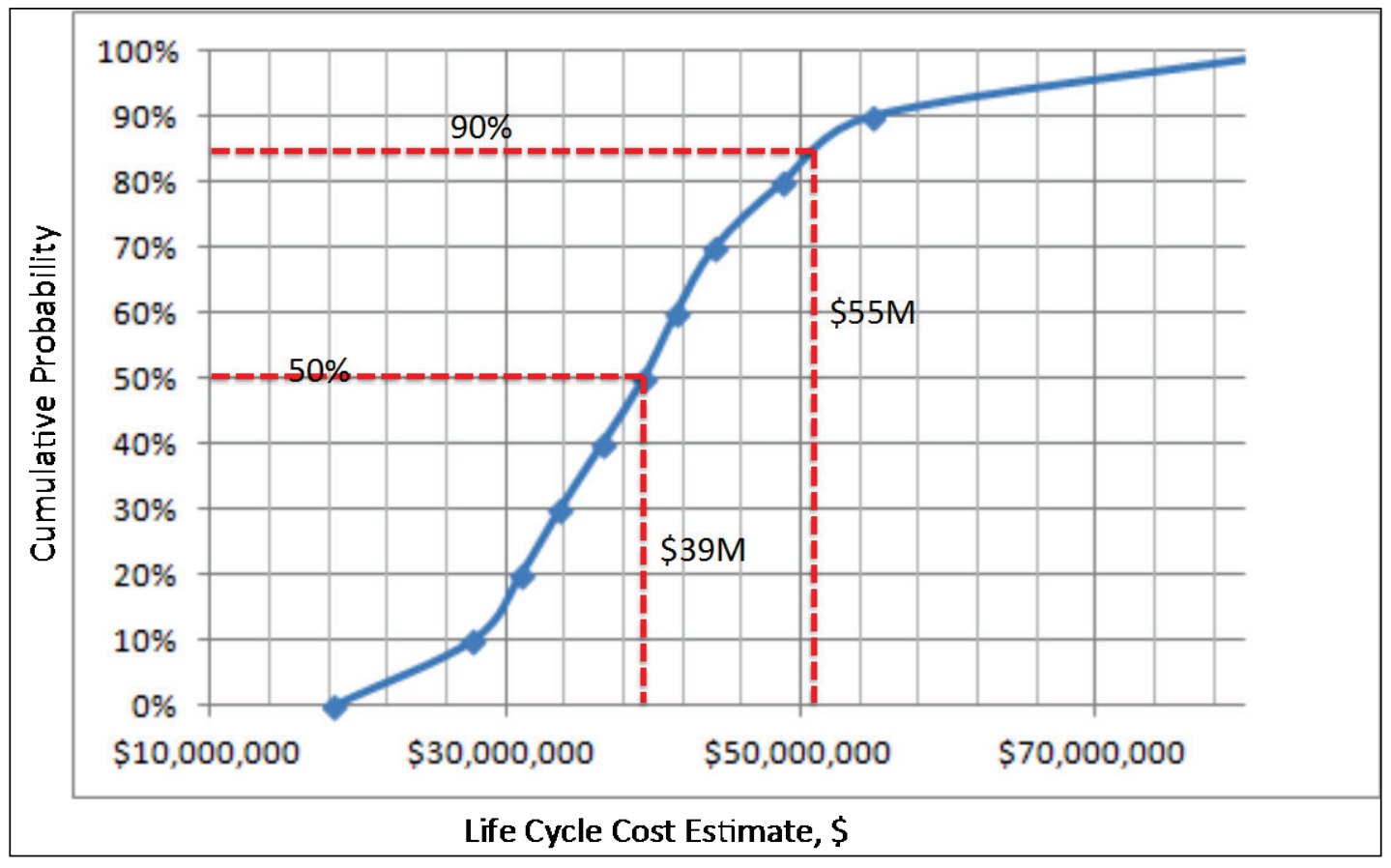

Figure 5-2. Sensitivity analysis of Alternative 3.

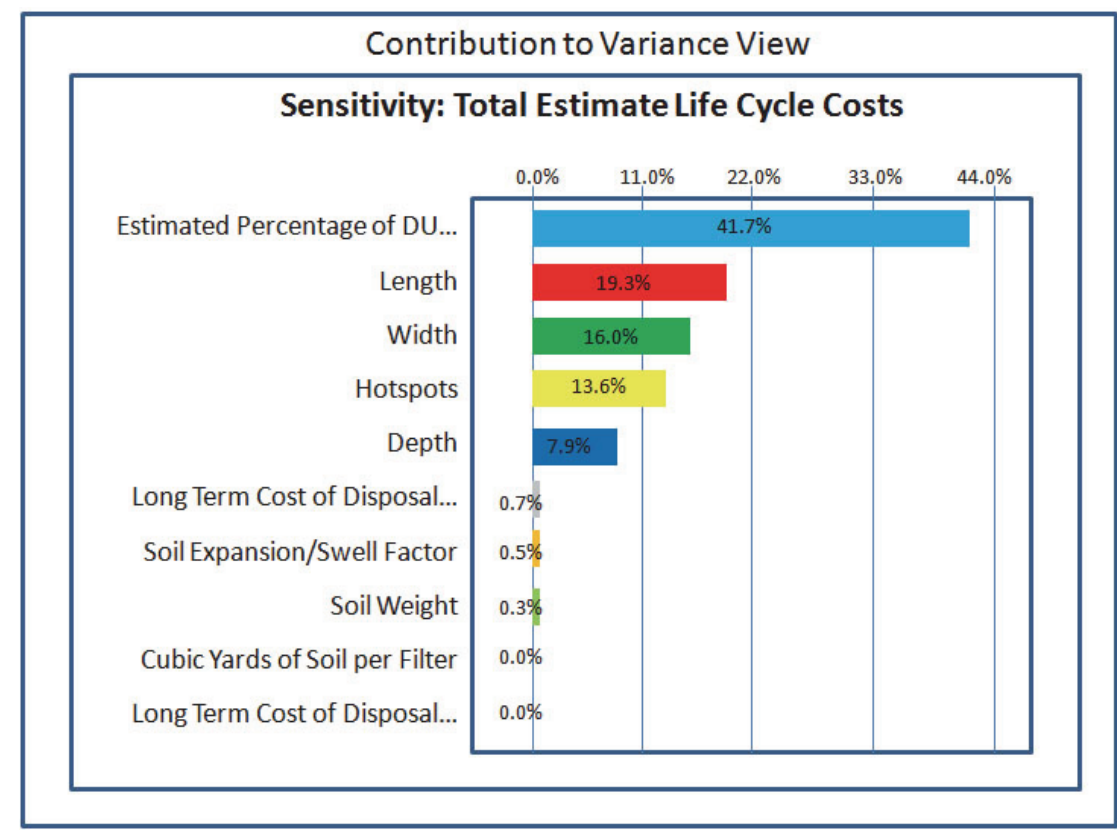


Note on Figure 5-1 how the team highlights the 90\% probability. Given the uncertainty of the amount of DU in the soil, effectiveness of some of the processes, etc., a 90\% estimate would probably be reasonable when budgeting for this project. Certainly, further research is needed into the amount of DU at a site.

This output sorts the variables by their total impact on the cost. The foremost cost driver here is the estimated percentage of DU removed from the soil - essentially the density of DU contamination in the hotspots. The next four variables, length, width, depth, and number of hotspots are also significant drivers because they directly impact the total volume of soil that will be excavated. This type of analysis elucidates which factors have a negligible impact on total cost and shifts the focus to decreasing uncertainty on the variables that do have significant impacts. This can be done by gathering data and doing additional research to tighten the confidence intervals and reduce the variance of these significant cost drivers.

\subsubsection{CER Model for Alternative 3}

The CER model was constructed using Minitab (http://www.minitab.com) statistical software and creating a regression model using over 70 data observations from the SBC model. The two factors chosen to build the model were the estimated percentage of DU removed and the number of hotspots. Using these two factors alone an $\mathrm{R}^{2}$ of roughly $80 \%$ was achieved which allows the model to be significantly simplified and still achieve a reasonable level of accuracy in prediction. The CER was determined to be (Equation 5-1):

$$
\text { Total Cost }=9.79667 E 06+15.3966 H+357505 D+2610.99 D H
$$

\section{Equation 5-1. CER equation for Alternative 3}

where $\mathrm{H}$ is the total number of hotspots and $\mathrm{D}$ is the estimated percentage of DU present in the excavated soil. The coefficients generated by this regresssion analysis are shown in Table 5-8. CER model residuals are shown in Figure 5-3. The CER allows for quick on site estimates by using the significant cost drivers as inputs and treating all of the other variables as constants due to their incidental impact on total cost. Also, given that the number of hotspots and the DU density are probably the two greatest unknowns, this CER is very useful for quick rough order of magnitude estimates when better estimates of these two unknowns are better measured/understood. 
Table 5-8. CER regression model: Total cost versus hotspots and DU for Alternative 3.

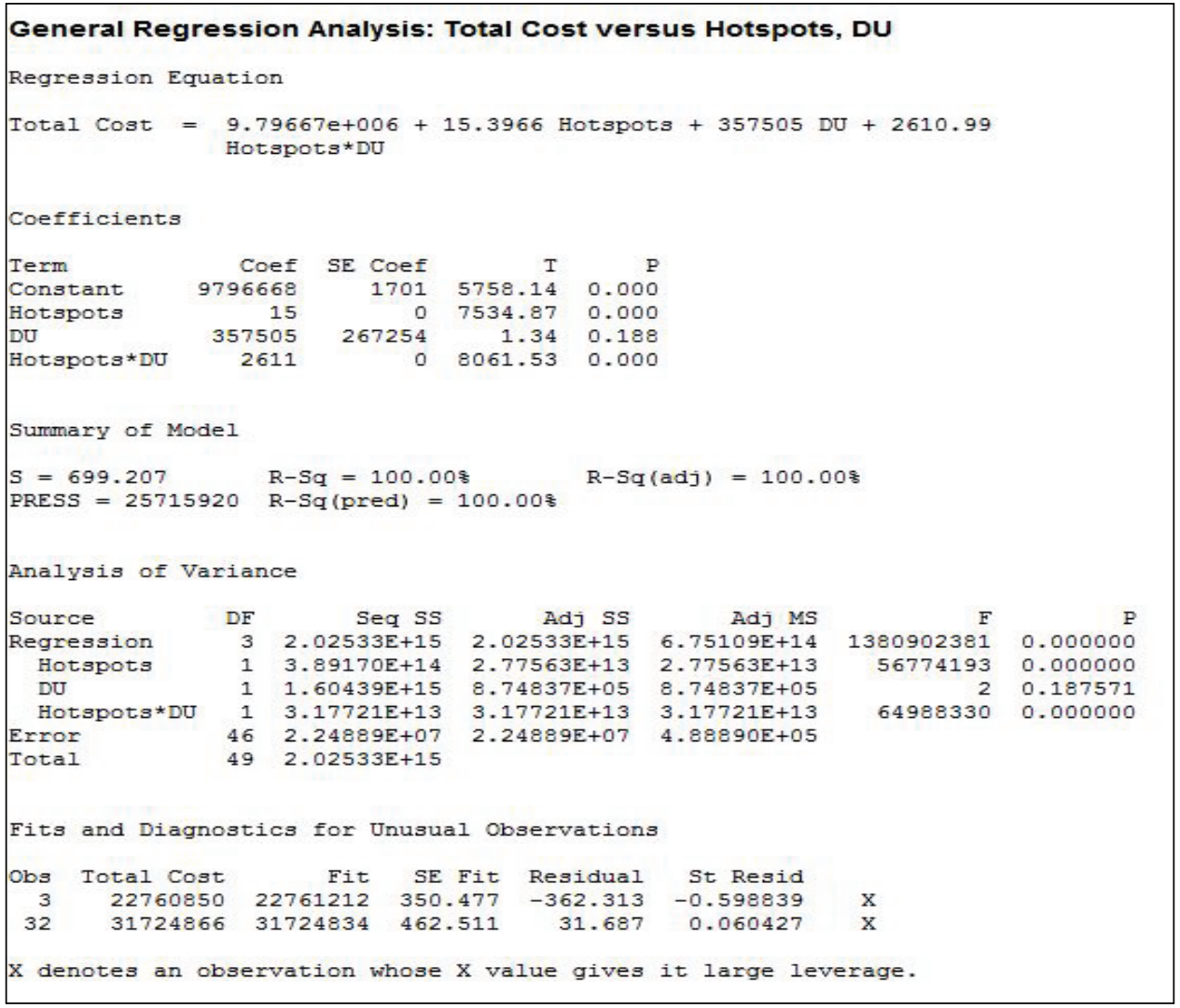

Figure 5-3. Residual plots for total cost.

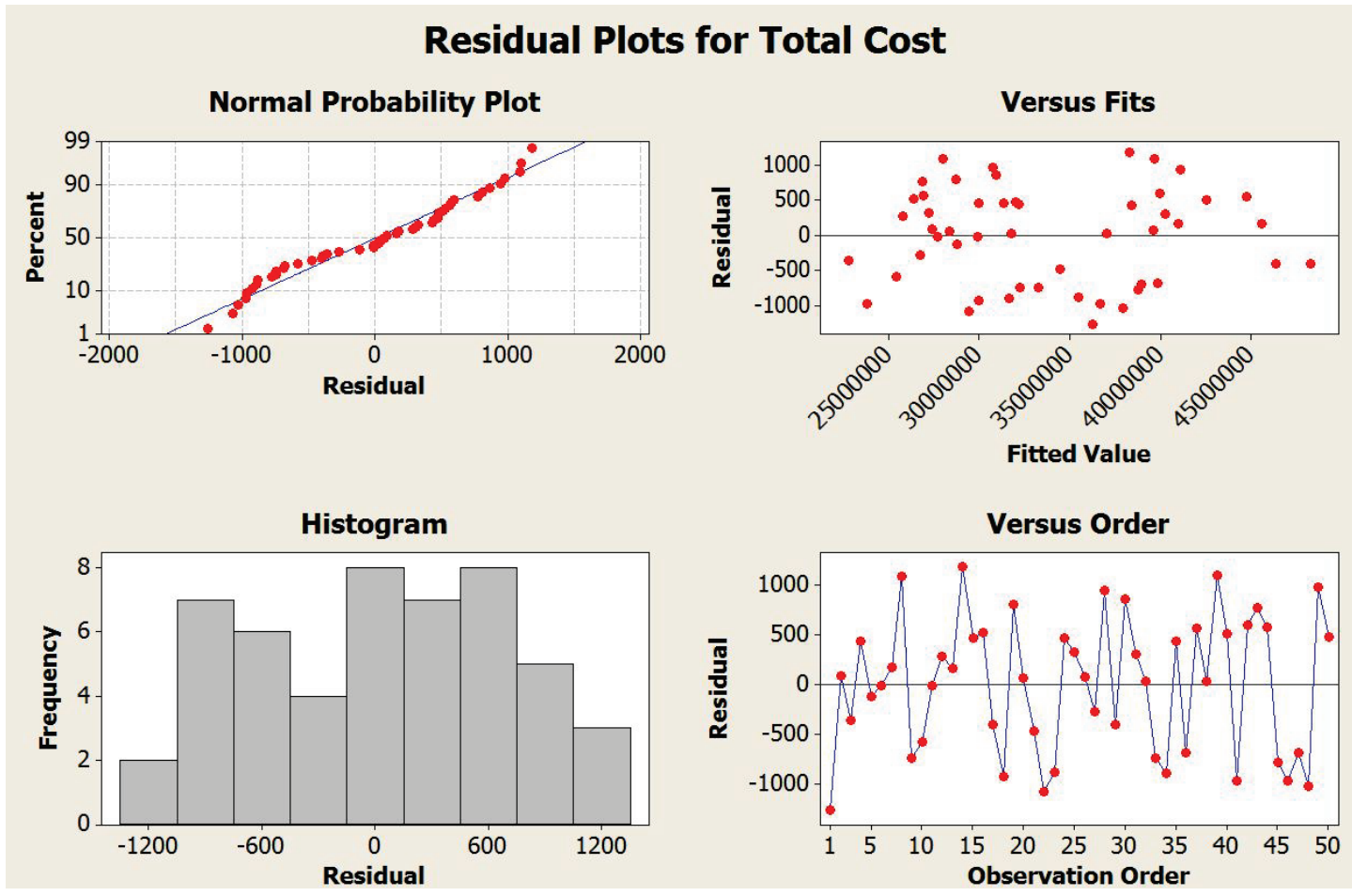




\subsubsection{Sensitivity Analysis of Major Cost Drivers}

The disposal cost of DU waste is between $\$ 343-\$ 1388$ per yd 3 depending on the classification of the waste. Though there is a significant effect on the cost it is clear that the volume is the largest cost driver, which towers over the cost of disposal. The effect of disposal cost on total cost for Alternative 1: Physical Separation and Chemical Treatment is shown in Figure 5-4.

Figure 5-4. Effect of disposal cost on total cost for Alternative 1: Physical separation and chemical treatment.

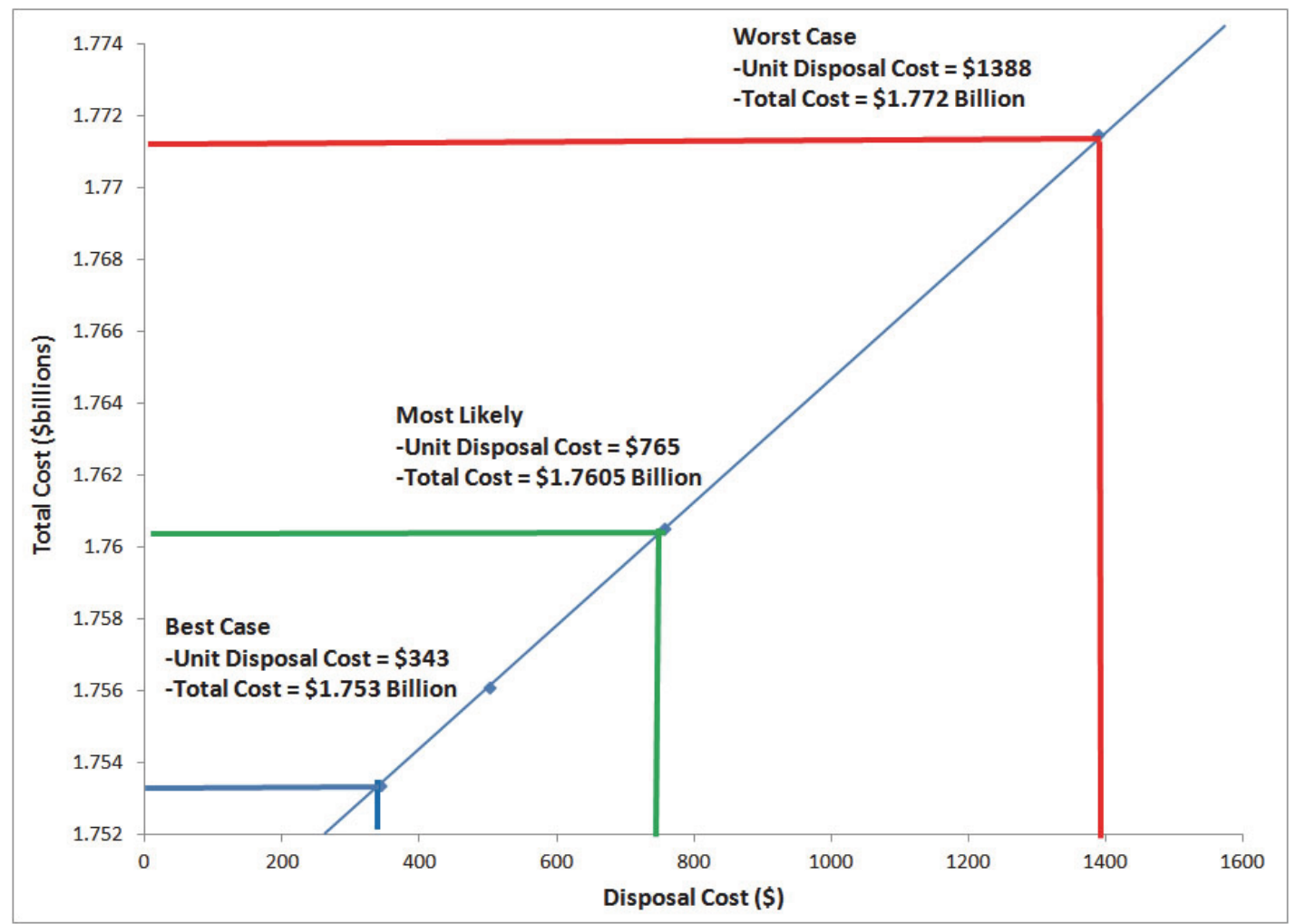

Figure 5-5 depicts a sensitivity plot on the input variable hotspots. The plot depicts three trend lines (20\% increases, baseline, 20\% decrease) with an $\mathrm{x}$-axis of increasing disposal costs and a y-axis of overall LCC. The percentage of DU removed was increased to $0.5 \%$ due to the increased potential of finding a higher concentration due to the hotspot scanning. The effect of increasing/decreasing the number of hotspots and disposal cost can be seen through model simulation. As disposal cost increases, the spread between each trend line expands as depicted on the graph. Overall, the need for an efficient system to accurately and effectively locate hotspots is very high due to the cost factors associated with the input variable hotspots. 
Figure 5-5. Number of hotspots sensitivity analysis for Alternative 3: Selective excavation with physical and chemical separation.

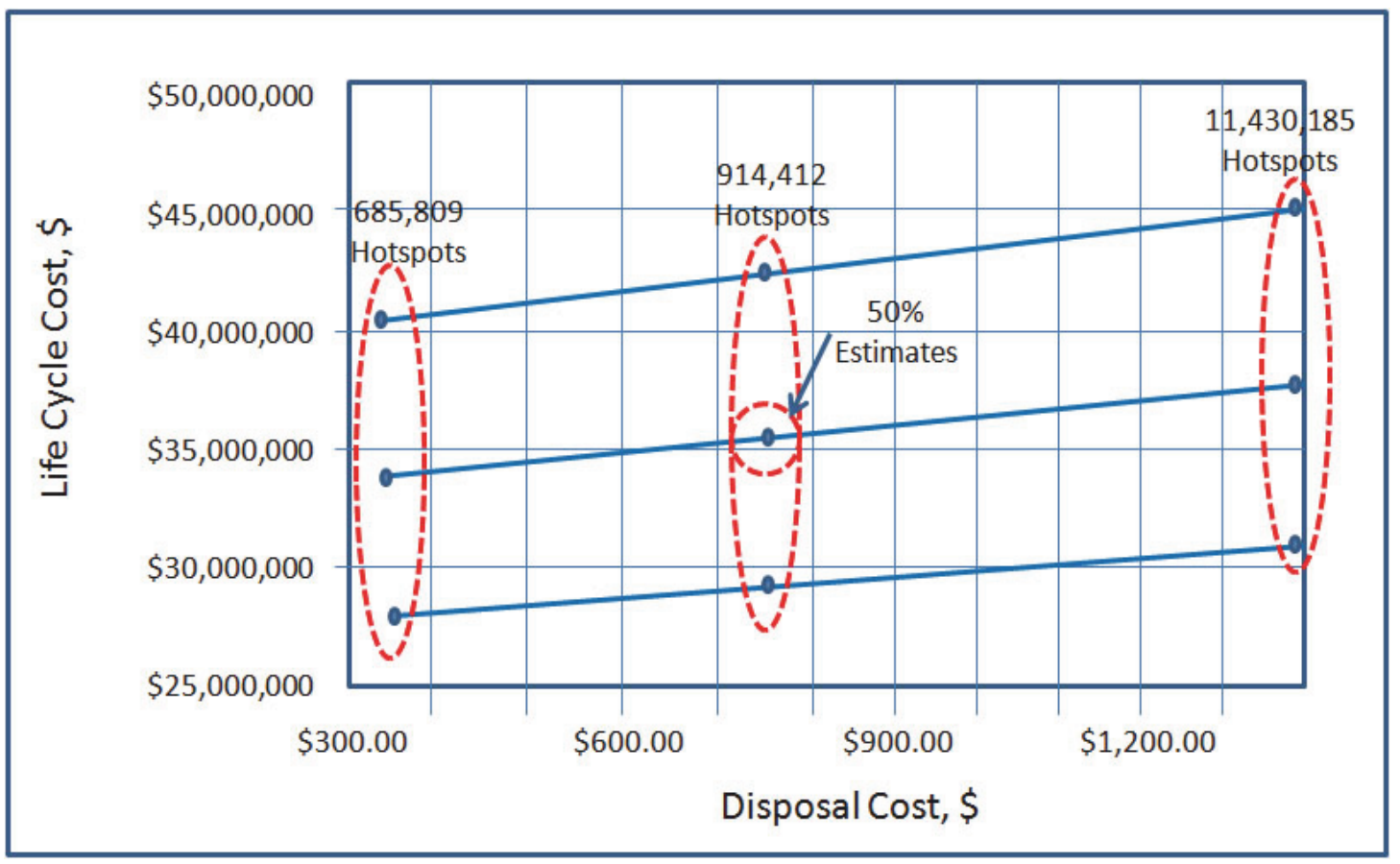

The relative small difference between the Worst Case, Most Likely, and Best Case is explained by the fact that it is not how much it costs to dispose of the material but the amount of contaminated material extracted during the remediation process. An increase in the amount of material has an exponential effect on the total cost based upon the determined disposal cost.

Figure 5-6 depicts another sensitivity plot (Alternative 3 ) that varies the amount of DU that is physically removed from the contaminated sample. As shown in the graph, the three lines include a baseline of $0.5 \%, 0.75 \%$, and $0.25 \%$ DU removed. The $\mathrm{x}$-axis is the disposal cost in cubic yards, and the y-axis is the total cost - also in cubic yards. All units are measured in millions of dollars. From this graph, one can see that as disposal cost increases, the total remediation cost also increases. More specifically, one can see that as more DU is physically removed from the soil before the soil is chemically treated, the higher the total cost will be. The physical removal process is held constant no matter the concentration of DU; therefore, the higher percentage of DU removed physically, the larger amount of DU in the contaminated sample. The larger the level of DU in the soil, the higher the disposal cost and total cost. 
Figure 5-6. Depleted uranium sensitivity plot for Alternative 3: Selective excavation with physical separation and chemical treatment.

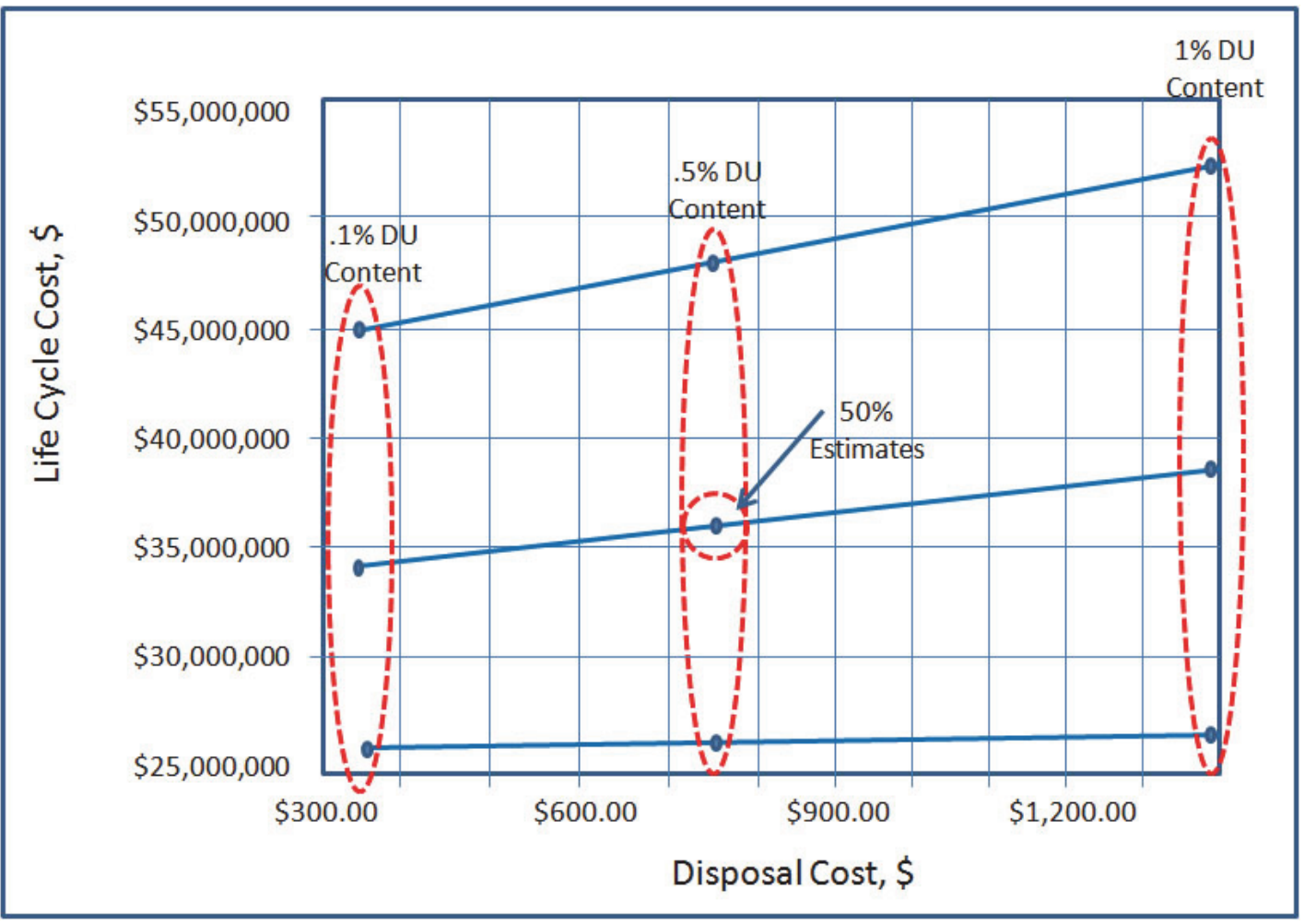

\subsubsection{Summary of Sandy Site LCC Analysis}

The "No Action" Alternative showed to be the least expensive option by far; however the real analysis comes when the assumption is made that something must be done to remove the DU from the site. The results from the LCC estimates and the SBC both point to the value of Selective Excavation and Chemical Treatment. The highest SBC estimate is still hundreds of millions of dollars lower than that of the other options. The SBC showed the value was largely determined by the amount of soil that could be written off as safe. Alternative 3 is the most cost-effective way of removing DU from the soil, but Alternative 4 is the most cost-effective way of dealing with the issue; however, there are many uncertainties and political implications.

\subsection{Catchbox Analysis}

Table 5-9 shows the output of conducting a bottom up build for Alternative 5 a based on Remediation Costs, Disposal Costs, Miscellaneous Costs, and Transportation Costs. The summation of these four categories provides the 
total estimated life cycle cost which is located in the last row. This is the value used to compare each Catchbox Alternative.

Table 5-9. Cost summary for Alternative 5a: Chemical filtration, catchbox.

\begin{tabular}{|l|l|r|}
\hline Category & Task & Net present value (\$) \\
\hline \multirow{4}{*}{ Remediation cost } & Excavation and short haul costs & 7,625 \\
\cline { 2 - 3 } & Physical separation & 155,265 \\
\cline { 2 - 3 } & Chemical separation & 101,131 \\
\cline { 2 - 3 } & Excavation, site closure & 153,554 \\
\hline \multirow{2}{*}{ Disposal Costs } & Disposal of DU waste chemicals & 45,965 \\
& and filter material & 117,704 \\
\hline \multirow{2}{*}{ Transportation Costs } & Project management & 156,939 \\
\cline { 2 - 3 } & Contingency & 78,469 \\
\cline { 2 - 3 } & Profit & 212,566 \\
\hline Total Estimate Life Cycle Costs & Rail & 108,588 \\
\cline { 2 - 3 } & Truck & $1,137,806$ \\
\hline
\end{tabular}

Table 5-10 shows the output of conducting a bottom up build for Alternative $5 \mathrm{~b}$ based on Remediation Costs, Disposal Costs, Miscellaneous Costs, and Transportation Costs. The summation of these four categories provides the total estimated life cycle cost which is located in the last row. This is the value used to compare each Catchbox Alternative. Note that these cost estimates do not include additional amounts for dealing with radioactive material. In some instances remote control equipment has been used because of radioactivity concerns.

Table 5-10. Cost summary for Alternative 5b: Hot spot scan and haul away, sandy site.

\begin{tabular}{|l|l|r|}
\hline Category & Task & Net present value (\$) \\
\hline Remediation cost & Excavation, site closure & 210,350 \\
\hline Disposal Costs & Disposal of DU waste & $2,260,440$ \\
\hline \multirow{2}{*}{ Miscellaneous Costs } & Project management & $1,466,791$ \\
\cline { 2 - 3 } & Contingency & $\mathbf{1 , 9 5 5 , 7 2 2}$ \\
\cline { 2 - 3 } & Profit & $\mathbf{9 7 7 , 8 6 1}$ \\
\hline \multirow{2}{*}{ Transportation Costs } & Rail & $5,907,330$ \\
\cline { 2 - 3 } & Truck & $1,400,490$ \\
\hline Total Estimate Life Cycle Costs & & $\mathbf{1 4 , 1 7 8 , 9 8 4}$ \\
\hline
\end{tabular}


Several testing areas across the US have built large catchboxes in order to contain munitions after testing. Catchboxes are essentially large boxes full of sand that serve as targets for gunnery practice and weapons development. Due to the speculative health concerns surrounding DU, catchboxes are often used when testing these munitions in order to minimize the area exposed. Catchboxes have been proven to contain approximately $85 \%$ of the fired DU; therefore, the DU is confined in a very small volume and much easier to remove and dispose of properly. Figure 5-7 includes images of the catchbox at YPG that is similar to catchboxes used at most DU test firing ranges.

Figure 5-7. Yuma Proving Ground DU Catchbox (from Martinell and Dillard 2010).

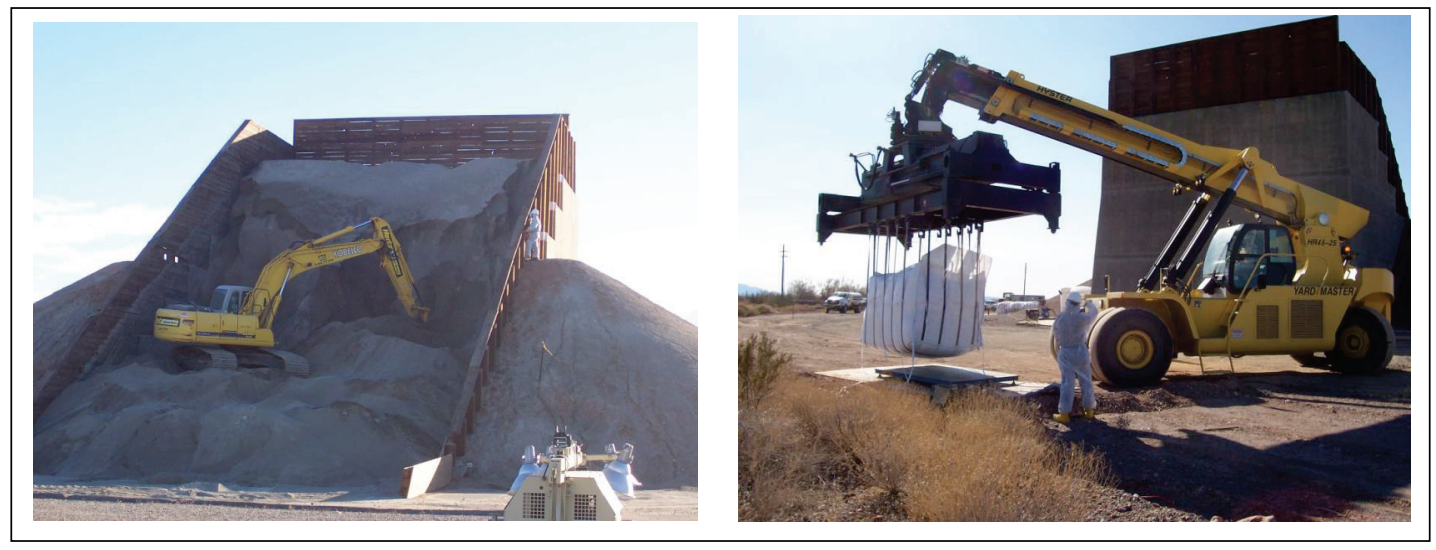

In the event of a rainstorm, runoff water from the catchbox must also be considered. Runoff water from the catchbox has a high likelihood of being contaminated with DU and must be dealt with accordingly. A solution to this problem is the creation of a runoff pond located under, or directly downhill, of the catchbox. The runoff pond must be located such that all rainwater seeping through the catchbox will eventually flow into the pond. The pond is lined with a waterproof plastic lining, which prevents the water from escaping into the ground. Depending on the frequency of rainstorms, the water from this runoff pond usually evaporates completely, leaving behind a layer of residual sediment from the catchbox. This sediment contains only fine particles that were dissolved in the rainwater or were small enough to be carried through the catchbox to the runoff pond. In either case, the sediment is most likely contaminated with DU and must be excavated each time the catchbox is excavated. Chemical treatment can play a huge role in minimizing the amount of DU that must be disposed of long term. 
With disposal costs in excess of $\$ 756 / \mathrm{yd}$, volume reduction is important. Catchbox cleaning costs can be reduced if screening can be done on site and the clean sand be returned to the catchbox immediately instead of being hauled away for disposal. This would require sifting equipment typically seen in the mining industry (Figure 5-8). However, due to the fine DU dust in the sand caused by long penetrator rods slamming into each other inside the catchbox; this would disperse a large amount of hazardous dust into the air. Efforts to mitigate this are being investigated and include the use of automated/remotely controlled sifting and excavating equipment. Table 5-11 contains the input data used in the catchbox cost analysis.

Figure 5-8. Heavy sifting equipment (from Martinell and Dillard 2010).

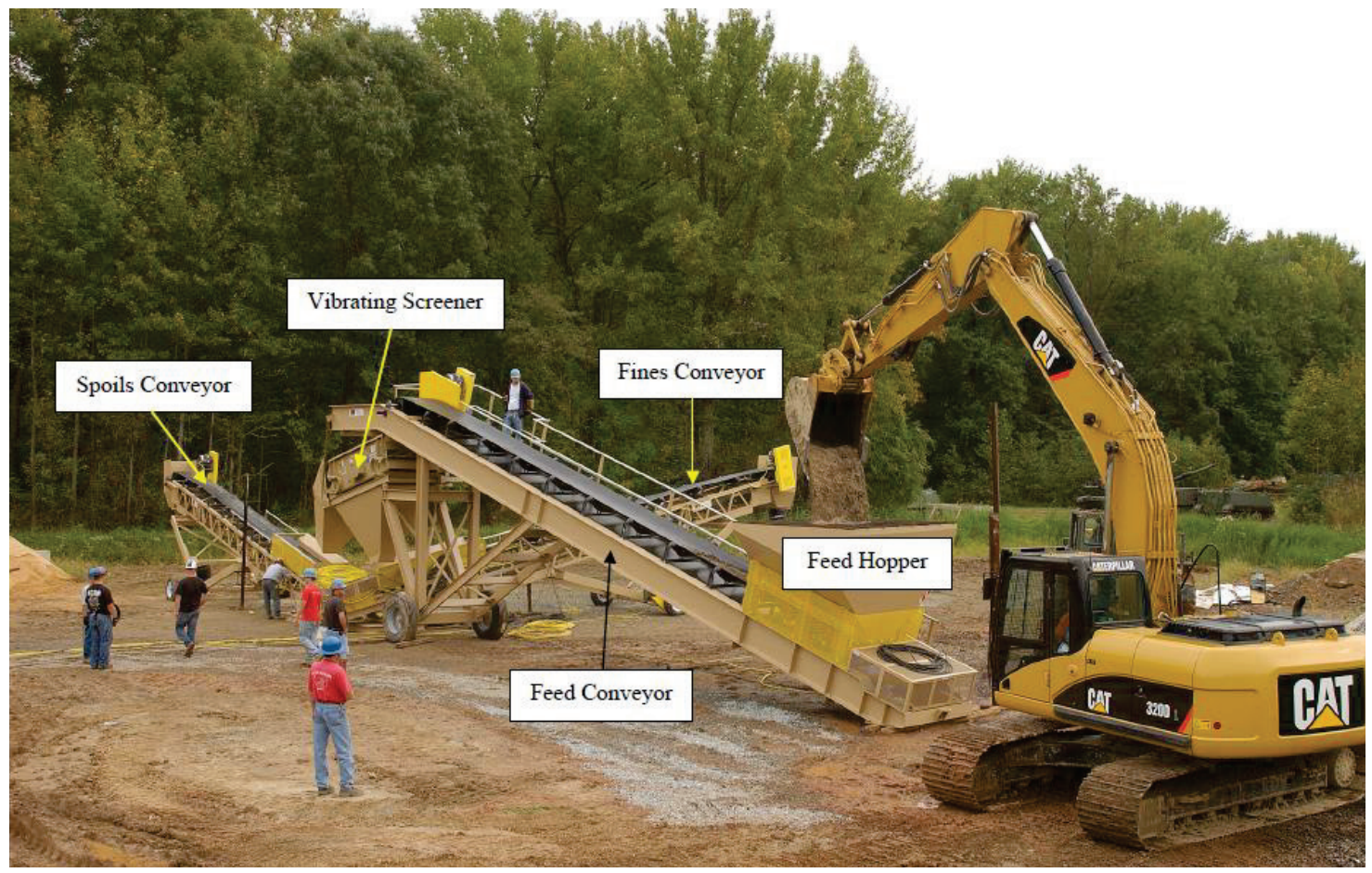

Table 5-11. Data variable sheet for Catchbox.

\begin{tabular}{|l|l|l|}
\hline Variable & Expected Values & Notes \\
\hline Volume & $2,600 \mathrm{yd}^{3}$ & Value provide by ERDC \\
\hline $\begin{array}{l}\text { Soil } \\
\text { Expansion/ } \\
\text { Swell Factor } \\
\text { (Sand) }\end{array}$ & $15 \%$ & Taken from http://www.engineeringtoolbox.com/soil-rock-bulking-factor-d_1557.html \\
\hline
\end{tabular}




\begin{tabular}{|c|c|c|}
\hline Variable & Expected Values & Notes \\
\hline Soil Weight & $100 \mathrm{lbs} / \mathrm{ft}^{3}$ & $\begin{array}{l}\text { Any test site as large as } 10 \text { square miles will have tremendous variability in soil } \\
\text { type and corresponding density, silt/clay content, water content, etc. For example, } \\
\text { using the YPG as representative of a generic site, there are at least } 34 \text { different } \\
\text { soil and rock formations identified (US Department of Agriculture, 1980). } \\
\text { References } \\
\text { Reade Advanced Materials (READE®). } \\
\underline{\text { http://www.reade.com/Particle_Briefings/spec_gra2.html }} \\
\text { and from Geotechnical Info.com accessed on } 11 \text { December } 2012 \text { at } \\
\text { http://www.geotechnicalinfo.com/soil unit_weight.html }\end{array}$ \\
\hline $\begin{array}{l}\text { Capital } \\
\text { Equipment } \\
\text { Costs } \\
\text { (Physical } \\
\text { Separation) }\end{array}$ & $\begin{array}{l}\$ 150,000 \\
(\text { ALT 5a) }\end{array}$ & This value was provided by SMEs at ERDC. \\
\hline $\begin{array}{l}\text { Estimated } \\
\text { Percentage of } \\
\text { DU } \\
\text { Contaminated } \\
\text { Soil }\end{array}$ & $2.0 \%(\mathrm{ALT} 5 \mathrm{a})$ & $\begin{array}{l}\text { This value was validated by the SMEs at ERDC. This number is a key cost driver and } \\
\text { was developed by SMEs. For the expected value, this will produce } 71 \text { cubic yards of } \\
\text { material of which to dispose. This is true ONLY for that material that can be } \\
\text { identified using possibly a Geiger counter and removed before chemical } \\
\text { processing. }\end{array}$ \\
\hline $\begin{array}{l}\text { Cost of } \\
\text { Physical } \\
\text { Separation }\end{array}$ & $\begin{array}{l}\$ 1.50 \text { dollars per } \\
\text { ton fixed } \\
\text { (ALT 5a) }\end{array}$ & This value was provided by SMEs at ERDC. \\
\hline $\begin{array}{l}\text { Capital } \\
\text { Equipment } \\
\text { Cost } \\
\text { (Chemical } \\
\text { Separation) }\end{array}$ & $\begin{array}{l}\$ 500,000 \\
(\text { ALT 5a) }\end{array}$ & This value was provided by SMEs at ERDC. \\
\hline Price of Filter & $\begin{array}{l}\$ 250 \text { fixed } \\
(\text { ALT 5a) }\end{array}$ & This value was provided by SMEs at ERDC. \\
\hline $\begin{array}{l}\text { Cubic Yards of } \\
\text { Soil per Filter }\end{array}$ & $\begin{array}{l}3,000 \\
\text { (ALT 5a) }\end{array}$ & This value was provided by SMEs at ERDC. \\
\hline $\begin{array}{l}\text { Initial } \\
\text { Treatment } \\
\text { Fluid Needed } \\
\text { per Cubic Yard } \\
\text { of Soil }\end{array}$ & $\begin{array}{l}13.26 \text { gallons per } \\
\text { cubic yard } \\
\text { (ALT 5a) }\end{array}$ & $\begin{array}{l}\text { Based upon information provided by ERDC. Built into the model is a recycle factor } \\
\text { that suggests the need to add only } 2 \text { additional gallons per } \mathrm{yd}^{3} \text { of soil }\end{array}$ \\
\hline $\begin{array}{l}\text { Cost per } \\
\text { Gallon of Fluid }\end{array}$ & $\begin{array}{l}\$ .15 / \text { gallon } \\
\text { (ALT 5a) }\end{array}$ & $\begin{array}{l}\text { Numerous web sources list bulk acetic acid for } \$ 1.50 \text { per gallon in } 55 \text { gallon } \\
\text { drums. A scale-up assumption of } 10 \% \text { of that price was made based upon the large } \\
\text { amount needed. This price also accounts for dilution of the acetic acid, which } \\
\text { reduces the volume required by } 90 \% \text {. } \\
\text { http://www.alibaba.com/trade/search?fsb=y\&IndexArea=product en\&Catld=\&SearchText= } \\
\text { acetic+acid+price }\end{array}$ \\
\hline $\begin{array}{l}\text { Mobilization } \\
\text { Cost }\end{array}$ & $\$ 100,000$ & $\begin{array}{l}\text { Mobilization shall include all activities and costs for transportation of personnel, } \\
\text { equipment, and supplies not required or included in the contract to the site. This is } \\
\text { a not a key cost driver. }\end{array}$ \\
\hline
\end{tabular}




\begin{tabular}{|c|c|c|}
\hline Variable & Expected Values & Notes \\
\hline $\begin{array}{l}\text { Equipment } \\
\text { Demobilization }\end{array}$ & $\begin{array}{l}\$ 150,000 \\
(\text { ALT 5a) } \\
\$ 80,000 \\
(\text { ALT 5b) }\end{array}$ & $\begin{array}{l}\text { Demobilization shall include all activities and costs for transportation of personnel, } \\
\text { equipment, and supplies not required or included in the contract from the site; } \\
\text { including the disassembly, removal, and site cleanup of offices, buildings, and } \\
\text { other facilities assembled on the site specifically for this contract. This is a not a } \\
\text { key cost driver. }\end{array}$ \\
\hline $\begin{array}{l}\text { Site } \\
\text { Restoration }\end{array}$ & $\$ 7{\text { per } y d^{3}}^{3}$ & $\begin{array}{l}\text { Based upon minimal restoration for sand; values came from numerous sources on } \\
\text { the web }\end{array}$ \\
\hline $\begin{array}{l}\text { Cost of short } \\
\text { haul }\end{array}$ & $\begin{array}{l}\$ 1.07 \text { per ton } \\
\text { mile }\end{array}$ & $\begin{array}{l}\text { Ogershok, Dave, and Richard Pray, National Construction Estimator, Carlsbad, CA, } \\
\text { Craftsman Book, } 2011\end{array}$ \\
\hline Excavation & $\$ 1.48$ per yd3 & $\begin{array}{l}\text { Ogershok, Dave, and Richard Pray, National Construction Estimator, Carlsbad, CA, } \\
\text { Craftsman Book, } 2011\end{array}$ \\
\hline $\begin{array}{l}\text { Loading and } \\
\text { Handling } \\
\text { Costs }\end{array}$ & $\$ 75$ per ton & Source: http://cms3.tucsonaz.gov/es/content/various-programs \\
\hline Trucking Cost & $\$ 21.60$ ton-mile & $\begin{array}{l}\text { Source: } \\
\text { *factor of } 10 \text { increase due to radioactivity } \\
\text { http://cab.cati.csufresno.edu/research_publications/99/990301/costs.htm low and high } \\
\text { values were averaged }\end{array}$ \\
\hline $\begin{array}{l}\text { Distance of } \\
\text { Solid/Filters } \\
\text { (Truck) }\end{array}$ & 15 miles & Estimated distance to local rail site \\
\hline $\begin{array}{l}\text { Distance of } \\
\text { Solid/Filters } \\
\text { (Rail) }\end{array}$ & 600 miles & Estimate based on distance to nearest waste site \\
\hline Soil Density & $2700 \mathrm{lbs} / \mathrm{yd}^{3}$ & SMEs at ERDC recommended the use of $100 \mathrm{lbs} / \mathrm{ft}^{3}$ converted to $\mathrm{lbs} / \mathrm{yd}^{3}$ \\
\hline Rail Cost & $\$ 2.68 /$ ton-mile & $\begin{array}{l}\text { Source: } \\
\text { https://wiki.umd.edu/lei/images/9/96/Forkenbrock 2001.pdf } \\
\text { (pg } 327 \text { brought to future and averaged) }\end{array}$ \\
\hline $\begin{array}{l}\text { Weight per } \\
\text { Filter }\end{array}$ & $500 \mathrm{lbs}$ & Estimate based off of the estimated size and weight of Chitin/Fish-bones \\
\hline $\begin{array}{l}\text { Long Term } \\
\text { Cost of } \\
\text { Disposal for } \\
\text { One Filter } \\
\text { (ALT5a) }\end{array}$ & $\$ 756$ per yd $^{3}$ & SMEs at ERDC recommended the use of $\$ 756{\text { per } \mathrm{yd}^{3}}^{3}$ \\
\hline $\begin{array}{l}\text { Long Term } \\
\text { Cost of } \\
\text { Disposal for } 1 \\
y^{3} \text { of DU } \\
\text { Contaminated } \\
\text { Soil }\end{array}$ & $\$ 756$ per yd $^{3}$ & SMEs at ERDC recommended the use of $\$ 756{\text { per } \mathrm{yd}^{3}}^{3}$ \\
\hline $\begin{array}{l}\text { Project } \\
\text { Management }\end{array}$ & $15 \%$ & These are standard and typical for these types of projects (Farr 2011) \\
\hline Contingency & $20 \%$ & These are standard and typical for these types of projects (Farr 2011) \\
\hline Profit & $10 \%$ & These are standard and typical for these types of projects (Farr 2011) \\
\hline
\end{tabular}




\subsection{Summary of Alternatives}

The way forward is largely dependant on what the government determines to be the next logical step. In the analysis, the key to reducing the cost of site remediation is to decrease the volume of material that requires disposal. This objective is best met when selective excavation and chemical separation are used in unison. The massive reduction in the volume of soil resulting from use of these processes causes transportation and disposal costs to plummet. The sensitivity of these transportation and disposal costs were analyzed and proven to be relatively negligible based on the significant decrease in waste volume.

Analysis of the Sandy Site, Table 5-5: Cost summary for Alternative 2: Selective Excavation and Table 5-6: Cost summary for Alternative 3: Selective Excavation with Physical Separation and Chemical Treatment shows the cost decreases dramatically due to chemical filtration; from roughly $\$ 2 \mathrm{~B}$ to around $\$ 35 \mathrm{M}$.

Analysis of the Catchbox alternatives in Table 5-9: Cost summary for Alternative 5a: Chemical Filtration, Catchbox, and Table 5-10 Cost summary for Alternative 5b: Haul Away, Hot Spot Scan, Sandy Site also shows the cost decrease due to chemical filtration; from $\$ 14,178,984$ to $\$ 1,137,806$.

This is reflective of the comparison of the actual costs of the remediation alternatives for the entire sandy site. This shows the best alternative is selective excavation and chemical separation used jointly in order to provide the most effective and efficient remediation alternative.

The roughly 13 to 1 savings that can be realized from volume reduction (screening and chemical filtration) is important and shows the high costs of disposing of contaminated material. 


\section{Summary}

\subsection{Comparison of Costs for Treatment Alternatives}

Depleted uranium is considered an environmental concern and the US Army has in some instances assumed stewardship for proper remediation of DU for its test ranges and manufacturing facilities. Through a bottom up analysis and development of LCC models, candidate DU remediation methods of soil remediation at military ranges were evaluated: physical and chemical separation, selective excavation, selective excavation with physical and chemical separation, and site containment and monitoring. Conducting a LCC of each alternative yielded an adequate estimate that incorporated risk in order to determine the net present value or present value that should be allocated to operate the system in the future. This provides the stakeholder with a direct and unprejudiced comparison of all remediation methods. The steps of each remediation method consist of identification, excavation, transportation to treatment site, treatment, transportation to disposal site, and disposal. These steps were compiled into three phases that will affect cost: separation and loading, hauling, and disposal. In order to demonstrate the LCC model, a 10-square-mile test site consisting of sandy soil was chosen for analysis.

After modeling each system through a bottom up build, cost estimating relationships and simulation-based costing was applied in order to develop a mathematical expression and run the risk model. Systems simulations on the alternatives yielded significant results showing the true underlying drivers in cost-soil volume, percentage of DU in the hotspot, and number of hotspots. Since these input variables came with a certain amount of uncertainty, a sensitivity analysis was completed on each one. The research conducted yielded promising results in designing, developing, and implementing an efficient and cost-effective solution for soil remediation.

Research has shown that the cost of selective excavation with physical and chemical separation is the most effiecient method for DU remediation. Appendix A contains detailed process charts that were used to obtain the costs for each alternative. The underlying cost drivers were the lowest with Alternative 3, making it the most cost-effective solution to the remediation problem. 


\subsection{Further Research}

Because of the tremendous TOCs required for these types of environmental remediation problems, additional funding for further research is warranted. Better identification of DU hotspots and techniques to reduce the volume of soil placed into a landfill are warranted. Based upon the research study conducted, it was determined that three significant cost drivers (soil volume, percentage of DU in the hotspot, and number of hotspots) within the DU remediation process should be the focus of research. Research can also be focused on long-term storage or disposal of DU. However, this is more of a national priority than an Army research and development issue. Regarding the percentage of DU in hotspots and the total number of hotspots, research should be focused on excavating only contaminated soil. The less uncontaminated soil that is excavated throughout the process, the more efficient and cost-effective the system will be. Through research, the process can become more efficient, decreasing these cost drivers and therefore reducing the overall cost for DU remediation. 


\section{References}

Buck, B. J., A. L. Brock, W. H. Johnson, and A. L. Ulery. 2004. Corrosion of depleted uranium in an arid environment: Soil-geomorphology, SEM/EDS, XRD, and electron microprobe analyses. Soil and Sediment Contamination 13:545-561.

Choy, C. C., G. P. Korfiatis, and X. Meng. 2006. Removal of depleted uranium from contaminated soils. Journal of Hazardous Materials 136:53-6o.

Department of Defense (DoD). Parametric Cost Estimating Handbook. Joint Government/Industry Initiative.1995.

Dong, W., G. Xie, T. R. Miller, M. P. Franklin, T. P. Oxenberg, E. J. Bouwer, W. P. Ball, and R.U. Halden. 2006. Sorption and bioreduction of hexavalent uranium at a military facility by the Chesapeake Bay. Environmental Pollution 142:132-142.

Farr, John. 2011. Systems life cycle costing: Economic analysis, estimation, and management. CRC Press, Boca Raton: Taylor \& Francis Group.

Johnson, W. H., B. Buck, H. Brogonia, and A. L. Brock. 2004. Variations in depleted uranium sorption and solubility with depth in arid soils. Soil and Sediment Contamination 13:533-544.

Kappes, D.W. 2002. Precious metal heap leach design and practice. Available at: http://www.kcareno.com/pdfs/mpd_heap_leach_desn_and_practice_07apr02.pdf

Larson, S., J. Ballard,V. Medina, M. Thompson, G. O'Connor, C. Griggs, and C. Nestler. 2009. Separation of depleted uranium from soil. ERDC/EL TR-09-1. Vicksburg, MS: US Army Engineer Research and Development Center.

Larson, S. L., V. F. Medina, J. Ballard, C. Griggs, M. Wynter, D. Mackie, B. King, and C. Nestler. 2012. Army range technology program large-scale physical separation of depleted uranium from soil. Army Range Technology Program. ERDC/EL TR12-25. Vicksburg, MS: US Army Engineer Research and Development Center.

Martinell, P. and J. Dillard. Depleted uranium catchbox cleanout 2010 - trench warfare 2 catchbox. 2010. Report Number DUCR-1 (FOUO). Aberdeen Proving Ground, MD: US Army Aberdeen Test Center.

Meinrath, A., P. Schneider, and G. Meinrath. 2003. Uranium ores and depleted uranium in the environment, with a reference to uranium in the biosphere from the Erzgebirge/Sachsen, Germany. Journal of Environmental Radioactivity 64:175193 .

Mellini, M., and F. Riccobono. 2005. Chemical and mineralogical transformations caused by weathering in anti-tank DU penetrators ("the silver bullets") discharged during the Kosovo war. Chemosphere 60:1246-1252.

National Aeronautics and Space Administration (NASA). Cost Estimating Handbook. 2008. (accessed August 2012) www.nasa.gov/ceh_2008/2008.htm) 
Ogershok, D. and R. Pray. 2011. 2011 National Construction Esimator, $59^{\text {th }}$ Edition. Carlsbad, CA: Craftsman Book: National Construction Estimator.

US Department of Agriculture. Soil Survey of Yuma Wellton Area, Part of Yuma County Arizona and Imperial Country, California. (accessed 11 December 2012) http://soildatamart.nrcs.usda.gov/manuscripts/AZ649/0/yuma.pdf

US Environmental Protection Agency. 2006. Depleted Uranium Technical Brief. Report Number EPA 402-R-06-011. Office of Radiation and Indoor Air Radiation Protection Division, Project Officer Brian Littleton. 


\section{Appendix A: Bottom Up High Resolution Spreadsheet Model}

This appendix contains the details of the high resolution, bottom up spreadsheet model used in conducting cost analysis for the remediation options. Specifically, figures and tables from Alternative 1 were used; however, the general thought process was consistent throughout all options. The figures were created to be general and give a broad picture of the process, whereas the tables go into depth on the tasks and subtasks involved in the implementation of Alternative 1. In the other options, tasks have been added or removed to create three unique alternatives, but the format is consistent. The intent of this appendix is to provide a baseline description of the spreadsheet that can be referenced in order to facilitate the use and comprehension of the spreadsheet models.

Table A1 (also Table 5-4) contains the estimated costs from the four distinct categories involved in remediation. Alternative 1: Physical and Chemical Separation of a Sandy Site. The categories are Remediation, Disposal, Miscellaneous, and Transportation costs. These, as well as their subcategories, are displayed in the summary alternative costing. Each of the subcategories are further subdivided into tasks. The Total Ownership Cost of these categories, subcategories, and tasks are displayed to provide a transparent view into the model and highlight potential areas of concern. When attempting to cut costs, these potential areas of concern could be a focus area. This table is a broad snapshot of the fully costed alternative. In the following tables, each of the categories are broken down in detail in order to ensure that the upfront numbers in Table A1 are numbers that are explained and justified.

Table A2 contains a detailed breakdown of the remediation category in Alternative 1. The general site characteristics of length, width, and depth gave a base value for the volume of excavation of the site's contaminated area. It was necessary to apply a soil expansion percentage that would account for the increased volume due to the aeration of the soil. This yielded the volume of soil that requires treatment after excavation. Additionally, an estimate of the density of sandy soil was used to estimate the weight in tons that would be excavated out of the ground. 
Table A1. Cost summary for Alternative 1: Physical and chemical remediation.

\begin{tabular}{|l|l|r|}
\hline Category & Task & Net present value (\$) \\
\hline Remediation cost & Clear and grub site & $22,784,000$ \\
\hline & Excavation and short haul costs & $90,837,120$ \\
\hline & Physical separation & $67,726,400$ \\
\hline & Chemical separation & $14,155,451$ \\
\hline Disposal costs & Excavation, site closure & $112,972,164$ \\
\hline Miscellaneous costs & Disposal of DU waste chemicals & $9,031,361$ \\
\hline & and filter material & $182,123,971$ \\
\hline & Project management & $242,831,962$ \\
\hline Transportation costs & Contingency & $121,415,981$ \\
\hline & Profit & $450,294,342$ \\
\hline Total estimate life cycle costs & Rail & $446,358,971$ \\
\hline & Truck & $\mathbf{1 , 7 6 0 , 5 3 1 , 7 2 3}$ \\
\hline
\end{tabular}

As seen in Table A2, the first step of treatment is physical remediation in which debris and vegetation that was not removed during the clearing and grubbing stage is physically separated from the DU. During this task the large fragments of DU are removed and treated as solid waste while the rest of the soil is moved on to be processed chemically. A new volume of soil, which accounts for the removal of DU during physical separation, is then carried into the next treatment task.

Chemical remediation occurs only on the soil that contains DU fragments too small to be physically separated. During this task, an acid wash is used to rinse the soil by suspending the DU in solution. The solution is then processed through a filter that strips the DU from the solution and stores it in the filter. The filter and the solid DU are then transported to the temporary disposal site. In Table A2, the number of filters, amount of fluid, and their respective costs combine to find the total chemical remediation cost. For both of the treatment tasks there is a capital equipment cost to set up the necessary treatment equipment.

Site closing is the final task in the remediation process. Equipment on the site needs to be broken down and removed or stored appropriately on-site. The cleaned soil needs to be backfilled, and the cleared and grubbed soil needs to be reseeded in order to complete site restoration. Once these tasks are accomplished the site will have met the desired remediation requirements. 
Table A2. Remediation details

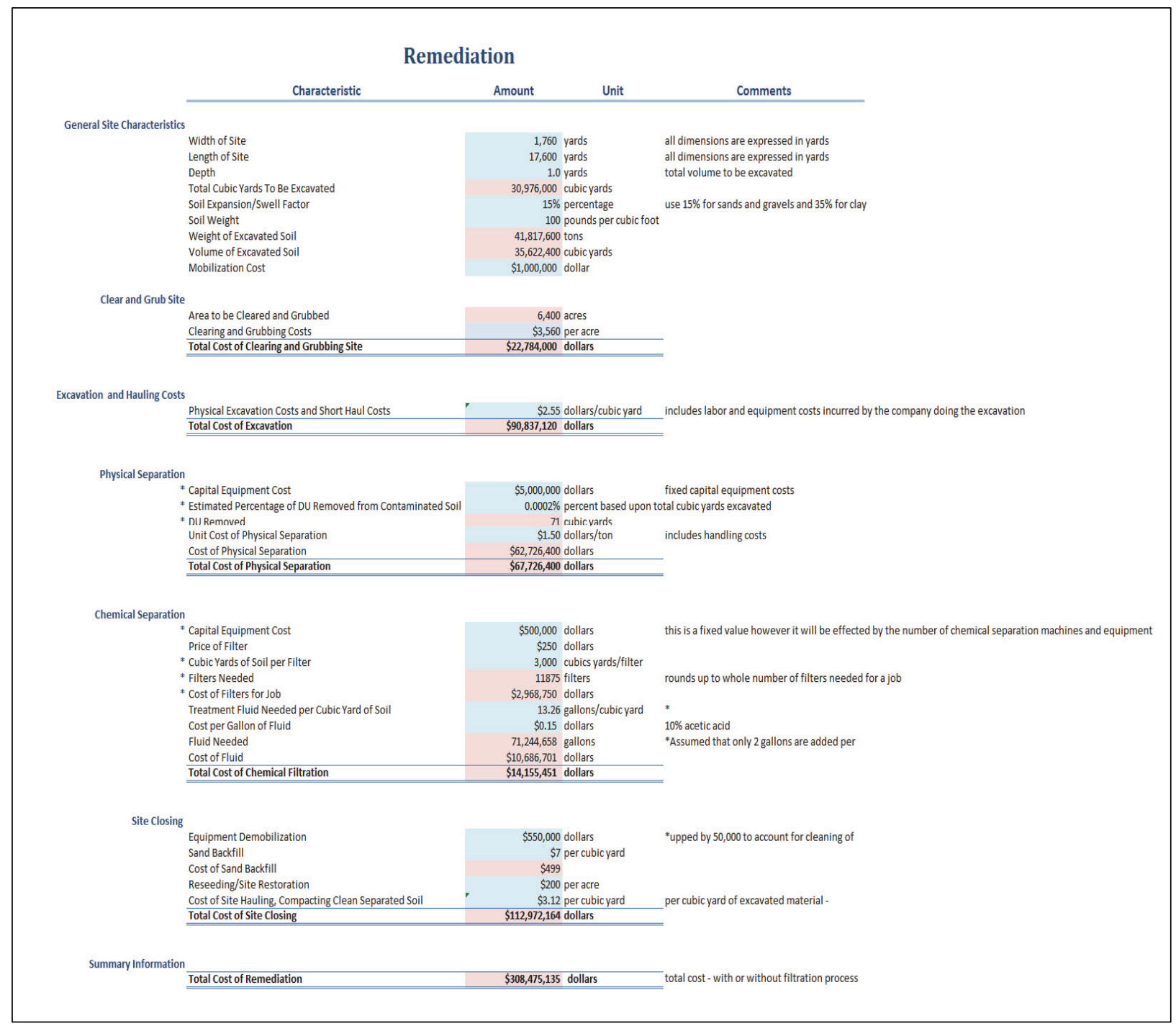

Figure A1 gives a visual depiction of the tasks in the remediation process without going into detail about the subtasks. This is the black box representation of the process that was layed out in more detail above in Table A2. 
Figure A1. Remediation flow chart.

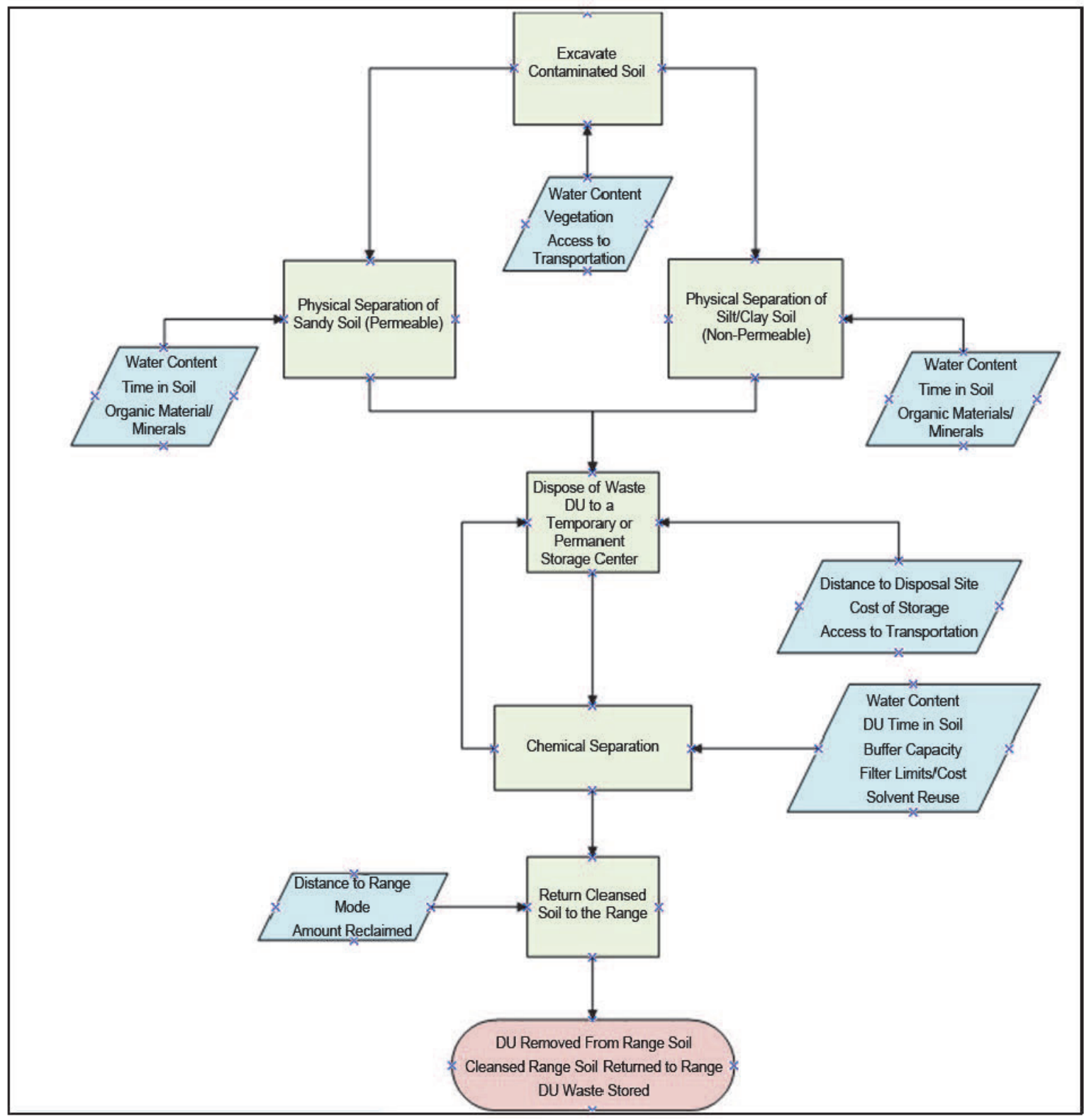

Table A3 depicts all the transportation calculations needed in order to properly transport contaminated material from the stockpile site to the rail station and from the rail station to the intermediate disposal site. Transportation by rail will have cargo that consists of solid DU and the used filters. The loading and handling cost of these two items are similar regardless of transportation method based upon data collected from a desert site. The solid DU density is based on the data collected from the periodic table, which was converted into usable units. The weight per filter is an estimate based off of the estimated size and weight of chitin/fish-bones. The rail cost of these two items is also similar based upon a research report done at the 
University of Iowa. The weight for solid DU in rail transportation and truck transportation is a calculation based on the DU removed in cubic yards multiplied by the soil density converted into tons. The weight for filters is the number of filters multiplied by the weight of the filter and converted into tons. The distance for rail transportation is an estimated number based on distance to nearest waste site. Trucking cost for truck transportation is based on a research publication from Fresno State University.

Table A3. Transportation Calculations.

\begin{tabular}{|c|c|c|c|c|}
\hline \multicolumn{5}{|c|}{ Baseline Costing DU Transpotation } \\
\hline & Characteristics & Amount & Unit & Comments \\
\hline \multirow[t]{7}{*}{ Transportation by Rail Solid } & Loading and Handling Unit Cost & \multicolumn{2}{|c|}{$\$ 75$ per ton } & \\
\hline & Loading and Handling Costs & & used a factor of ten increase due to radioactivity \\
\hline & Soil Density & \multicolumn{2}{|c|}{2,700 Ibs per cubic yard } & \\
\hline & Rail cost & \multicolumn{2}{|c|}{$\$ 2.68$ dollars per ton-mile } & \\
\hline & Weight & \multirow{2}{*}{\multicolumn{2}{|c|}{$\begin{array}{l}96.2 \text { tons } \\
600 \text { miles }\end{array}$}} & this is the amount of waste from the remediation process \\
\hline & Distance & & & \\
\hline & Total Cost & \multicolumn{2}{|c|}{$\$ 208,092$ dollars } & \\
\hline \multirow[t]{8}{*}{ Transportation by Truck Solid } & Loading and Handling Unit Cost & \multicolumn{2}{|c|}{$\$ 75$ per ton } & \\
\hline & Loading and Handling Costs & \multicolumn{2}{|c|}{$\$ 53,434$} & used a factor of ten increase due to radioactivity \\
\hline & Trucking cost & \multirow{2}{*}{$\$ 21.60$} & dollars per ton-mile us & used a factor of ten increase due to radioactivity \\
\hline & Weight & & 96.2 tons & \\
\hline & Distance & \multicolumn{2}{|c|}{15 miles } & \\
\hline & Total Cost & \multicolumn{2}{|c|}{$\$ 84,596$ dollars } & \\
\hline & Total solid DU Transportation Cost & \multicolumn{2}{|l|}{$\$ 292,688$} & \\
\hline & Characteristics & Amount & Unit & Comments \\
\hline \multirow[t]{7}{*}{ Transportation by Rail Filters } & Loading and Handling Unit Cost & \multicolumn{2}{|c|}{$\$ 75$ per ton } & \\
\hline & Loading and Handling Costs & $\$ 445,312,500$ & & \\
\hline & Weight per Filter & \multicolumn{2}{|c|}{$\begin{array}{r}\$ 445,312,500 \\
500 \text { pounds/filter }\end{array}$} & \\
\hline & Rail Cost & \multicolumn{2}{|c|}{$\$ 2.68$ dollars per ton-mile } & \\
\hline & Weight & $2,968.8$ & tons th & this is the amount of waste from the remediation process \\
\hline & Distance & \multicolumn{2}{|c|}{600 miles } & \\
\hline & Total Cost & $\$ 450,086,250$ & dollars & \\
\hline \multirow[t]{10}{*}{ Transportation by Truck Filters } & Loading and Handling Unit Cost & \multicolumn{2}{|c|}{$\$ 75$ per ton } & \\
\hline & Loading and Handling Costs & \multicolumn{2}{|c|}{$\$ 445,312,500$} & \\
\hline & Trucking Cost & $\$ 21.60$ & dollars per ton-mile tr & truck to disposal site from railhead \\
\hline & Weight & $2,968.8$ & tons & \\
\hline & Distance & & \\
\hline & Total cost & $\$ 446,274,375$ & $\begin{array}{c}15 \text { miles } \\
\mathbf{\$ 4 6 , 2 7 4 , 3 7 5} \text { dollars }\end{array}$ & \\
\hline & Total Filter Transportation Cost & \multicolumn{2}{|c|}{$\$ 896,360,625$} & \\
\hline & Total Cost by Rail & $\$ 450,294,342$ & & \\
\hline & Total Cost by Truck & $\$ 446,358,971$ & & \\
\hline & Total Transportation Cost & $\$ 896,653,313$ & & \\
\hline
\end{tabular}

Figure A2 gives a visual depiction of the tasks in the transportation process without going into detail about the subtasks. This is the black box representation of the process that was layed out in detail above in Table A3. 
Figure A2. Transportation flow diagram.

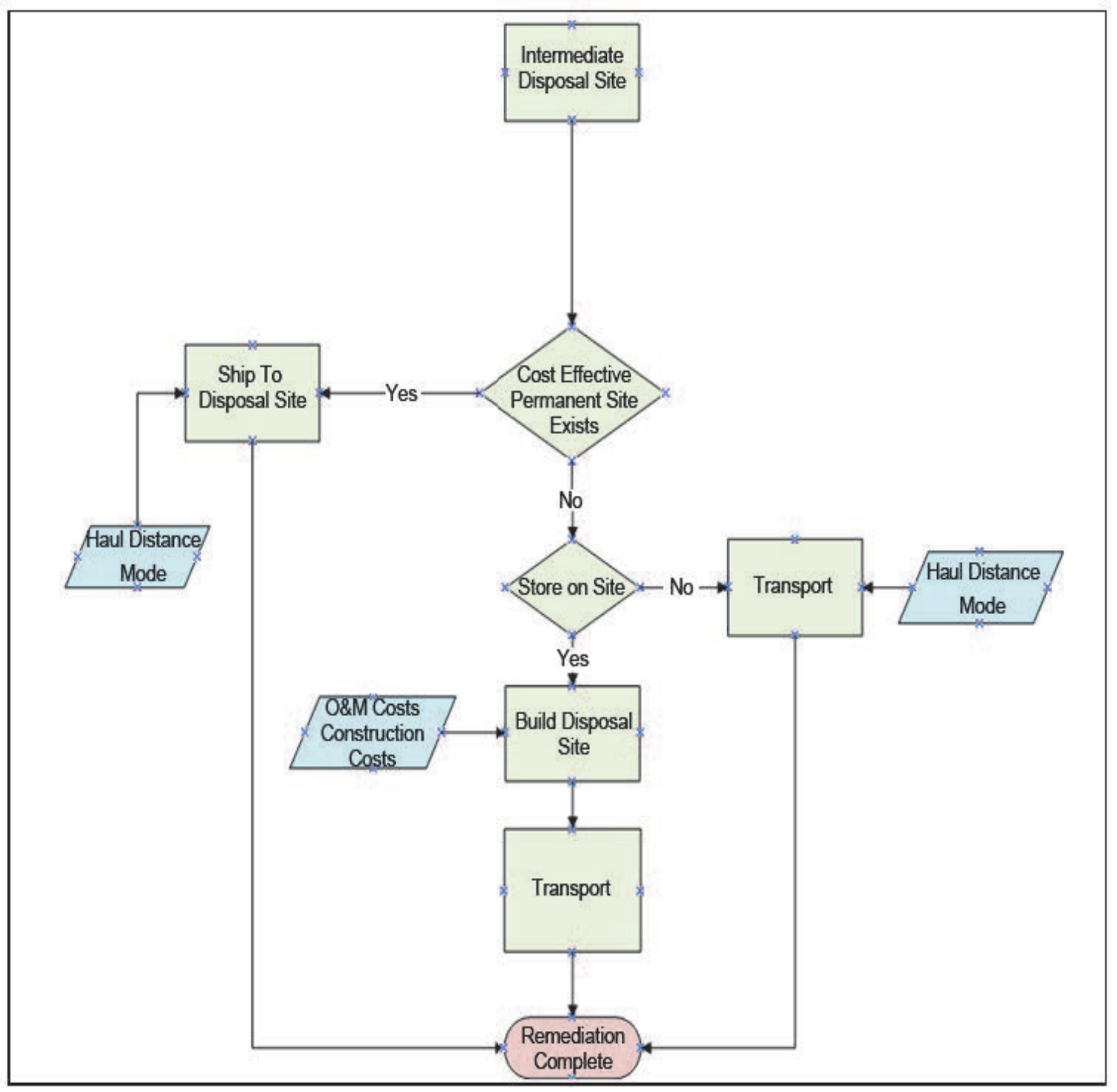

Table A4 depicts disposal and management cost calculations which consist of the number of filters used, long-term disposal cost of a filter, long-term disposal cost of one cubic yard of DU, filter disposal costs, and solid DU disposal cost. The number of filters used is dictated by the project and the amount of contaminated soil excavated. The long-term cost to dispose of a filter and long-term cost of disposal for one cubic yard of DU are recommended prices by ERDC SMEs. The total filter disposal cost is the number of filters used variable multiplied by the longterm cost of disposal for one filter. The total solid DU disposal cost is long-term cost of disposal for one cubic yard of DU multiplied by the DU removed (cubic yards). The overall cost to dispose of DU waste chemicals and filters is the combination of the filter disposal cost and solid DU disposal cost. 
Table A4. Disposal cost calculations of DU waste chemicals and filters.

\begin{tabular}{|l|r|}
\hline Characteristic & Amount (\$) \\
\hline Number of filters used & 11,875 \\
\hline Long-term disposal cost of 1 filter & 756 \\
\hline Long-term disposal cost of 1 yd ${ }^{3}$ of DU & 756 \\
\hline Filter disposal cost & $8,977,500$ \\
\hline Solid DU disposal cost & 53,861 \\
\hline Total disposal cost & \multicolumn{2}{|c|}{} \\
\hline
\end{tabular}

Figure A3 shows the process from processing material at the intermediate disposal site until remediation completion. After the DU is properly treated, it is shipped to an intermediate site for temporary or permanent storage. Once at the intermediate site, if no cost-effective site is in operation, the DU will remain at the intermediate site unless the facility does not have the resources to properly dispose of the radioactive material. If the facility is adequate, a proper disposal site will be constructed in order to safely provide a permanent area of containment.

The miscellaneous costs are comprised of a project management cost, contingency costs, and profits. Project management cost is the price needed to properly manage this project and is calculated as $15 \%$ of the project total. Contingency cost is the variable, uncertainty cost associated with the project and is calculated as $20 \%$ of the project total. This is added as part of a control account. This control account is used to cover any costs incurred by risk during the project. Profit is the amount that the contracted company plans to make for the entirety of this project and is calculated as $10 \%$ of the project total.

In conclusion, this basic walk through covers a large portion of all three models due to the similarities that run through all of the models. One additional task not presented above is the hot spot scanning technique. When this technique is used, other tasks such as clearing and grubbing the entire site become unnecessary and other tasks associated with scanning the site, such as the scanning cost itself, are added to the model. The same can be said about Alternative 2 where the site is scanned and selectively excavated with no treatment to the soil. In this option, site scanning costs come into play, but the clearing and grubbing cost, as well as all of the treatment costs, have been removed because they are not applicable. These subtle changes to the plan make significant differences in the cost and are where the majority of the cost is accrued. 
Figure A3. Disposal flow diagram.

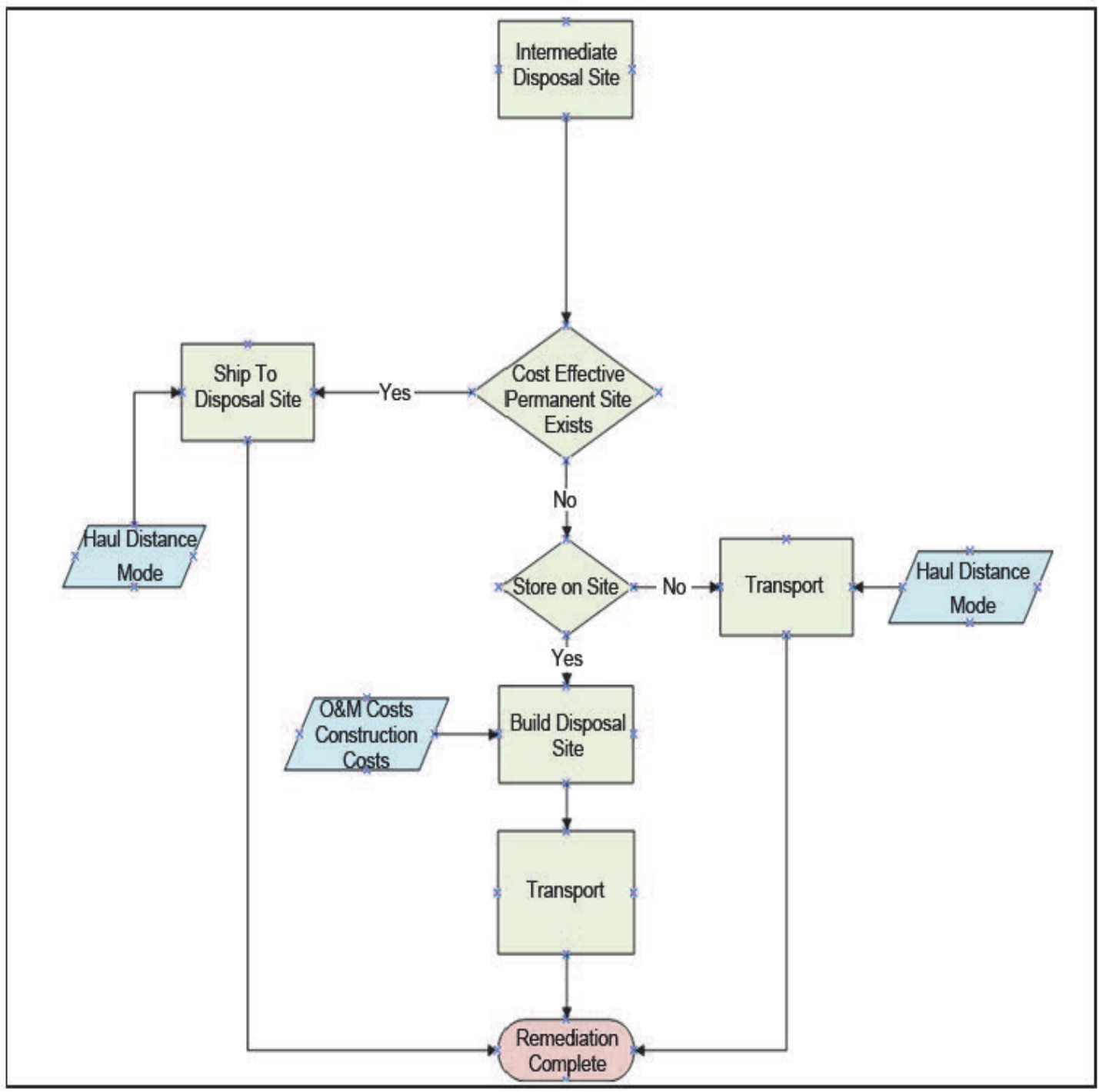




\section{Appendix B: High Resolution Excavation and Hauling Model}

For some of the alternatives, the excavation and hauling costs were the largest components of the lifecycle costs, excluding disposal costs of contaminated material. Therefore, a high resolution excavation and hauling model was developed to ensure that the process was properly captured. Figure B1 depicts this model.

Figure B1. Schematic of excavation and transportation process.

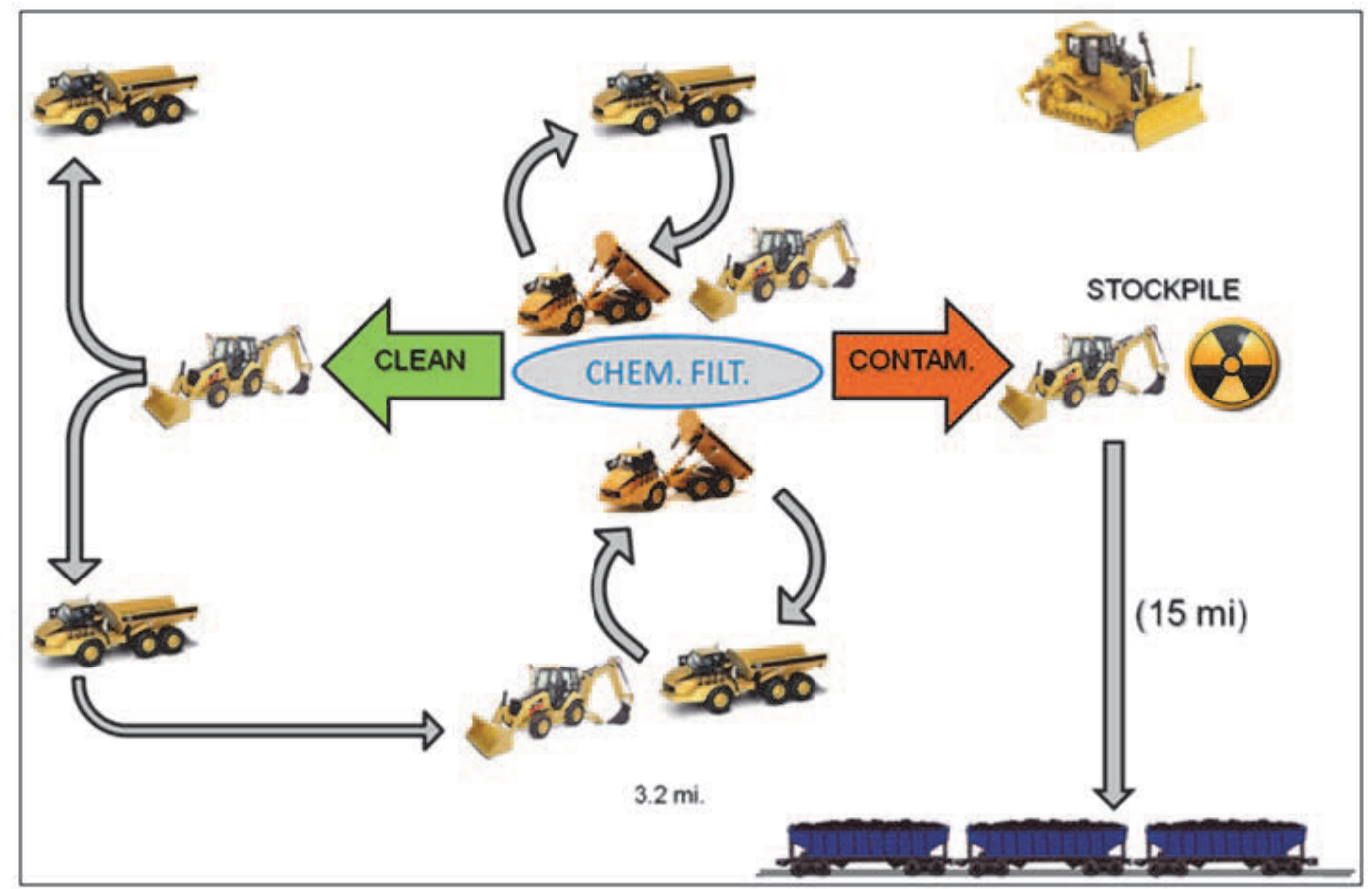

The estimates are based on the assumption that the total process is designed to be completed in three years. For analysis, the inflation rate was assumed to be equal to the internal rate of return (IRR). In essence, the actual dollar values are equal to the real dollar values. Thus, the TOC is equal to the NPV and can be calculated by simply adding up the cash flows. For government projects this is a viable and simplifying assumption. For example, using $3 \%$ for inflation as well as the IRR is justifiable. Therefore, an appropriate number of backhoes, dump trucks, and bulldozers will be purchased in order to complete this project on time. Additionally, all heavy equipment will be purchased as opposed to rented. After comparing the cost of purchasing all equipment to the cost of renting it, it was determined that 
purchasing equipment is significantly cheaper. This comparison did not include the salvage value that the heavy equipment would have at the end of the three years, which would make the choice even more obvious.

In the following paragraphs, each stage of the remediation process will be described in more detail. The stage 1 of the process is choosing an appropriate "hot spot" to begin digging, based on the GPS analysis provided by Picatinny Arsenal. Once a hotspot is selected, a backhoe will begin digging and excavate the entire hotspot to a depth of three feet. The contaminated soil will be loaded onto a dump truck and driven to the chemical filtration center, located approximately in the middle of the ten -square-mile area of operations. This minimizes the distance that any one dump truck has to transport material and reduces the total time of operation. In order to keep the backhoe from sitting idle while the dump truck transports material, there will be two dump trucks for each backhoe operating at a hot spot. Two dump trucks operating at all times will make the process more efficient. The first step of the process is complete once all the contaminated material is excavated and transported to the chemical filtration center.

Stage 2 of the process occurs in the chemical filtration center. In this step, the DU is removed from the contaminated soil, producing clean soil that can be placed back in its original environment and a concentrated contaminate that is ready for removal. Once the contaminated soil is delivered to the chemical filtration center from the hot spots, it is dumped in a pile at the filtration site. At the filtration site, all the soil is sifted, and pieces of soil larger than approximately $1 / 2$ inch are removed and piled up at the treatment site. All the larger pieces of soil are subjected to a nuclear screening device that detects which pieces contain radiation. All of the soil that contains radiation is contaminated, so it is taken directly to the DU stockpile location. At the treatment site, where the smaller pieces of soil $(<1 / 2$ inch) are piled, a chemical solution that contains $10 \%$ acetic acid is sprinkled over the pile. As the acetic acid permeates through the contaminated soil, it gathers all the DU and takes it to the bottom of the pile, where it drains through PVC pipes to a recycling center. At the recycling center, the acid solution is neutralized so it can be reused. What is left at that point is the concentrated DU that is ready for removal. This DU is then taken to the stockpile location. What is left in the original pile is now clean dirt that is ready to be transported back to its original location. Stage two is complete once all DU has been extracted and stockpiled, and the rest of the soil is ready to be returned to its original location. 
Stage 3 begins with piles of decontaminated soil and ends when this soil is returned to its original excavation site. There will be one backhoe located at the chemical filtration site dedicated to loading dump trucks with clean soil. The dump trucks then transport the clean soil back to the original site. One dump truck will be dedicated to each excavation site. There will also be one bulldozer on standby to fill and level each site once the clean dirt is returned.

Stage 4 consists of transporting the DU and other contaminated soil from the stockpile at the chemical filtration site to the train station located approximately 15 miles south of the area of operations. There will be no backhoe or dump truck(s) strictly devoted to this process because this only needs to be completed approximately once per year. Whenever the stockpile needs to be removed, the backhoe that normally unloads the dump trucks at the chemical filtration site will be used to load up the dump truck(s). These trucks will be the same trucks that return the clean soil to the excavation sites. If needed, more/different dump trucks can be borrowed from other processes as well. Depending on the resources available at the train station, a backhoe will most likely be needed to load the train cars. If this is the case, then a backhoe will be driven south along the same road as the dump trucks. Stage 4 is complete once all the contaminated material from the stockpile is loaded on the train and ready for removal. 


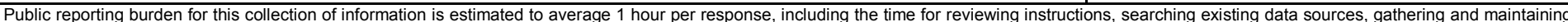

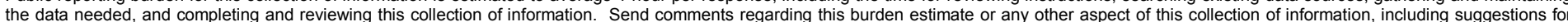

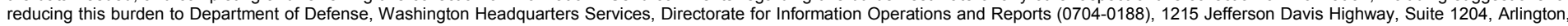

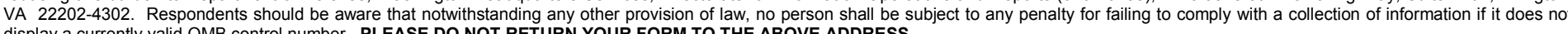
display a currently valid OMB control number. PLEASE DO NOT RETURN YOUR FORM TO THE ABOVE ADDRESS
1. REPORT DATE (DD-MM-YYYY) April 2014 2. REPORT TYPE Final report

\section{TITLE AND SUBTITLE}

Cost Analysis of Remediation Systems for Depleted Uranium

\section{DATES COVERED (From - To)}

5a. CONTRACT NUMBER

5b. GRANT NUMBER

5c. PROGRAM ELEMENT NUMBER

\section{AUTHOR(S)}

Joseph Walters, Jarrett Mackey, Kahlan Maki, Raymond Northcutt, John V. Farr, W. Andy Martin, Steven L. Larson, John H. Ballard, and Catherine Nestler

\section{5d. PROJECT NUMBER}

\section{5e. TASK NUMBER}

\section{5f. WORK UNIT NUMBER}

\section{PERFORMING ORGANIZATION NAME(S) AND ADDRESS(ES)}

8. PERFORMING ORGANIZATION REPORT NUMBER

US Army Engineer Research and Development Center

Environmental Laboratory

ERDC/EL TR-14-5

3909 Halls Ferry Road

Vicksburg, MS 39180-6199

\section{SPONSORING / MONITORING AGENCY NAME(S) AND ADDRESS(ES)}

Armament Research, Development and Engineering Command (ARDEC)

Picatinny Arsenal, NJ

10. SPONSOR/MONITOR'S ACRONYM(S)

11. SPONSOR/MONITOR'S REPORT NUMBER(S)

\section{DISTRIBUTION / AVAILABILITY STATEMENT}

Approved for public release; distribution unlimited.

\section{SUPPLEMENTARY NOTES}

\section{ABSTRACT}

The United States (US) Army and the other services are mandated to comply with all federal, state, and local environmental regulations. Recent concerns over potential human exposure to depleted uranium (DU) at US Army test ranges, primarily, have resulted in research into numerous innovative remediation technologies. Developing methods and processes for estimating the life cycle costs (LCC) of implementing these various techniques is important in identifying cost-effective solutions. Total ownership costs (TOC) models were developed for four candidate alternatives using two new technologies; Alternative 1- Physical Separation and Chemical Treatment; Alternative 2- Selective Excavation; Alternative 3- Selective Excavation with Physical Separation and Chemical Treatment; Alternative 4Containment and Monitoring. The team chose a generic sandy soil site roughly 10 miles square for cost estimates. A bottom up estimate was applied to all alternatives in order to get a baseline cost; Alternative 3 had the best estimate for an efficient and effective remediation method. A cost-estimating relationship was generated and simulation-based costing (SBC) was then applied to Alternative 3. Lastly, two alternatives were evaluated for DU remediation of catchboxes. Identifying the key cost drivers from SBC modeling is significant to future investments in research and development.

\begin{tabular}{|lll|}
\hline 15. SUBJECT TERMS & Depleted uranium & Total ownership costs \\
Bottom up estimate & Life cycle costing & Site remediation \\
Cost estimating relationships & Simulation-based costing & \\
&
\end{tabular}

16. SECURITY CLASSIFICATION OF:

\begin{tabular}{|l|l|l|}
\hline $\begin{array}{l}\text { a. REPORT } \\
\text { UNCLASSIFIED }\end{array}$ & $\begin{array}{l}\text { b. ABSTRACT } \\
\text { UNCLASSIFIED }\end{array}$ & $\begin{array}{c}\text { c. THIS PAGE } \\
\text { UNCLASSIFIED }\end{array}$ \\
\hline
\end{tabular}

\begin{tabular}{|l|c|}
$\begin{array}{l}\text { 17. LIMITATION } \\
\text { OF ABSTRACT }\end{array}$ & $\begin{array}{c}\text { 18. NUMBER } \\
\text { OF PAGES }\end{array}$ \\
& 77 \\
\hline
\end{tabular}

19a. NAME OF RESPONSIBLE
PERSON
W. Andy Martin
19b. TELEPHONE NUMBER (include
area code)
601-634-3710

